\title{
BNWL-88
}

$82-$

\section{EFFECTS OF FAST NEUTRON IRRADIATION, FABRICATION HISTORY, AND WATER OXYGEN ON THE ENVIRONMENTAL BEHAVIOR OF ZIRCONIUM ALLOYS}

DEVELOPMENT REPQRT
W. A. BURNS

AUGUST, 1965

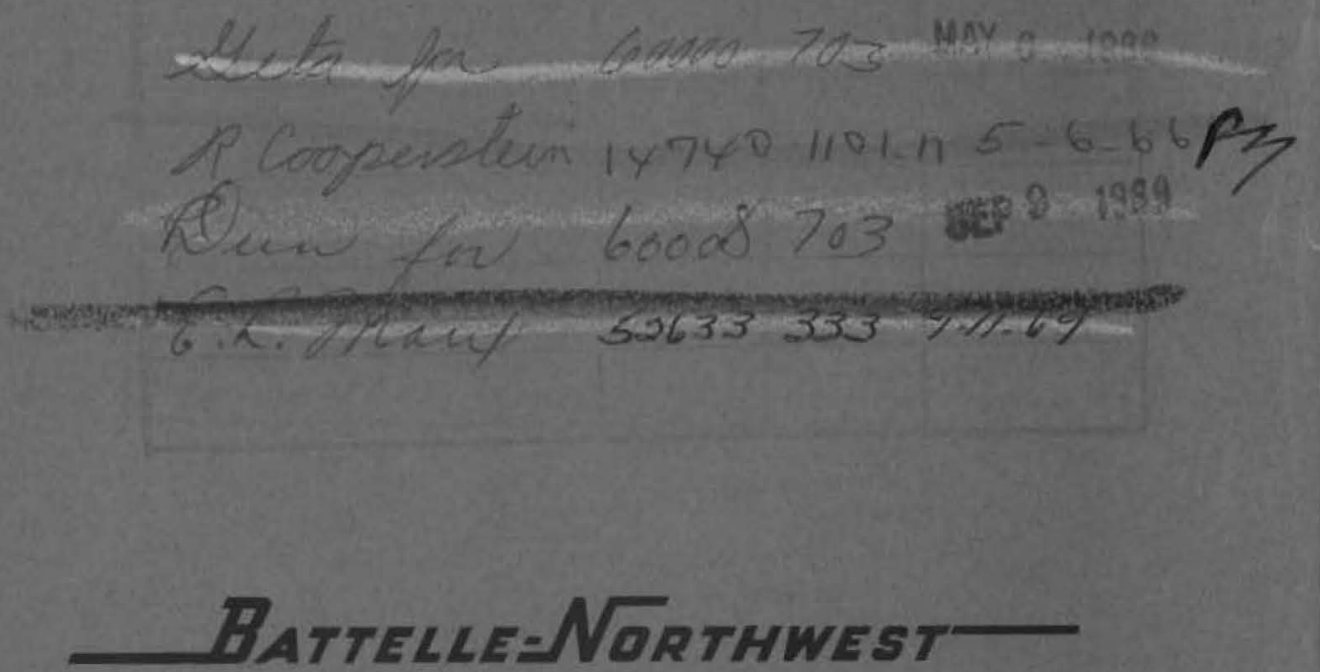

BATTELLE MEMORIAL INSTITUTE / PACIFIC NORTHWEST LABORATORY 


\section{LEGAL NOTICE}

This report was prepared as an account of Government sponsored work. Neither the United States, nor the Commission, nor any person acting on behalf of the Commission:

A. Makes any warranty or representation, expressed or implied, with respect to the accuracy, completeness, or usefulness of the information contained in this report, or that the use of any information, apparatus, method, or process disclosed in this report may not intringe privately owned rights; or

B. Assumes any liabilities with respect to the use of, or for damages resulting from the use of any information, apparatus, method, or process disclosed in this report.

As used in the above, "person acting on behalf of the Commission" includes any employee or contractor of the Commission, or employee of such cantractor, to the extent that such employee or contractor of the Commission, or employee of such contractor prepares, disseminates, or provides access to, any information pursuant to his employment or contract with the Commission, or his employment with such contractor.

\section{PACIFIC NORTHWEST LABORATORY}

RICHLAND, WASHINGTON

operated by

BATTELLE MEMORIAL INSTITUTE

for the

UNITED STATES ATOMIC ENERGY COMMISSION UNDER CONTRACT AT(45-1)-1830 


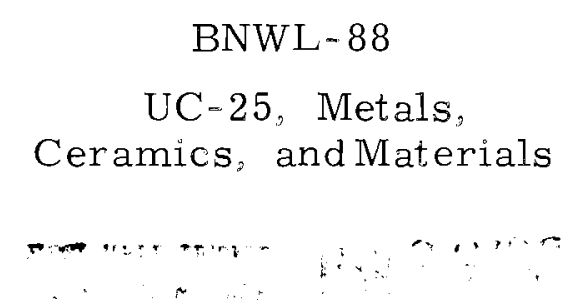

EFFECTS OF FAST NEUTRON IRRADIATION, FABRICATION HISTORY; AND WATER OXYGEN

ON THE ENVIRONMENT AL BEHAVIOR

OF ZIRCONIUM ALLOYS

Manuscript Dated February, 1965

\author{
By \\ W. A. Burns \\ Metallurgy Research Section \\ Reactor and Materials Technology Department
}

August, 1965

PACIFIC NORTHWEST LABORATORY RICHLAND, WASHINGTON 



\section{TABLE OF CONTENTS}

1. INTRODUCTION . . . . . . . . . . . . . . . . . . . . . . 1

2. PURPOSE AND SCOPE . . . . . . . . . . . . . . . . . . . 3

3. SUMMARY. . . . . . . . . . . . . . . . . . . . . . . . 3

3. 1 High-Oxygen Water . . . . . . . . . . . . . . . . . . 3

Exposure Conditions. . . . . . . . . . . . . . . . . . 3

3. 1. 1 Weight Gain. . . . . . . . . . . . . . . . .4

3. 1. 2 Hydrogen Pickup . . . . . . . . . . . . . . . .4

3. 1. 3 Heat Treatment Effects . . . . . . . . . . . . .4

3.2 Low-Oxygen Water . . . . . . . . . . . . . . . . . 5

Exposure Conditions. . . . . . . . . . . . . . . . . 5

3. 2. 1 Weight Gain. . . . . . . . . . . . . . . . . 5

3. 2. 2 Hydrogen Pickup . . . . . . . . . . . . . . . . . 5

3. 2. 3 Heat Treatment Effects . . . . . . . . . . . . . . 6

3. 3 General Observations . . . . . . . . . . . . . . . . . . . . .

4. EXPERIMENTAL . . . . . . . . . . . . . . . . . . . . . . 6

4. 1 Specimen Preparation . . . . . . . . . . . . . . . . . 6

4. 2 Exposure Facilities and Methods . . . . . . . . . . . . . . .7

4. 2. 1 Specimen Arrangement . . . . . . . . . . . . . . . .7

4. 2.2 Test Facilities . . . . . . . . . . . . . . . . . . . .7

4. 2.3 Temperature . . . . . . . . . . . . . . . . . . 10

4. 3 Analytical Methods . . . . . . . . . . . . . . . 10

4. 3. 1 Neutron Flux . . . . . . . . . . . . . . . . . . . . 10

4. 3. 2 Metal Hydrogen . . . . . . . . . . . . . . . . . 11

4. 3. 3 Dissolved Gases in Water . . . . . . . . . . . . 11

5. RESULTS AND DISCUSSION . . . . . . . . . . . . . . . . . . 11

5. 1 High-Oxygen Water . . . . . . . . . . . . . . . . . . 11

5. 1. 1 Weight Gain and Hydrogen Pickup . . . . . . . . . . 11

5. 1. 2 Heat Treatment Effects . . . . . . . . . . . . . 19

5. 1. 3 Irradiated Coolant Effects . . . . . . . . . . . . 22 
5. 2 Low-Oxygen (Hydrogenated) Water . . . . . . . . . . . . . 24

5. 2. 1 Weight Gain and Hydrogen Pickup-General . . . . . . . 26

5. 2. 2 Weight Gain and Hydrogen Pickup for Zircaloy-2 . . . . 28

5. 2. 3 Weight Gain and Hydrogen Pickup for Zircaloy-4, Nickel-Free Zircaloy-2, and $\mathrm{Zr}-3 \mathrm{wt} \% \mathrm{Nb}-1 \mathrm{wt} \% \mathrm{Sn}$. . 36

5. 3 Postirradiation Effects . . . . . . . . . . . . . . . . . . 40

6. CONCLUSIONS . . . . . . . . . . . . . . . . . . . . . 46

7. ACKNOWLEDGMENTS . . . . . . . . . . . . . . . . . . . 52

8. APPENDIXES . . . . . . . . . . . . . . . . . . . . . . 53

8. 1 Appendix A - Zirconium Alloy Specimen Compositions and Fabrication Histories. . . . . . . . . . . . . 53

8. 1. 1 Table A-1 - Zirconium Alloy Specimen Compositions . . 53

8. 1. 2 Table A-2 - Zirconium Alloy Specimen Fabrication History. . . . . . . . . . . . . . 54

8. 2 Appendix B - Metallographic Observations . . . . . . . . . . 55

8. 2. 1 Hydride Platelet Gradients . . . . . . . . . . . . . . 55

8. 2. 2 Anisotropic Effects . . . . . . . . . . . . . . . . . 57

8. 2. 3 Heat Treatment and Radiation Effects on Microstructure and Second-Phase Agglomerates . . . . . . . . . . 62

8. 2. 4 Electron Microscopy. . . . . . . . . . . . . . . . . 67

9. REFERENCES . . . . . . . . . . . . . . . . . . . . . . . . 75 


\section{LIST OF FIGURES}

Figure

Title

Page

1 Specimen Test Rack and Quadrant Assembly

2 ETR Reactor Vertical Cross Section

3 Effect of Fast Neutron Flux and Time on Oxidation of Zircaloy-2 in High-Oxygen Water

4 In- and Out-of-Reactor Corrosion Characteristics of Zircaloy-2 in High-Oxygen Water

5 Comparison of Surface Appearance of Zircaloy-2 Coupons Exposed In- and Out-of-Reactor 125 Days at $540{ }^{\circ} \mathrm{F}$

6 Metallographic Comparison of Oxide Films Formed on Zircaloy-2 In- and Out-of-Reactor in High-Oxygen Water at $540^{\circ} \mathrm{F}$

7 Effect of Heat Treatment and Reactor Ir radiation on Oxidation of Etched Zircaloy-2 in High-Oxygen Water-49 Days at $540{ }^{\circ} \mathrm{F}$

8 Influence of Dissolved Oxygen and Fast Neutron Flux on Zircaloy-2 Corrosion in $540^{\circ} \mathrm{F}$ Water

9 Comparison of In- and Out-of-Reactor Corrosion of Zirconium Alloys in Low-Oxygen Water

10 Comparison of In- and Out-of-Reactor Hydrogen Pickup Behavior of Zirconium Alloys

11 Microstructure of $\mathrm{Zr}-3 \mathrm{wt} \% \mathrm{Nb}-1 \mathrm{wt} \%$ Sn After Exposure to $534^{\circ} \mathrm{F}$ Low-Oxygen Water for 16.5 Days

B-1 Variation of Hydride Platelet Concentration in Annealed Irradiated Zircaloy-2 Tensile Specimens

B-2 Anistropic Oxide Formation on Irradiated Zircaloy-2 in High-Oxygen Water

B-3 Texture of Annealed and Cold-Rolled Zircaloy-2

B-4 Comparison of the Microstructure of Cold-Worked Zircaloy-2 Before and After 49-Day Exposure In- and Out-of-Reactor at $540^{\circ} \mathrm{F}$

B-5 Comparison of the Microstructure of Heat-Treated Zircaloy-2 Before and After 49-Day Exposure In- and Out-of-Reactor at $540^{\circ} \mathrm{F}$

B-6 Electron Micrographs of Replicas of Oxide Formed on Zircaloy-2 During 264-Day In-Reactor Exposure to $540^{\circ} \mathrm{F}$ High-Oxygen Water 
B-7 Electron Micrographs of Replicas of Oxide Formed on Zircaloy-2 During 264-Day In-Reactor Exposure to $540^{\circ} \mathrm{F}$ High-Oxygen Water

B-8 Micrographs of Cathodically Etched Oxide on Annealed Zircaloy-2 After 264-Day Exposure to High-Oxygen Water In-Reactor at $540^{\circ} \mathrm{F}$

B-9 Electron Micrographs of Replicas of Oxide Formed on Zircaloy-2 During 1242-Day Out-of-Reactor Exposure to $680^{\circ} \mathrm{F}$ Water

B-i0 Micrographs of Cathodically Etched Oxide Formed on Zircaloy-2 During 1242-Day Out-of-Reactor Exposure to $680^{\circ} \mathrm{F}$ Water

B-11 Comparison of the Appearance of Replicas of Bare and Anodized Surfaces of Irradiated and Unirradiated Zircaloy-2 


\section{EFFECTS OF FAST NEUTRON IRRADIATION, FABRICATION HISTORY, AND WATER OXYGEN ON THE ENVIRONMENTAL BEHAVIOR OF ZIRCONIUM ALLOYS}

\section{INTRODUCTION}

This report discusses the investigation of zirconium alloys relative to the effects of nuclear irradiation on surface reactions between metals and their environments. For many years, information generated in this area has presented a somewhat confused picture of cause-and-effect relationships. No general criteria, guidelines, or bases for predicting the effects of radiation on metal-environment reactions can be discerned. It appears that much of this difficulty can be traced to the absence of true similarity of materials, experimental conditions, methods, and analytical techniques. Part of the problem also results from the complexity of the processes involved.

Listed below are a few of the many ways in which neutron irradiation may affect a chemical reaction between a metal and its water environment.

- Radiolysis of the water into a variety of oxidizing free radicals and hydrogen peroxide

- Ionization of water and dissolved impurities, including dissolved gases

- Creation of new diffusion and/or migration paths through the protective oxide layer by knock-on disruption of the oxide lattice

- Creation and utilization of lattice defects, interstitial atoms, and vacancies as sites for chemical attack and penetration of the matrix

- Increased electrical conductivity within the oxide by creation of an excess of free electrons as a consequence of primary and secondary electron-stripping events

- Excitation of reactant molecules and atoms

- Transmutation of elements, including impurity elements, in the environment, oxide, or metal substrate into various species with a spectrum of characteristics which may either aid or inhibit some one or more steps in the processes involved. 
Complete characterization of the effects of in-reactor irradiation on the environmental reaction processes for heavy-element-free reactor structural materials in nonfissioning environments would require a detailed knowledge of the system seldom if ever obtainable. The contribution of neutrons as a class is important to all of these processes. To obtain an ideal characterization, however, it is necessary to have a knowledge of the relative contributions of neutrons of different energy levels, neutron flux, gamma energy, gamma flux, beta effects related to decay of unstable isotopes within the oxide and within or near the oxide-water or oxide metal interfaces, fast electron effects associated with gamma absorption, the modifying effects of temperature, alloy composition and nature and amount of impurity elements present, and all of the interrelationships. This would be extremely helpful in providing (1) bases for material selection for in-reactor service, (2) guidelines for development of new alloys, and (3) material indices for use in design life prediction. Because of the obvious difficulty in achieving a complete characterization of irradiation effects, it is highly unlikely that the quantitative effects of irradiation will become known in such detail in the near future. Eventually, however, certain patterns will appear, and ultimately complete characterization of irradiation effects may be realized.

At Hanford, Zircaloy-2 has been the metal most extensively investigated with regard to in-reactor effects on reactions with pressurized water coolant. A previous report ${ }^{(1)}$ presented early findings on the corrosion and hydrogen pickup behavior of reactor-grade Zircaloy-2 exposed to the environment of the G-7 water loop in the core of the Engineering Test Reactor (ETR). Data reported at that time were based on exposure of specimens to 34 days and to fast neutron flux levels from 1.7 to $4.2 \times 10^{13} \mathrm{nv}(>1 \mathrm{MeV})$. Maximum integrated fast flux exposure was $1.1 \times 10^{20}$ nvt. Water conditions were nominal $540^{\circ} \mathrm{F}$, pH $10(\mathrm{LiOH})$, with a median oxygen content of $0.8 \mathrm{ppm}$. Specimens were tested in metallurgical conditions ranging from alpha annealed to $40 \%$ cold work.

Results of the early investigations showed order of magnitude differences in oxide weight gains between in-reactor specimens and out-of-reactor controls. Fractional pickup of corrosion hydrogen in-reactor was generally 
less than for out-of-reactor controls, but within the range normally found for unirradiated exposure. No significant or consistent effect of cold work on weight gain or hydrogen pickup was observed. Hydrogen pickup was unaffected by changes in neutron flux over the range investigated, but weight gains appeared to be very slightly sensitive to flux, indicating a possible saturation effect above an undetermined threshold flux level. Posttransition in-reactor oxidation at constant flux approached a steady-state rate near $1 \mathrm{mg} /\left(\mathrm{dm}^{2}\right)$ (day).

\section{PURPOSE AND SCOPE}

This report describes in a semiquantitative manner some recent laboratory observations of irradiation effects on zirconium alloys of known composition and fabrication history in reasonably well-identified environments. The early radiation effects studies have been extended to further define the characteristics of the in-reactor environmental behavior of Zircaloy-2. The experimental program was broadened to include other zirconium alloys (Zircaloy-4, nickel-free Zircaloy-2, and $\mathrm{Zr}-3 \mathrm{wt} \% \mathrm{Nb}-1 \mathrm{wt} \% \mathrm{Sn}$ ) and the effects of heat treatment, preirradiation, coolant irradiation alone, anisotropy of texture, heavy cold work, and hydrogen addition to the water environment. Exposure data have now been obtained on over 350 specimens and include time to 264 days, neutron flux intensities from $2 \times 10^{12}$ to $1 \times 10^{14} \mathrm{nv}(>1 \mathrm{MeV})$, integrated fast neutron exposure to $1.9 \times 10^{21} \mathrm{nvt}$, and variations in water oxygen content from $\sim 1 \mathrm{ppm}$ to $<0.1 \mathrm{ppm}$.

3. SUMMARY

\section{1 High-Oxygen Water}

Exposure Conditions

Temperature 520 to $540^{\circ} \mathrm{F}$ $\mathrm{pH}$ $10(\mathrm{LiOH})$

Oxygen $0.8 \mathrm{ppm}$ (median)

Neutron Flux $1.7 \times 10^{13}$ to $1.0 \times 10^{14} \mathrm{nv}$ $(>1 \mathrm{MeV})$ Exposure Time

19. 2 to 264 days 


\subsubsection{Weight Gain}

Following periods of in-reactor exposure, weight gains for Zircaloy-2 specimens are higher than for out-of-reactor controls by factors of 10 to 16. No significant effect of extent of cold work or of cold work versus annealing on weight gain was observed through $40 \%$ cold work.

The results of a single experiment involving $86 \%$ cold-worked material showed a marked apparent effect of cold work on in-reactor weight gains lonly 2 - to 4 -fold higher weight gain than for normal out-of-reactor exposured. One long exposure, 40\% cold-worked specimen also showed only about half the oxide film thickness of an adjacent annealed specimen.

Cumulative weight gains in the post-transition region increase only slightly with increasing fast flux intensity and show a possible saturation effect of neutron flux. Over the rarge of flux studied, in-reactor weight gains at constant flux approach a steady-state rate near $1 \mathrm{mg} /\left(\mathrm{dm}^{2}\right)$ (day).

Optical measurements of oxide film thickness are in good agreement with weight gains, indicating reasonable uniformity of oxide thickness and absence of interference from unremoved crud or oxide dissolution phenomena.

Following in-reactor exposure, oxide film thickness was observed to be greater on roll-plane surfaces than on transverse surfaces.

\section{1. 2 Hydrogen Pickup}

Fractional pickup of corrosion hydrogen in-reactor is generally within the low part of the range normally found for out-of-reactor exposure, and no significart or consistent relationship with flux or extent of cold work was observed.

Hydride platelet concentration gradients were observed in thick, annealed specimens exposed isothermally in-reactor to high weight gains.

\subsubsection{Heat Treatment Effects}

Heat treatment above the $\alpha / \alpha+\beta$ transition followed by slow cooling is detrimental to corrosion resistance in-reactor. Original in-reactor 
corrosion resistance can be restored by $\beta$ heat treatment followed by an air quench and $\alpha$ anneal. Radiation effects a re additive to heat treatment effects.

\subsection{Low-Oxygen Water}

Exposure Conditions

$\begin{array}{ll}\text { Temperature } & 520 \text { to } 536^{\circ} \mathrm{F} \\ \mathrm{pH} & 10(\mathrm{LiOH}) \\ \text { Oxygen } & <0.1 \mathrm{ppm} \\ \text { Hydrogen } & >10 \mathrm{~cm}^{3} / \mathrm{kg} \\ \text { Neutron Flux } & 2.0 \times 10^{12} \text { to } 6.6 \times 10^{13} \mathrm{nv} \\ & \left(>1 \mathrm{MeV}^{2}\right. \\ \text { Exposure Time } & 16.5 \text { days }\end{array}$

\subsubsection{Weight Gain}

In-reactor weight gains for Zircaloy-2, Zircaloy-4, nickel-free Zircaloy-2, and Zr-3 wt\% Nb-1 wt Sn are similar (minor differences) at each flux position and increase with increasing flux. Neither a saturation effect of flux nor an effect of cold work or cold work versus annealing (through $86 \%$ cold work) on weight gain was observed. In general, weight gains for Zircaloy-2 are less than half those observed during exposure in high-oxygen water for similar periods of time and flux intensities.

Oxidation rates a re less sensitive to changes in fast neutron flux below a flux level of $\sim 1.6 \times 10^{13} \mathrm{nv}$.

\subsubsection{Hydrogen Pickup}

Fractional pickup of hydrogen is greater than for unirradiated exposure and about twice as great as found during in-reactor exposure in highoxygen water. Maximum pickup was exhibited by heavily cold-worked Zircaloy -2 .

The environmental behavior of the $\mathrm{Zr}-3 \mathrm{wt} \% \mathrm{Nb}-1 \mathrm{wt} \% \mathrm{Sn}$ alloy, as heat treated for maximum corrosion resistance, was the alloy least affected by in-reactor exposure both with regard to hydrogen pickup and weight gain. 
Hydrogenpickup rankings established out-of-reactor for Zircaloy-4 and nickel-free Zircaloy-2 remain unaffected by irradiation.

\section{2.3 Heat Treatment Effects}

Annealing of heavily cold-worked Zircaloy-2 produced a marked decrease in hydrogen pickup under all exposure conditions.

\section{3 General Observations}

Postirradiation corrosion of Zircaloy-2 in out-of-reactor steam autoclaves gave no evidence of a significant residual effect of ir radiation on corrosion or hydrogen pickup behavior.

In the course of metallographic studies, an increase was observed in the population of second-phase precipitates and/or growth or migration of previously existing second-phase deposits in Zircaloy-2 during extended periods of heating at moderate temperatures.

Some differences in the appearance of oxide (extent of microcracking) have been observed for irradiated and unirradiated Zircaloy-2, but no differences in the metal substrate have been resolved by electron micrography at magnifications to $15,000 \mathrm{X}$.

\section{EXPERIMENTAL}

\section{1 Specimen Preparation}

The zirconium alloy specimens used in this study measured $33 / 8$ in. in length and 1 in. in width. They were mill-cut from nominal $0.050 \mathrm{in.}$ thick plate in the annealed, $10,20,40$, or $86 \%$ cold-worked condition. Such coupons weigh approximately $17 \mathrm{~g}$ and have a surface area of $0.46 \mathrm{dm}^{2}$.

All specimens were pretreated by vapor blasting and etching, and most were autoclaved before exposure in the test facilities. Metal was removed to a depth of more than 1 mil from each surface by a controlled hydrofluoric-nitric acid etch, followed by hot aluminum nitrate and flowing water rinses in accordance with standard procedures. ${ }^{(2)}$ Autoclaving consisted of a $48 \mathrm{hr}$ exposure in $572^{\circ} \mathrm{F}$ refreshed demineralized water at $\mathrm{pH} 6$. 
Out-of-reactor specimens were weighed before and after autoclaving, and following exposure, on a microbalance accurate to about $\pm 30 \mu \mathrm{g}$ at the $90 \%$ confidence level. In-reactor samples were weighed after autoclaving and after exposure on two automatic balances, one for preexposure use and one for use with the irradiated samples. Weighing procedures included periodic weighing of reference standards. Coupon weighings on the automatic balances were within $\pm 250 \mu \mathrm{g}$ at the $90 \%$ confidence level. All irradiated specimens were cleaned ultrasonically before weighing.

\subsection{Exposure Facilities and Methods}

4.2.1 Specimen Arrangement

Following preparation and weighing, samples were loaded into a utoclaved stainless steel holders (quadrants) on test racks of special design (Figure 1) for insertion into the test sections of the in-and out-of-reactor loops. Four quadrants are attached side by side in a cylindrical array on the test rack which accommodates seven such arrays. The test rack hangs in a vertical position in the in-core section of the ETR G- 7 loop, and all samples in quadrants $w$ ithin a particular cylindrical array are thus exposed to the neutron flux existing at that position in the reactor.

Out-of-core coupon holders located upstream and downstream of the active zone (Figure 2) provide coolant transport delays from less than $1 \mathrm{sec}$ to more than 1 min out of the flux and permit studying the role of neutron-irradiated coolant alone on corrosion-related phenomena.

\subsection{Test Facilities}

Both the G-7 loop at the ETR and the High-Temperature Test Loop (out-of-reactor) at Hanford are steam-pressurized, recirculating test facilities normally operating without hydrogen overpressure and using lithium mixed-bed ion exchange for control of water quality and $\mathrm{pH}$. 

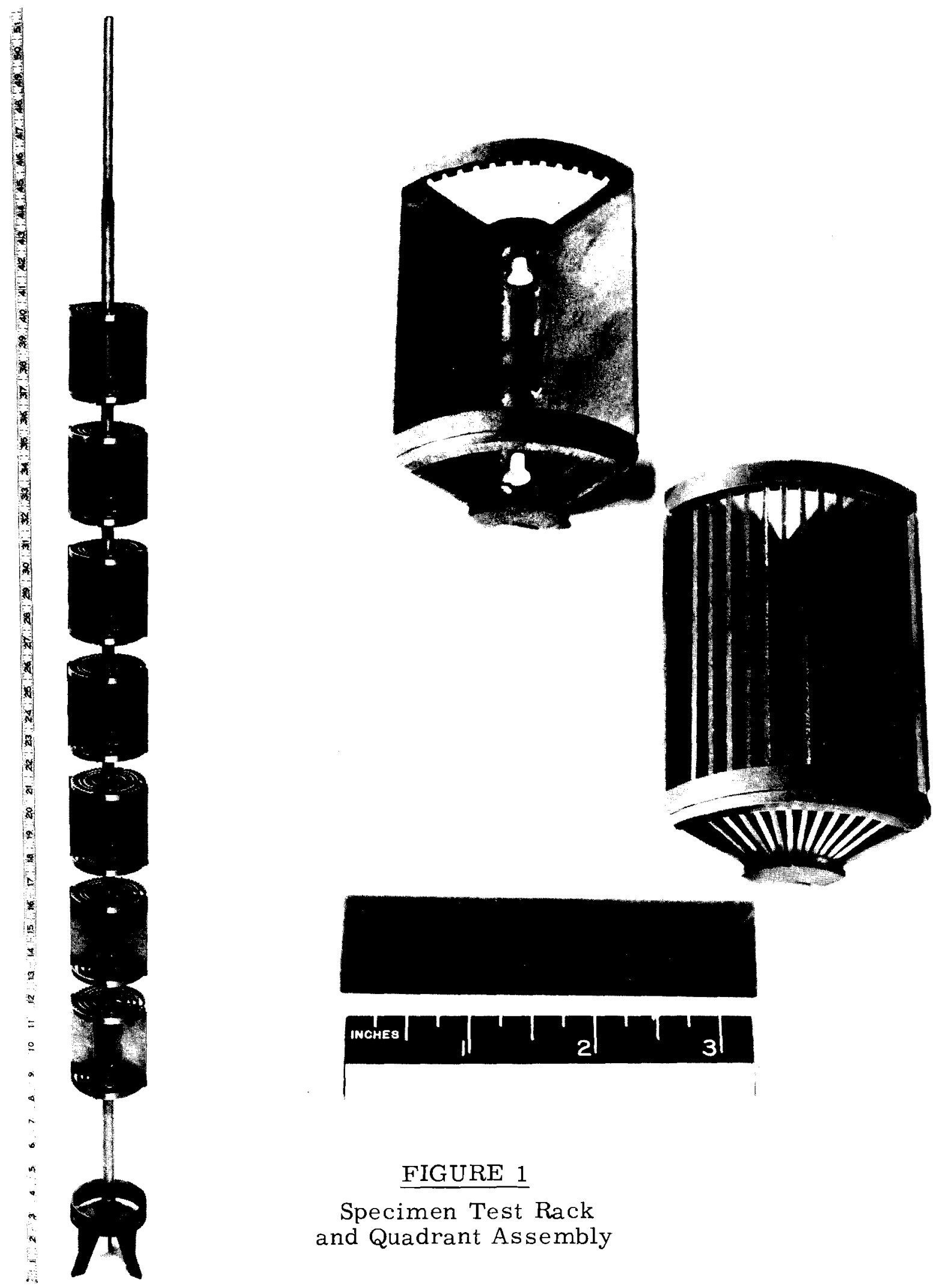

\section{FIGURE 1}

Specimen Test Rack and Quadrant Assembly

No. 0631869 


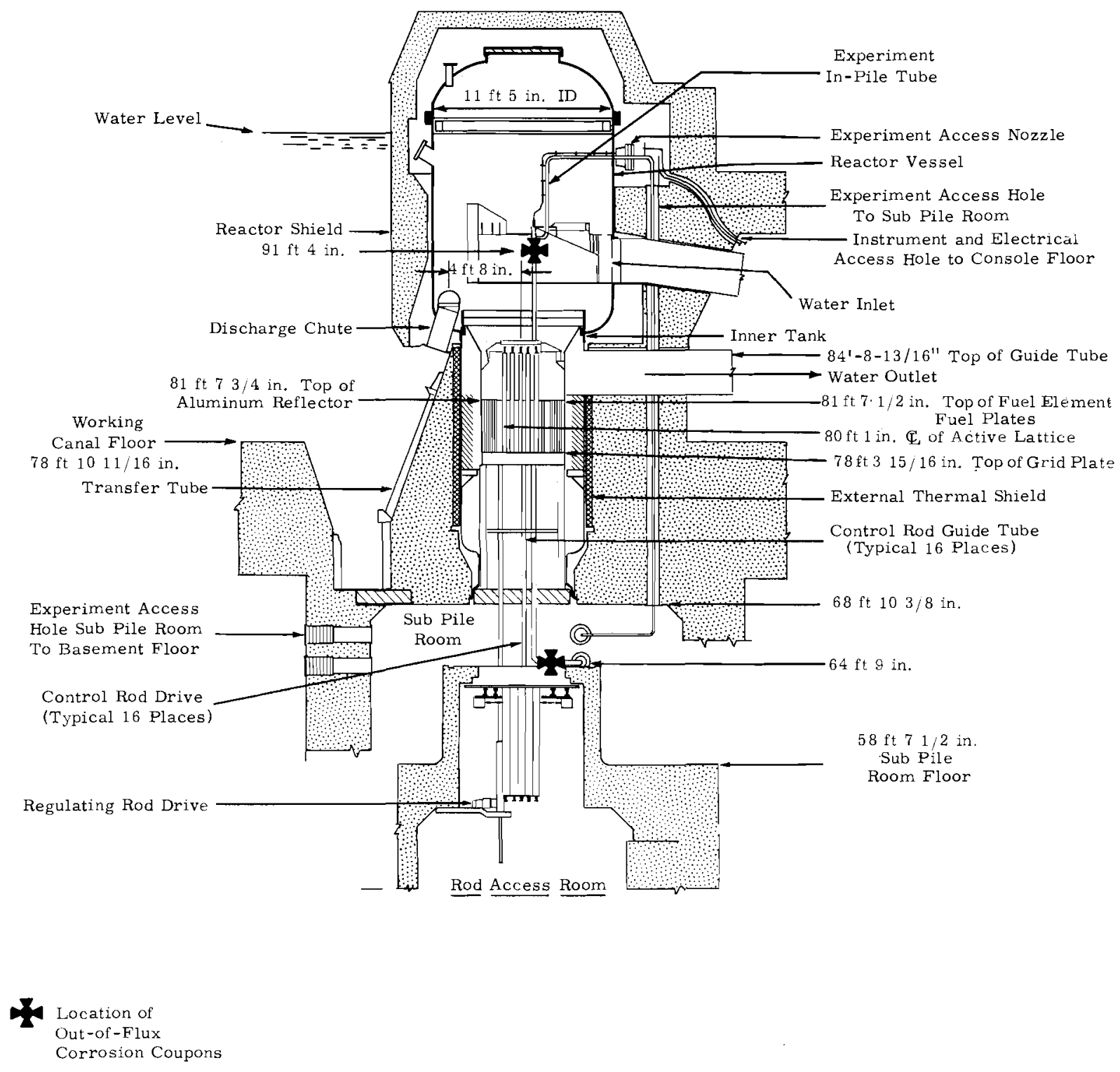

FIGURE 2

ETR Reactor Vertical Cross Section 
Water flow through the G-7 loop varies from 75 to $200 \mathrm{gal} / \mathrm{min}$, depending upon heat transfer demands, while flow is controlled at a nominal $50 \mathrm{gal} / \mathrm{min}$ in the test sections of the out-of-reactor loop. Bulk water velocities in the test sections are on the order of $10 \mathrm{ft} / \mathrm{sec}$. The water volumes of the G-7 and High-Temperature Loops are approximately 85 and 15 gal, respectively.

Makeup water for the G-7 loop is normally not deaerated. Oxygen content for this loop has been noted to vary from $\sim 0.07$ to $\sim 2 \mathrm{ppm}$ with a median concentration of $\sim 0.8 \mathrm{ppm}$, while the oxygen content of HighTemperature Test Loop water is maintained at nominally less than 0.1 ppm.

\subsection{Temperature}

Bulk outlet water temperature from the in-core test section of the G-7 loop is used as the basis for comparing experimental results and for controlling the temperature of the out-of-reactor test loop. The maximum bulk outlet water temperature is nominally $540{ }^{\circ} \mathrm{F}$ but has varied down to as low as $520^{\circ} \mathrm{F}$ for some reactor operating periods.

During full-power operation of the reactor, heat generation in the test assembly results in a bulk coolant temperature rise of approximately $15^{\circ} \mathrm{F}$ across the in-core section. Thermocouples embedded in AISI Type 304 specimens indicated that for $540{ }^{\circ} \mathrm{F}$ bulk outlet water such specimens operate at temperatures ranging from about $540^{\circ} \mathrm{F}$ to about $570^{\circ} \mathrm{F}$, depending upon the flux intensity and water temperature prevailing at a specific location. Consequently, it is reasonable to assume that these temperatures represent maxima for Zircaloy specimens.

\section{3 Analytical Methods}

\section{3. 1 Neutron Flux}

Neutron flux values a re based on the specific activity resulting from

the $\mathrm{Fe}^{54}$ (n, p) $\mathrm{Mn}^{54}$ transmutation in iron wires encased in stainless steel capillary tubing. One flux monitoring wire extends through the hollow central shaft of the test rack, and shorter sections are attached to the periphery 
of each quadrant. Activation measurements were made at the MTR-ETR Counting Laboratory of the National Reactor Testing Station of Idaho Falls, and at Hanford's Redox Analytical Laboratory.: By the use of the Fortran FOILS program, ${ }^{(3)} \mathrm{Mn}^{54}$ activity data were translated into neutron flux information.

\section{3.2 Metal Hydrogen}

Hydrogen analyses on the irradiated and unirradiated coupons were obtained by the hot vacuum extraction method, using $1 / 4 \mathrm{in}$-diam punchings which were carefully degreased in a two-stage $\mathrm{CCl}_{4}$ wash. Control samples of reasonably well-known hydrogen content were included with each loading of the apparatus to provide a check on analytical accuracy and precision. Hydrogen results are considered to be accurate within about $10 \%$.

\subsubsection{Dissolved Gases in Water}

Water oxygen was determined by a modified Winkler method which has a reliable detection limit of $50 \mathrm{ppb}$. Water hydrogen was determined at the ETR site by gas-phase thermal conductivity measurements, using the apparatus described by Robinson and Conklin. (4)

\section{RESULTS AND DISCUSSION}

\section{1 High-Oxygen Water}

\section{1. 1 Weight Gain and Hydrogen Pickup}

Summaries of all weight and hydrogen gain data obtained on weighed specimens of Zircaloy-2 exposed to $540^{\circ} \mathrm{F}, \mathrm{pH} 10$ ( $\mathrm{LiOH}$ ), $0.8 \mathrm{ppm}$ median $\mathrm{O}_{2}$ water in the ETR G-7 loop are presented in Table I and Figure 3. Each data line in Table I contains information from approximately equal numbers of specimens in the annealed, 10,20 , or $40 \%$ cold-worked condition. The previous work ${ }^{(1)}$ and detailed study of the more recent results have shown no dependence of weight gain or hydrogen pickup on the extent of cold work, with the except of a few isolated cases which are discussed in subsequent sections. Chemical analyses and work/heat treatment history for all of the plate stocks tested a re given in Appendix A. 
TABLE I

WEIGHT GAIN AND HYDROGEN PICKUP SUMMARY

FOR HIGH-OXYGEN WATER

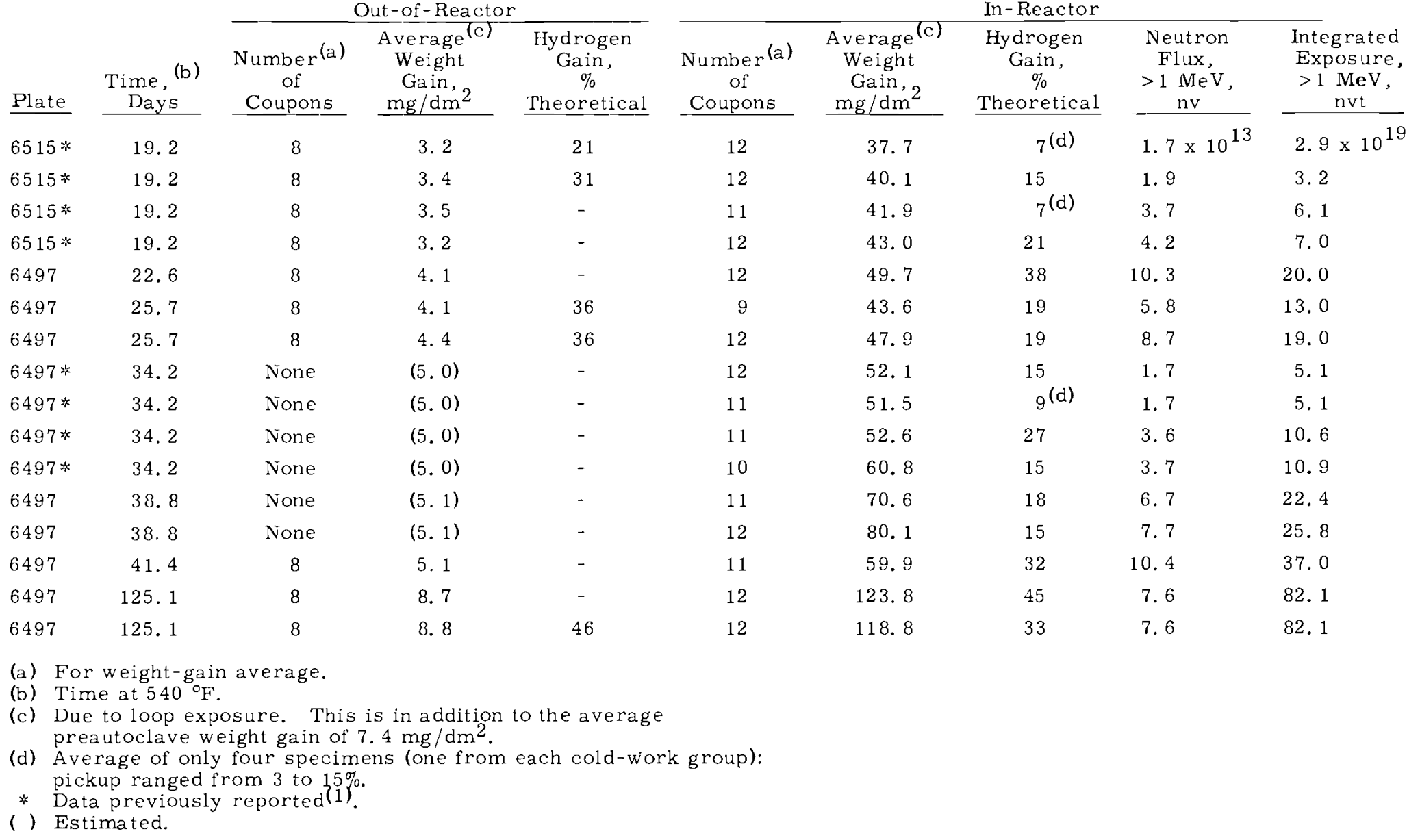




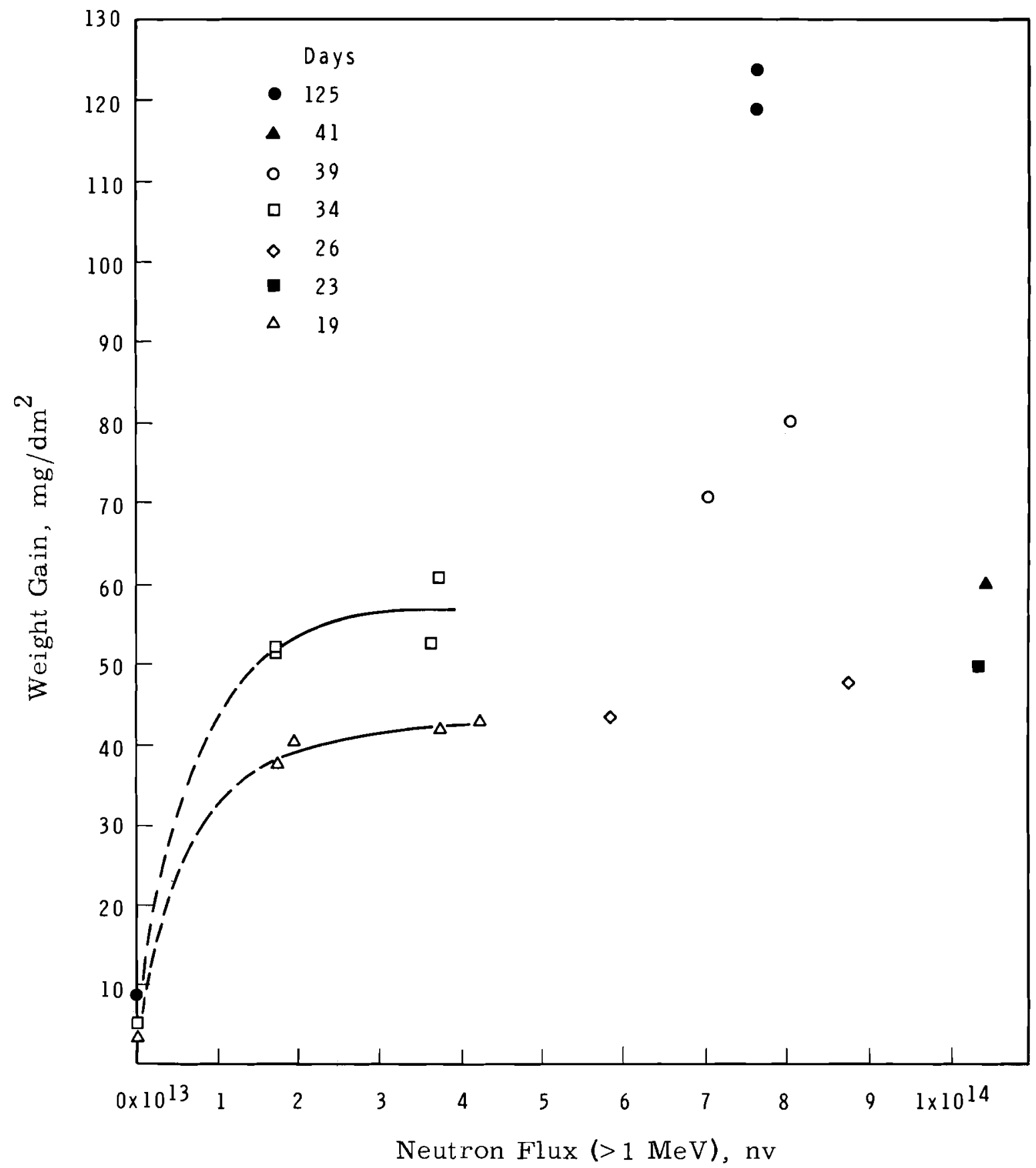

FIGURE 3

Effect of Fast Neutron Flux and Time on Oxidation of Zircaloy-2 in High-Oxygen Water

No. $0642135-1$ 
Table II summarizes oxide thickness information obtained by metallographic measurement of films on single Zircaloy-2 annealed tensile test specimens which had not been weighed before insertion into the reactor. Previously, this method of measurement was shown to yield results which agreed with weight gain measurements within about $25 \%$. While these tensile specimens were obtained from a different plate material than was used for the corrosion specimens, it was of essentially the same composition and work history.

TABLE II

WEIGHT GAIN AND HYDROGEN PICKUP

\begin{tabular}{|c|c|c|c|c|c|}
\hline \multirow[b]{2}{*}{ Plate } & \multicolumn{5}{|c|}{$\begin{array}{l}\text { FOR ANNEALED ZIRCALOY - } 2 \text { TENSILE TEST SPECIMENS } \\
\text { EXPOSED TO HIGH-OXYGEN WATER IN-REA CTOR }\end{array}$} \\
\hline & $\begin{array}{l}\text { Time, } \\
\text { Days, at } \\
540^{\circ} \mathrm{F} \\
\end{array}$ & $\begin{array}{l}\text { Total Weight } \\
\text { Gain, (b) } \\
\mathrm{mg} / \mathrm{dm}^{2}\end{array}$ & $\begin{array}{l}\text { Total } \\
\text { Hydrogen, } \\
\text { ppm }\end{array}$ & $\begin{array}{c}\text { Hydrogen, } \\
\% \\
\text { Theoretical }\end{array}$ & $\begin{array}{l}\text { Neutron Flux, } \\
(>1 \mathrm{MeV}), \mathrm{nv}\end{array}$ \\
\hline 6513 & 23.7 & 48 & 27 & 15 & $2.1 \times 10^{13}$ \\
\hline 6513 & 23.7 & 47 & 30 & 18 & 5.5 \\
\hline 6513 & 23.7 & 86 & 41 & 15 & 10.0 \\
\hline 6513 & 42.9 & 148 & 60 & 15 & 6.3 \\
\hline 6513 & 77.1 & 154 & 100 & 25 & 4.7 \\
\hline 6513 & 144 & 370 & 176 & 20 & 8.7 \\
\hline 6509 & 264 & 426 & 450 & 45 & 8.2 \\
\hline
\end{tabular}

(a) Oxide thicknesses calculated from metallographic measurements. Hydrogen pickup fractions based on hot vacuum extraction analyses. (b) Weight gain includes preexposure autoclave oxide $\left(7.4 \mathrm{mg} / \mathrm{dm}^{2}\right)$.

The differences between oxidation rates indicated for these specimens in comparison with the others (Table I) for approximately the same exposure conditions may be partially attributed to a combination of error in the method of measurement and the fact that the data were obtained by examination of only one specimen for each exposure condition.

A summary of all in-core corrosion results (including metallographic measurements) in high-oxygen water is shown in Figure 4, with corrosion curves taken from Lustman and Kerze ${ }^{(5)}$ for reference purposes. Inreactor corrosion rates are comparable with rates obtained for out-ofreactor exposure to steam at a temperature more than $200^{\circ} \mathrm{F}$ higher than the irradiation temperature. Also shown in Figure 4 and attesting to the 


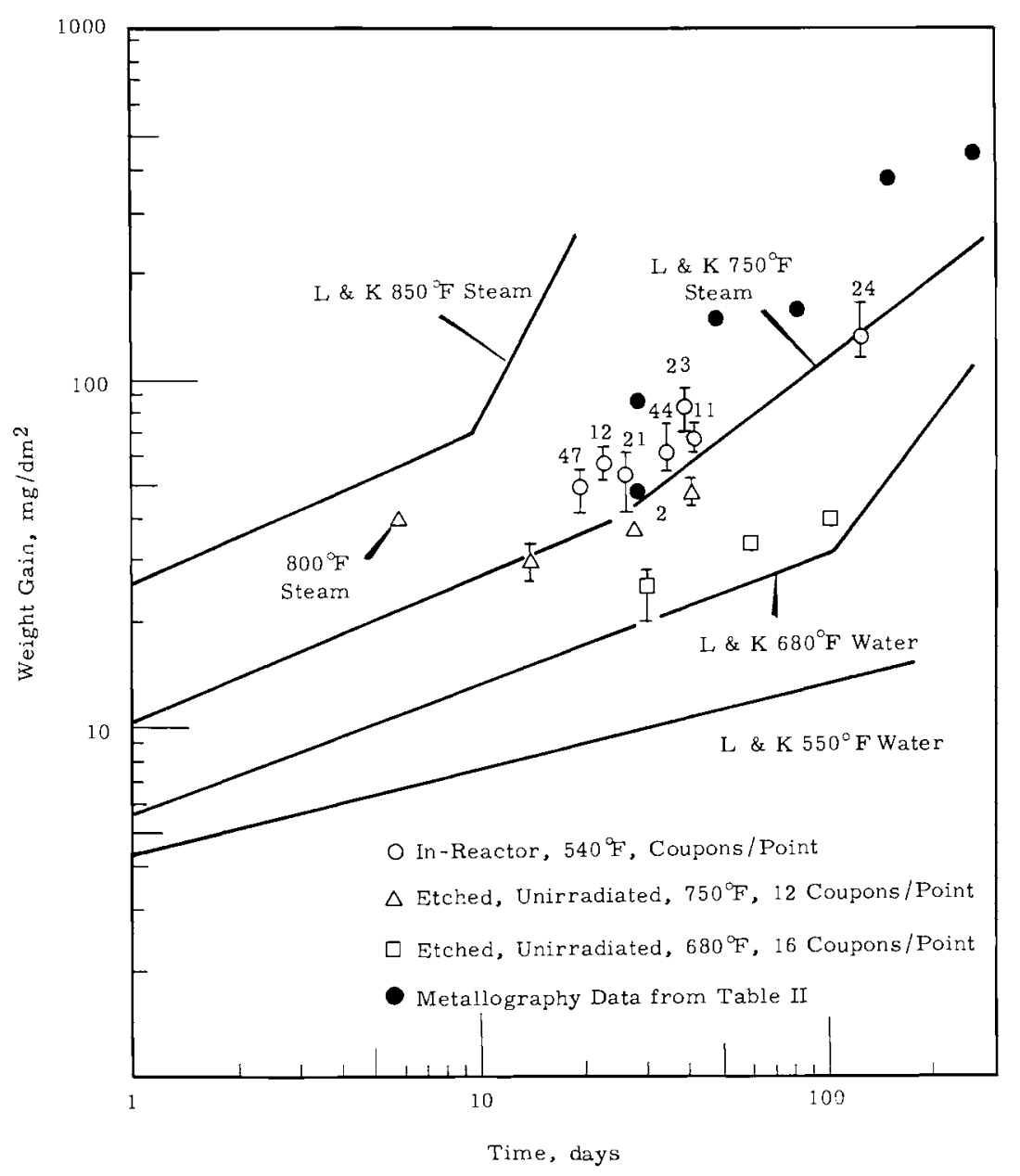

FIGURE 4

In- and Out-of-Reactor Corrosion Cha racteristics of Zircaloy-2 in High-Oxygen Water

acceptable quality of the base plate materials being used in these investiga tions are data points resulting from out-of-reactor autoclave exposure of coupons to 1500 psi refreshed, nondeaerated steam at $750^{\circ} \mathrm{F}$, and to 3000 psi refreshed, nondeaerated water at $680^{\circ} \mathrm{F}$.

In general, the results described in this section show that in the high-oxygen in-reactor environment, weight gains are 10- to 16-fold greater, and hydrogen pickup fractions are generally less than for out-ofreactor exposure.

Similar findings in high-oxygen water have been reported by other investigators. At Vallecitos Laboratory, metallographically measured 
oxide film thicknesses on several VBWR fuel rods exposed to $546{ }^{\circ} \mathrm{F}$ water (pH 5. 5 to $7.0,0.25 \mathrm{ppm} \mathrm{O}_{2}$ in water, $12 \mathrm{ppm} \mathrm{O}_{2}$ in steam) have shown oxidation rates equivalent to exposure to $700^{\circ} \mathrm{F}$ steam. Associated hydrogen pickup fractions we re also low, ranging from 12 to $18 \%$. $(6,7)$

Surfaces of irradiated coupons a ppeared smooth and uniformly dark and glossy. There was no evidence of gross discoloration of the oxide coatings, spalling, blistering, or other irregularities, even at sharp edges and corners, which would indicate a transformation of the oxide structure to the less protective white oxide. All of the coupons, however, bore a thickness of oxide greater than that which is normally considered to be the transition thickness ( 30 to $40 \mathrm{mg} / \mathrm{dm}^{2}$ ). Coupons exposed for 125 days in-reactor are compared in Figure 5 with one specimen exposed out-of-reactor.

Photomicrographs of the corrosion-product films on several dozen in- and out-of-reactor coupons were prepared and examined to compare the appearance and thickness of the films and the subfilm microstructure. Typical oxide photomicrographs covering a wide range of exposures are shown in Figure 6. Large vertical cracks appearing in the oxide of some of the irradiated specimens are believed to have been caused by distortions resulting from use of a punch to remove the specimens from the large coupons, since cracks of this type have not been observed on specimens removed by use of a milling machine.

Although each photomicrograph at 500X includes only about 0.008 linear in. of oxide cross section, continued good agreement was obtained between measured film thicknesses and actual weight gains for weighed specimens, indicating an absence of significant error attributable either to the presence of crud or nonuniformity in the film thickness. Metallography appears to provide a reasonable basis for assessing effects of in-reactor exposure on unweighed specimens.

In the course of metallographic measurements of oxide thickness on 0, 1-in。-thick tensile test specimens, some evidence of effects of cold work and preferred crystallographic orientation on oxidation rate (oxide thickness) 


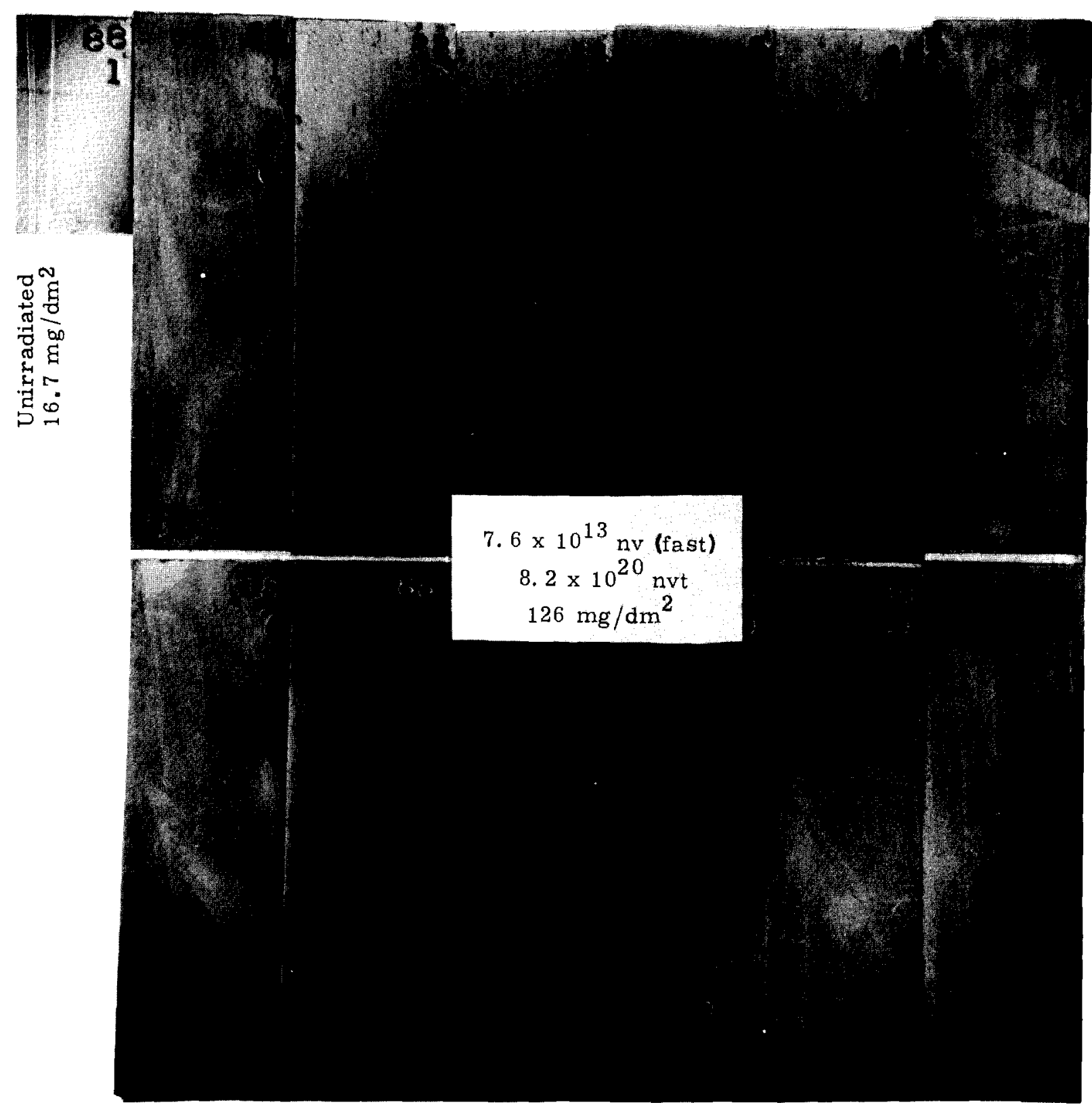

\section{FIGURE 5}

Comparison of Surface Appearance of Zircaloy-2 Coupons Exposed In- and Out-of-Reactor 125 Days at $540^{\circ} \mathrm{F}$ 


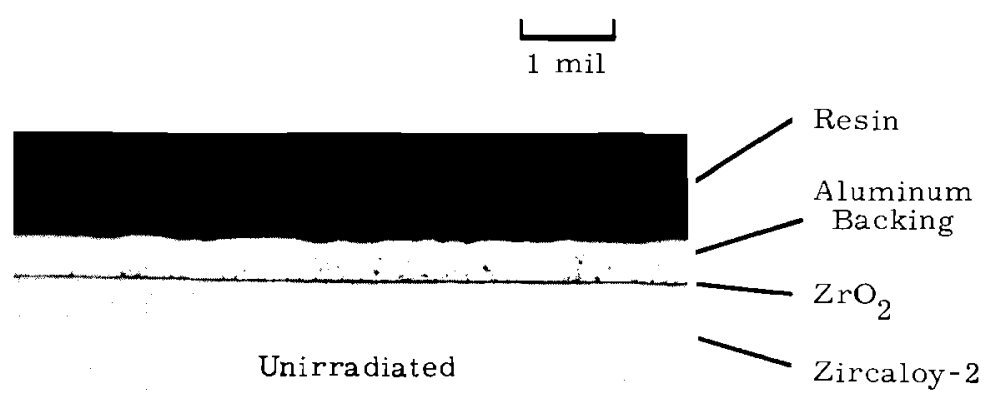

Film Thickness: $0.026 \mathrm{mil}\left(10.7 \mathrm{mg} / \mathrm{dm}^{2}\right)$

Weight Gain: $10.8 \mathrm{mg} / \mathrm{dm}^{2}$

19 Days

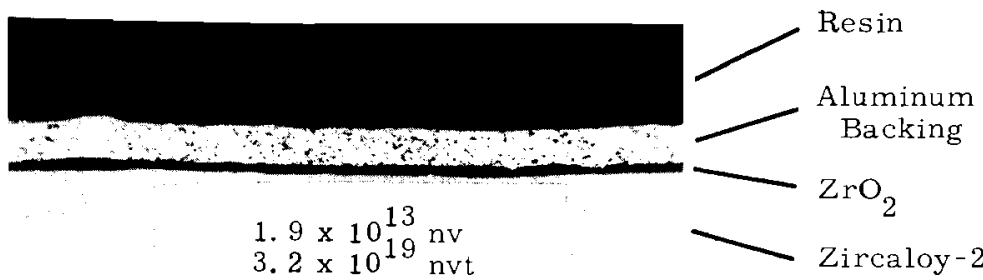

Film Thickness: $0.096 \mathrm{mil}\left(39.7 \mathrm{mg} / \mathrm{dm}^{2}\right.$ )

Weight Gain: $48.6 \mathrm{mg} / \mathrm{dm}^{2}$

19 Days
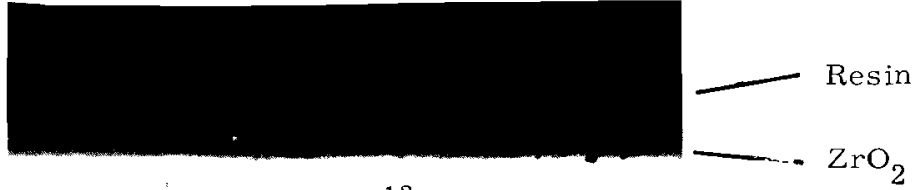

$7.6 \times 10^{13} \mathrm{nv}$
$8.2 \times 10^{20} \mathrm{nv}$

Film Thickness: $0.313 \mathrm{mil}\left(129 \mathrm{mg} / \mathrm{dm}^{2}\right.$ )

Weight Gain: $143 \mathrm{mg} / \mathrm{dm}^{2}$

125 Days

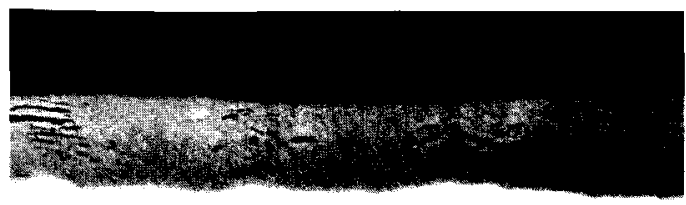

Resin

$$
\begin{aligned}
& \text { 8. } 2 \times 10^{13} \mathrm{nv} \\
& \text { 1. } 9 \times 10^{21} \mathrm{nvt}
\end{aligned}
$$

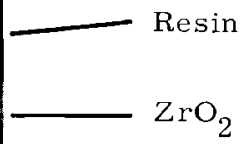

Zircaloy-2

Film Thickness: $1.03 \mathrm{mil}\left(426 \mathrm{mg} / \mathrm{dm}^{2}\right)$

Unweighed Specimen

264 Days

\section{FIGURE 6}

Metallographic Comparison of Oxide Films Formed on Zircaloy-2 In- and Out-of-Reactor in High-Oxygen Water at $540^{\circ} \mathrm{F}$ 
was observed. In addition, photomicrographs of precipitated hydride showed several cases of a marked decrease in the concentration of platelets from the edge to the center of annealed specimens of this type following exposure to high weight gains. These findings are described in detail in Appendix B.

\subsubsection{Heat Treatment Effects}

The effect of heat treatment on in-reactor corrosion performance was investigated briefly by use of a few Zircaloy-2 coupons taken from Hanford's New Production Reactor (NPR) process tube stock (subsequently $86 \%$ cold-worked) and from plate stock 6515 in the $10 \%$ cold-worked condition. Metallurgical conditions and heat treatments represented by the irradiated and control specimens were as follows:

i. As cold-worked

2. Heat treated $8 \mathrm{hr}$ in the $\alpha+\beta$ region $\left(1715^{\circ} \mathrm{F}\right)$ followed by furnace cooling

3. Treatment 2 ( bove) followed by heating $8 \mathrm{hr}$ in the $\beta$ region $\left(1850{ }^{\circ} \mathrm{F}\right)$ with a subsequent air quench $\left(>300^{\circ} \mathrm{F} / \mathrm{min}\right)$.

All specimens were sealed in helium-purged and evacuated quartz capsules during heat treatment and cooling. Half of the specimens of each treatment group were preautoclaved for $48 \mathrm{hr}$ in $572{ }^{\circ} \mathrm{F}$ water to form a protective oxide coating, while the remainder were tested in the bright-etched condition.

The results of a 49 -day exposure of these specimens to $540^{\circ} \mathrm{F}$ water in the ETR and in an out-of-reactor autoclave are summarized in Table III. The results for Plate 6515 material are shown in Figure 7 , along with outof-reactor results obtained by Goodwin ${ }^{(8,9)}$ in $750^{\circ} \mathrm{F}$ steam for Zircaloy-2 specimens similarly heat treated. Zircaloy-2 oxidation curves from Lustman and Kerze ${ }^{(5)}$ are included for reference purposes only. Fast flux intensity for the in-reactor specimens was $6.1 \times 10^{13} \mathrm{nv}(>1 \mathrm{MeV})$.

Data were obtained for only one coupon representing each treatment and surface condition, but these results generally confirm the out-of-reactor findings of Goodwin and others which have shown heat treatment above the 


\section{TABLE III}

EFFECT OF HEAT TREATMENT

ON OXIDA TION CHARACTERISTICS OF ZIRCALOY - 2

IN - AND OUT-OF - REACTOR

IN $540^{\circ} \mathrm{F}$ WATER*

\begin{tabular}{ccc}
\multicolumn{3}{c}{ Out-of-Reactor } \\
\hline Total & Hydrogen & \\
Weight & Gain, & Hardness, \\
Gain, & $\%$ & Rockwell \\
$\mathrm{mg} / \mathrm{dm}^{2}$ & Theoretical & $\mathrm{B}$ \\
\end{tabular}

\begin{tabular}{ccc}
\multicolumn{3}{c}{ In-Reactor } \\
\hline Total & Hydrogen & \\
Weight & Gain, & Hardness, \\
Gain, & $\% \%$ & Rockwell \\
mg/dm & Theoretical & B \\
\end{tabular}

NPR Zircaloy-2

As-cold-worked,

preautoclaved

13

17

105

23

25

107

As-cold-worked, etched

11

15

105

24

12

108

$\alpha+\beta$, furnace-cooled, preautoclaved

28

10

94

106

24

102

etched

59

22

110

19

$a+\beta$, furnace-cooled,

$B$ quenched,

preautoclaved

13

0

93

51

16

101

$a+R$, furnace-cooled,

$P$ quenched, etched

11

0

56

5

PLATE 6515

Zircaloy -2

As-cold-worked,

preautoclaved

13

14

100

61

35

103

As-cold-worked,

etched

\section{1}

22

100

45

23

103

$\alpha+\beta$, furnace-cooled, prea utoclaved

$16 \quad 41$

92

120

16

102

$a+R$, furnace-cooled,

etched

13

60

100

12

$\alpha+\beta$, furnace-cooled,

8 quenched,

preautoclaved

13

19

90

62

11

100

$10 \quad 25$

46

11

$B$ quenched, etched

* Weight gains include preexposure autoclave weight gain where applicable. 
BNWL - 88

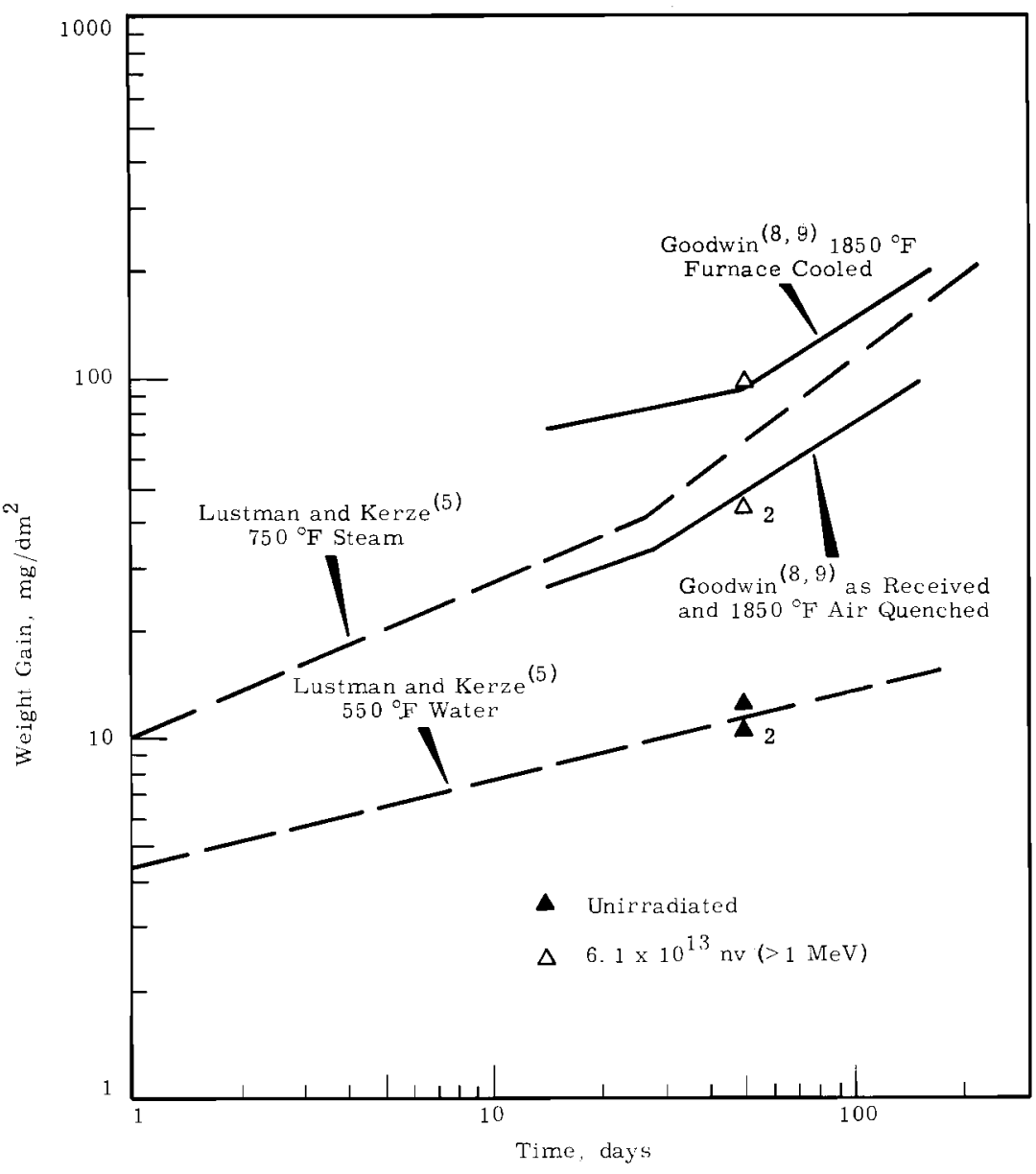

FIGURE 7

Effect of Heat Treatment and Reactor Irradiation on Oxidation of Etched Zircaloy-2 in High-Oxygen Water- 49 Days at $540^{\circ} \mathrm{F}$

$\alpha / \alpha+\beta$ transition followed by slow cooling to be detrimental to the corrosion resistance of Zircaloy-2. The original corrosion resistance, according to these findings, can be restored by a $\beta$ quench treatment followed by $\alpha$ anneal. The results also indicate that the irradiation effects are additive to heat treatment effects.

The extremely low weight gains of the $86 \%$ cold-worked NPR specimens in-reactor represent additional though meager evidence of a possible effect of extensive cold work or plate texture on the in-reactor corrosion process. It is noteworthy that in the test at hand, the $\beta$ quench heat treatment of the corrosion-prone, furnace-cooled NPR material restored 
corrosion resistance equivalent only to that of the less heavily cold-worked 6515 material, thus tending to minimize the significance of any small differences in composition between the two materials as a cause of the discrepancy in weight gain shown by the two materials in the original cold-worked condition.

The cause of the poor corrosion resistance of Zircaloy- 2 following slow cooling from the $\alpha+\beta$ or $\beta$ region has been adequately covered by Schwartz and co-workers ${ }^{(10)}$ and Kneppel, ${ }^{(11)}$ who pointed out that slow cooling is the heat treatment which most favors the precipitation of secondphase compounds of iron and nickel. Massive agglomerations of such second-phase materials have been shown to decrease the corrosion resistance of the alloy. However, as indicated by Schwartz, et al., these compounds in a finely dispersed state (as in $\beta$ quenched material) may serve to inhibit corrosion by means of a sacrificial mechanism.

Additional observations relative to apparent effects of heat and irradiation on second-phase particles are given in Appendix B.

\section{1. 3 Irradiated Coolant Effects}

The effect of reactor irradiation on the water coolant environment, though not well defined, is known to be extensive and variable depending upon the nature, composition, and energy of the radiation and the composition of the water. Complete characterization of the in-reactor corrosion mechanis $m$ requires a better understanding of the separate contributions of irradiated coolant and irradiated metal. Consequently, an exploratory experiment was conducted to gain an improved qualitative understanding of the contributions of irradiated $G-7$ loop coolant.

Zircaloy-2 coupons from Plate 6497 were exposed to irradiated highoxygen coolant at the two out-of-core positions indicated in Figure 2 for approximately 18 full power ( $175 \mathrm{MW}$ ) operating days at the indicated temperatures shown in Table IV. Four coupons were exposed at each location, two with a $48 \mathrm{hr}, 572^{\circ} \mathrm{F}$ water preautoclave oxide film and two in the asetched condition. 
TABLE IV

SUMMARY OF EFFECT OF OUT-OF-CORE EXPOSURE OF ZIRCALOY-2 TO IRRADIA TED HIGH-OXYGEN

ETR G-7 LOOP COOLANT

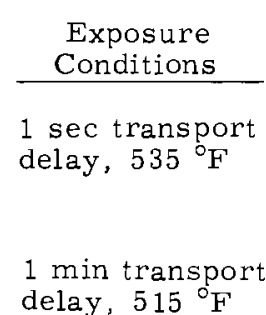

delay, $515^{\circ} \mathrm{F}$
Time,

Full Power Operating Days

18

17. 6

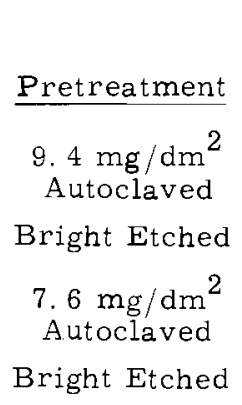

Average Total Weight Gain, $\mathrm{mg} / \mathrm{dm}^{2}$
Average Overall Hydrogen Gain, * $\%$ Theoretical

* Based on theoretical corrosion hydrogen associated with total weight gain.

Surfaces of all coupons exposed to coolant 1 min out of the core were smooth and glossy and showed interference colors over large areas. Preautoclaved coupons exposed to coolant $1 \mathrm{sec}$ out of the core also bore the typical dark, glossy oxide and showed interference colors over a few small areas. On the other hand, large a reas of the etched coupons in the $1 \mathrm{sec}$ location were covered with a rough, gray-white film of $\mathrm{ZrO}_{2}$, as determined by $\mathrm{X}$-ray diffraction. In general, the weight and hydrogen gains exhibited by preautoclaved material, particularly at the 1 min location, are not greatly different from out-of-reactor experience, but those specimens exposed to coolant freshly discharged from the active zone show higher weight gains and lower hydrogen pickup fractions than those farther downstream. In the case of the etched specimens, the differences are magnified.

In view of the small number of coupons involved and the fact that testing at the two locations was performed during two different reactor operating periods and not simultaneously, any general conclusions must be drawn with caution. It is noteworthy, however, that the oxidation and hydrogen sorption data do indicate a more strongly oxidizing character for loop coolant in the active zone of the reactor, becoming rapidly less oxidizing with time following discharge from the core. Such an effect is not unexpected in view of what is known of the radiolytic water decomposition 
processes taking plate in the active zone. These processes produce shortlived free radicals of various degrees of oxidizing power and hydrogen peroxide which itself undergoes rapid decomposition under the influence of radiation and in response to the catalytic activity of solid surfaces and minor amounts of impurities in the water. $(12,13)$

\section{2 Low-Oxygen (Hydrogenated) Water}

All of the foregoing in-reactor corrosion results showed an acceleration of the Zircaloy-2 oxidation process which was considerably greater than that observed by most other investigators who have explored irradiation effects on zirconium alloys up to this time. Aside from probable differences in metallurgical and environmental factors of unknown importance (and neglecting for the moment any attempt to reconcile gas or vapor versus liquid-environment data) two major differences between the G-7 loop experiments and many of the others are readily identified: (1) a high flux of highenergy neutrons and (2) considerable dissolved oxygen in the water environment. Therefore, in order to evaluate the effect of dissolved oxygen and provide data more representative of behavior in typical power-reactor water environments, an experiment was designed to suppress the equilibrium concentration of oxygen in the in-reactor environment. Concurrently, advantage was taken of an opportunity to obtain radiation effects information on other zirconium alloys of interest to reactor designers and to extend the range of flux to include intensities below $10^{13} \mathrm{nv}(>1 \mathrm{MeV})$. Materials selected for testing included the standard Zircaloy-2 plate stocks 6515 and 6497, NPR Zircaloy-2, Zircaloy-4, nickel-free Zircaloy-2, and $\mathrm{Zr}-3 \mathrm{wt} \% \mathrm{Nb}-1 \mathrm{wt} \% \mathrm{Sn}$. Chemical analyses and treatment histories for these materials are given in Appendix A.

As originally planned, the experimental program was to include two reactor cycles of exposure to low-oxyger water with representative specimens being removed at the end of the first cycle to provide data on shortterm effects. Specimens of each alloy were to be simultaneously exposed over a range of fast neutron flux from $<10^{10}$ to $>10^{14} \mathrm{nv}$. New quadrants 
to be exposed during the second cycle were to include specimens of each alloy in the bright-etched condition (as well as with preautoclaved films) to magnify the effects of variations in the concentration of radiolytically generated oxidants in the coolant. It was further planned that the entire series would be repeated at a later time in high-oxygen water.

Unfortunately, a fuel element rupture in the parallel M-3 loop at the ETR forced early termination of the first cycle of operation, and a severe crud burst at the beginning of the second reactor cycle (following removal of first-cycle specimens and deconta mination of loop piping) forced a shutdown of the loop and removal of second-cycle specimens for cleaning. Consequently, only coupons from short-term exposure in hydrogen-bearing water become available for study, and at this time it appears improbable that the experiment can be continued in the near future.

Analyses of quadrant flux wires showed that the fast neutron flux in the upper fringe of the active zone in the G-7 loop was not as severely attenuated as previous traverses had indicated, and the specimens exposed in that region consequently saw a flux only about one decade lower than the lowest levels previously obtained, instead of the two or three decades anticipated. In addition, the maximum fast flux obtained during the run was only about half as high as anticipated.

In spite of these disappointments, the data obtained do permit some very interesting comparisons of the relative behavior of Zircaloy-2, Zircaloy-4, nickel-free Zircaloy-2, and Zr-3 wt\% Nb-1 wt\% Sn in-reactor in the low-oxygen environment and comparisons of Zircaloy-2 in-reactor behavior in low and high oxygen water. The low neutron flux data, while not low enough to show a threshold level for effects on environmental reactions, do permit a more meaningful comparison of corrosion results in the ETR with those obtained elsewhere.

During the experimental run, oxygen and hydrogen were monitored at least once each shift, and $\mathrm{pH}$ was recorded continuously and checked in the laboratory once each day, as was water conductivity. Although it was intended to maintain hydrogen levels between 15 and $25 \mathrm{~cm}^{3} / \mathrm{kg}$ and oxygen 
at less than 0.1 ppm throughout the run, operating and analytical difficulties resulted in a few indications of off-specification performance, with hydrogen ranging from 6 to $85 \mathrm{~cm}^{3} / \mathrm{kg}$ and oxygen concentrations varying to $1 \mathrm{ppm}$. Most of the high oxygen indications occurred during periods of operation with low water temperatures $\left(<200^{\circ} \mathrm{F}\right)$, and therefore it is unlikely that this affected the experimental results significantly, if at all. Outlet water temperature exceeded $500{ }^{\circ} \mathrm{F}$ for 16.5 days of loop operation and remained near $536{ }^{\circ} \mathrm{F}$ during the major part of this period.

\section{2. 1 Weight Gain and Hydrogen Pickup-General}

Weight gain, hydrogen, and surface hardness results for the various alloys are shown in Table V. The weight gains of all of these alloys are similar at each flux position, they increase with increasing flux intensity, and no significant effect of cold work or of cold work versus annealing is discernible. The surface hardness of all coupons increased with increasing neutron exposure.

The ratio of weight gain in-reactor to weight gain out-of-reactor increased from about two to one at the lowest fast flux $\left(<6 \times 10^{12} \mathrm{nv}\right)$ to about five or six to one at the highest fast flux position $\left(>6 \times 10^{13} \mathrm{nv}\right)$, except for the $\mathrm{Zr}-3 \mathrm{wt} \% \mathrm{Nb}-1 \mathrm{wt} \% \mathrm{Sn}$ alloy, which showed no significant effect of flux on weight gain through $1.6 \times 10^{13} \mathrm{nv}$ and a maximum weight gain ratio of only two to one at the highest flux position. Environmental temperatures varied across the specimen rack as a consequence of gamma heating, but these temperature effects could not be expected to account for more than about $0.5 \mathrm{mg} / \mathrm{dm}^{2}$ of the weight gain differences during the short exposure period.

Oxide metallography on representative specimens of each alloy exposed at $6.2 \times 10^{13} \mathrm{nv}(>1 \mathrm{MeV})$ showed film thicknesses which agreed with weight gains within $10 \%$. Measured film thicknesses for three samples were less than indicated by weight gains, while one sample had a thicker film than corresponded to the specimen weight gain. These comparisons 
$\underline{\text { TABLE V }}$

NEUTRON FLUX EFFECTS ON THE BEHAVIOR

OF PREAUTOCLAVED ZIRCONIUM ALLOYS

IN LOW-OXYGEN WATER ${ }^{(a)}$

\begin{tabular}{|c|c|c|c|c|c|c|c|c|c|c|}
\hline $\begin{array}{l}\text { Neutron Flux } \\
(>1 \mathrm{MeV}) \text { nv }\end{array}$ & $\begin{array}{l}\text { Temperature, } \\
{ }_{\mathrm{O}}^{\mathrm{O}} \\
\end{array}$ & $\begin{array}{l}\text { Weight }(c) \\
\text { Gain, } \\
\underline{\mathrm{mg} / \mathrm{dm}^{2}} \\
\end{array}$ & $\begin{array}{c}\text { Hardness, } \\
\text { Rockwell } \\
\text { B } \\
\end{array}$ & $\begin{array}{c}\text { Hydrogen, } \\
\% \\
\text { Theoretical }\end{array}$ & $\begin{array}{l}\text { Weight }(\mathrm{c}) \\
\text { Gain, } \\
\underline{\mathrm{mg} / \mathrm{dm}} \\
\end{array}$ & $\begin{array}{c}\text { Hardness, } \\
\text { Rockwell } \\
\text { B } \\
\end{array}$ & $\begin{array}{c}\begin{array}{c}\text { Hydrogen, } \\
\%\end{array} \\
\text { Theoretical } \\
\end{array}$ & $\begin{array}{l}\text { Weight(c) } \\
\text { Gain, } \\
\underline{m g / \mathrm{dm}^{2}} \\
\end{array}$ & $\begin{array}{c}\text { Hardness, } \\
\text { Rockwell } \\
\text { B } \\
\end{array}$ & $\begin{array}{c}\underset{\%}{\text { Hydrogen }} \\
\text { Theoretica }\end{array}$ \\
\hline & & \multicolumn{3}{|c|}{ Plate 6515} & \multicolumn{3}{|c|}{ Plate 64.97} & \multicolumn{3}{|c|}{ NPR Zircaloy-2 } \\
\hline $0^{(\mathrm{b})}$ & 536 & 3. $1^{20(\mathrm{~d})}$ & 100 & 23 & $2.6^{20}$ & 100 & 29 & $\begin{array}{l}2.7^{86} \\
2.7_{2}\end{array}$ & $\begin{array}{r}102 \\
96\end{array}$ & $\begin{array}{l}53 \\
14\end{array}$ \\
\hline $2.5 \rightarrow 6 \times 10^{12}$ & 520 & $4.8^{40}$ & 102 & 54 & $\begin{array}{l}4.5^{20} \\
4.8\end{array}$ & $\overline{96}$ & $\begin{array}{r}56 \\
103\end{array}$ & $\begin{array}{l}3.1^{86} \\
3.3^{8}\end{array}$ & $\begin{array}{l}- \\
-\end{array}$ & $\begin{array}{l}94 \\
37\end{array}$ \\
\hline $2 \rightarrow 6.6 \times 10^{12}$ & 520 & $5.7^{20}$ & 100 & 35 & 4. $8^{20}$ & 100 & 47 & $\begin{array}{l}5.5^{86} \\
6.0_{2}\end{array}$ & $\begin{array}{r}102 \\
98\end{array}$ & $\begin{array}{l}68 \\
34\end{array}$ \\
\hline $1.6 \times 10^{13}$ & 523 & $6.8_{2}^{40}$ & 104 & 44 & $\begin{array}{l}\text { 6. } 8^{10} \\
6.4^{20}\end{array}$ & $\begin{array}{l}101 \\
102\end{array}$ & $\begin{array}{l}38 \\
36\end{array}$ & $\begin{array}{l}6.4^{86} \\
6.6^{8}\end{array}$ & $\begin{array}{l}106 \\
101\end{array}$ & $\begin{array}{l}76 \\
24\end{array}$ \\
\hline $6.2 \times 10^{13}$ & 534 & 16. $72^{40}$ & 104 & 35 & $\begin{array}{l}14.8^{10} \\
14.2^{40}\end{array}$ & $\begin{array}{l}102 \\
106\end{array}$ & $\begin{array}{l}34 \\
45\end{array}$ & $\begin{array}{l}14.2^{86} \\
13.0\end{array}$ & $\begin{array}{l}106 \\
102\end{array}$ & $\begin{array}{r}50 \\
9\end{array}$ \\
\hline \multirow[t]{2}{*}{$6.6 \times 10^{13}$} & 532 & 20. $0_{2}$ & $101^{(\mathrm{e})}$ & 38 & & & & & & \\
\hline & & \multicolumn{3}{|c|}{ Zircaloy -4} & \multicolumn{3}{|c|}{ Nickel-Free Zircaloy-2 } & \multicolumn{3}{|c|}{ Zircaloy -3 wt $\% \mathrm{Nb}-1 \mathrm{wt} \% \mathrm{Sn}$} \\
\hline $0^{(\mathrm{b})}$ & 536 & $2.6_{2}$ & 92 & 5 & 3. $1_{2}$ & 94 & 18 & 6. $1_{2}$ & 97 & 14 \\
\hline $2.5 \rightarrow 6 \times 10^{12}$ & 520 & 3. $8_{2}$ & - & 35 & 4. $6_{2}$ & - & 19 & - & - & - \\
\hline $2-6.6 \times 10^{12}$ & 520 & 4. $3_{2}$ & 92 & 28 & 4. ${ }^{2} 2$ & 94 & 16 & 4. 42 & 100 & 17 \\
\hline $1.6 \times 10^{13}$ & 523 & 6. $1_{2}$ & 95 & 37 & 6.32 & 97 & 22 & $6.6{ }_{2}$ & 104 & 16 \\
\hline $6.2 \times 10^{13}$ & 534 & $13.6_{2}$ & 95 & 45 & 13. $1_{2}$ & 99 & 34 & 12.42 & 106 & 16 \\
\hline
\end{tabular}

(a) 16.5 days exposure at indicated approximate temperatures.

(b) Zero flux data from exposure in out-of-reactor autoclave.

(c) Indicated weight gains are in addition to $48 \mathrm{hr}$ preautoclave film averaging $8.0 \mathrm{mg} / \mathrm{dm}^{2}$

for Zircaloy-2, $7.3 \mathrm{mg} / \mathrm{dm}^{2}$ for Zircaloy-4, $7.7 \mathrm{mg} / \mathrm{dm}^{2}$ for nickel-free Zircaloy-2, and

$7.4 \mathrm{mg} / \mathrm{dm}^{2}$ for Zircaloy-3 wt\% Nb-1 wt \% Sn

(d) Superscripts indicate percent cold work if not annealed; subscripts indicate number

of specimens averaged.

(e) Original plate hardness: 94. 
are consistent with film thickness-weight gain comparisons mentioned previously in connection with testing in high-oxygen water and confirm the uniformity of oxide films and absence of significant error from unremoved crud or oxide dissolution in low- as well as high-oxygen water.

Hydrogen pickup fractions were generally higher for irradiated specimens than for nonirradiated specimens except in the case of the $\mathrm{Zr}-3 \mathrm{wt} \% \mathrm{Nb}-1 \mathrm{wt} \%$ Sn alloy, which exhibited no significant change.

\section{2. 2 Weight Gain and Hydrogen Pickup for Zircaloy-2}

The weight-gain results for Zircaloy-2 are plotted in Figure 8, along with 19, 23, and 26-day high-oxygen water data for comparison purposes. Of course, in this case low weight-gain (pretransition) results in

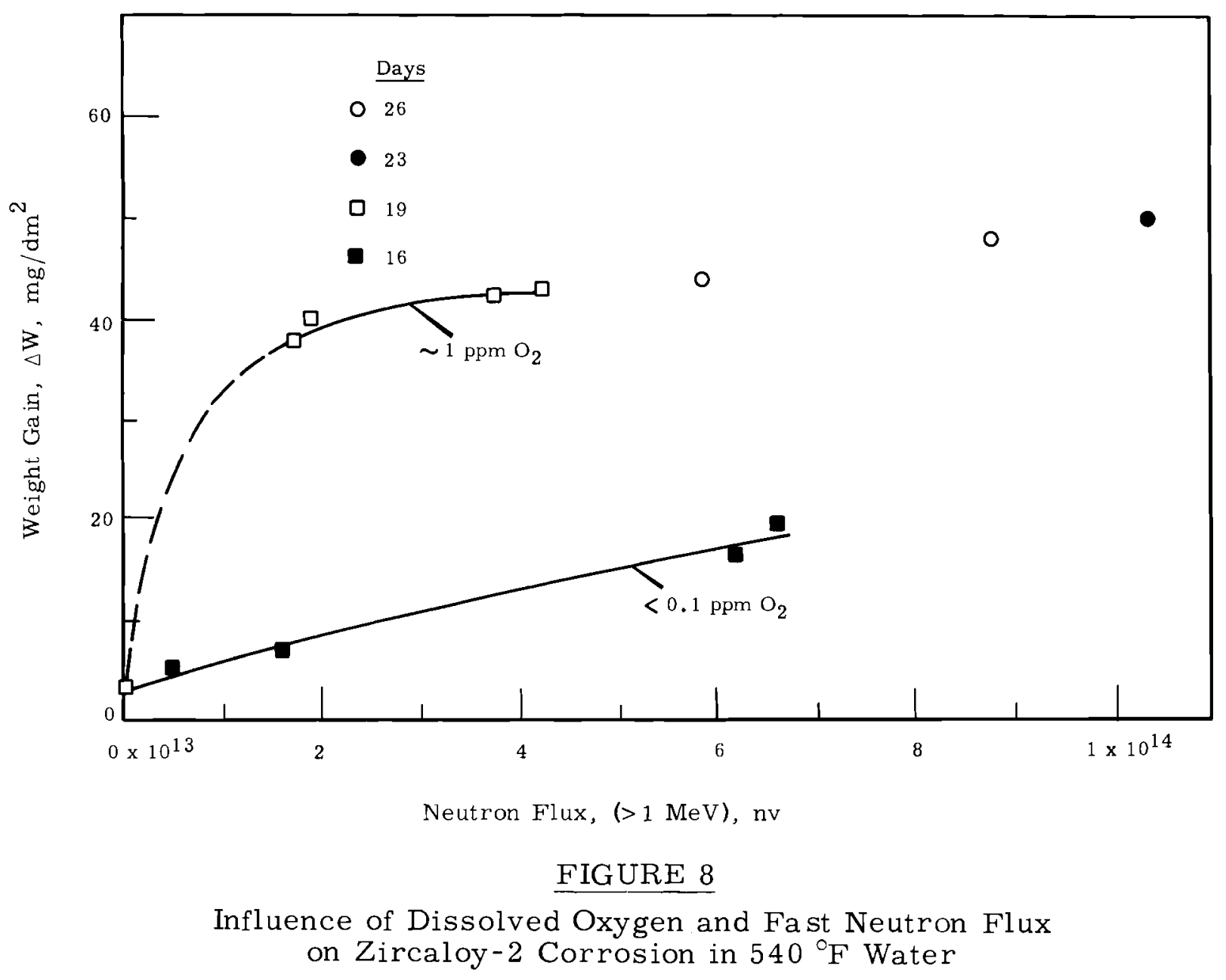

No. $0650581-2$ 
the low-oxygen water environment are being compared with post-transition data previously obtained. There is no indication of a saturation effect of flux over this range of weight gains in low-oxygen water. Whether the apparently linear flux-weight gain relationship would continue beyond transition for low-oxygen water or would occur below transition for high-oxygen water must remain a matter of conjecture pending further experimental work in these areas. These curves do show that over the range of weight gains and flux intensities studied, average oxidation rates in the low-oxygen water are less than half those obtained in high-oxygen water.

Further comparis on of low-oxygen in-reactor weight-gain results for Zircaloy-2 with out-of-reactor data obtained el sewhere ${ }^{(14)}$ at higher temperatures (Figure 9) shows an oxidation rate greater than for unirradiated exposure to $680^{\circ} \mathrm{F}$ water. Previously it was noted that in-reactor exposure to high-oxygen $\mathrm{G}-7$ loop water resulted in oxidation rates greater than those obtained out-of-reactor in $750^{\circ} \mathrm{F}$ steam (Figure 4).

The effect of heavy cold work in reducing oxidation rates in-reactor which was observed for NPR material in the higher oxygen water (Table III) is conspicuously absent in the low-oxygen environment. The weight-gain data were derived from only a few specimens exposed in each environment, but the validity of the results was confirmed by metallography. Consequently, although the difference is known to be real, factors other than reactor irradiation and oxygen content of the water environment could be operative, and any attempt to explain the discrepancy based on the limited data available from these two experiments would indeed be premature.

In-reactor hydrogen pickup fractions for Zircaloy-2 during the lowoxygen cycle were generally higher by a factor of about two than either for unirradiated exposure or the higher oxygen in-reactor condition. Lowoxygen ETR hydrogen pickup data for Zircaloy-2 are compared in Figure 10 with out-of-reactor results obtained elsewhere at higher temperatures. 

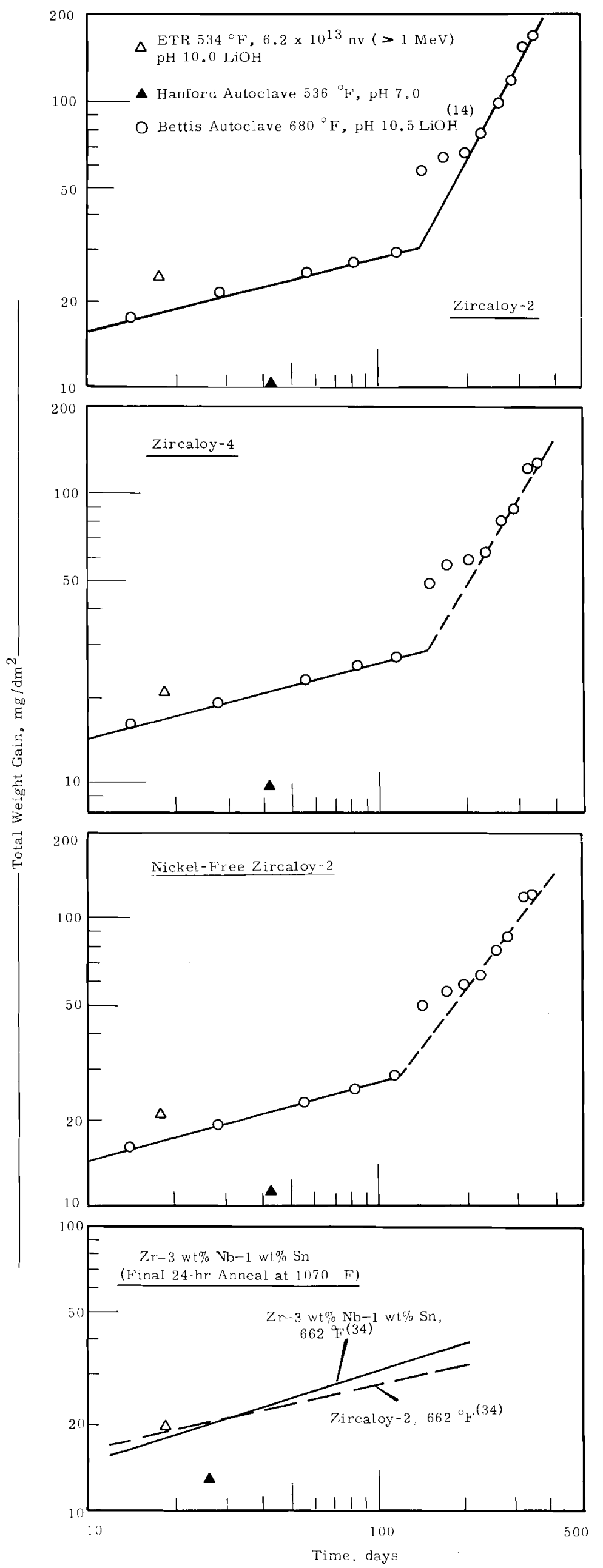

FIGURE 9
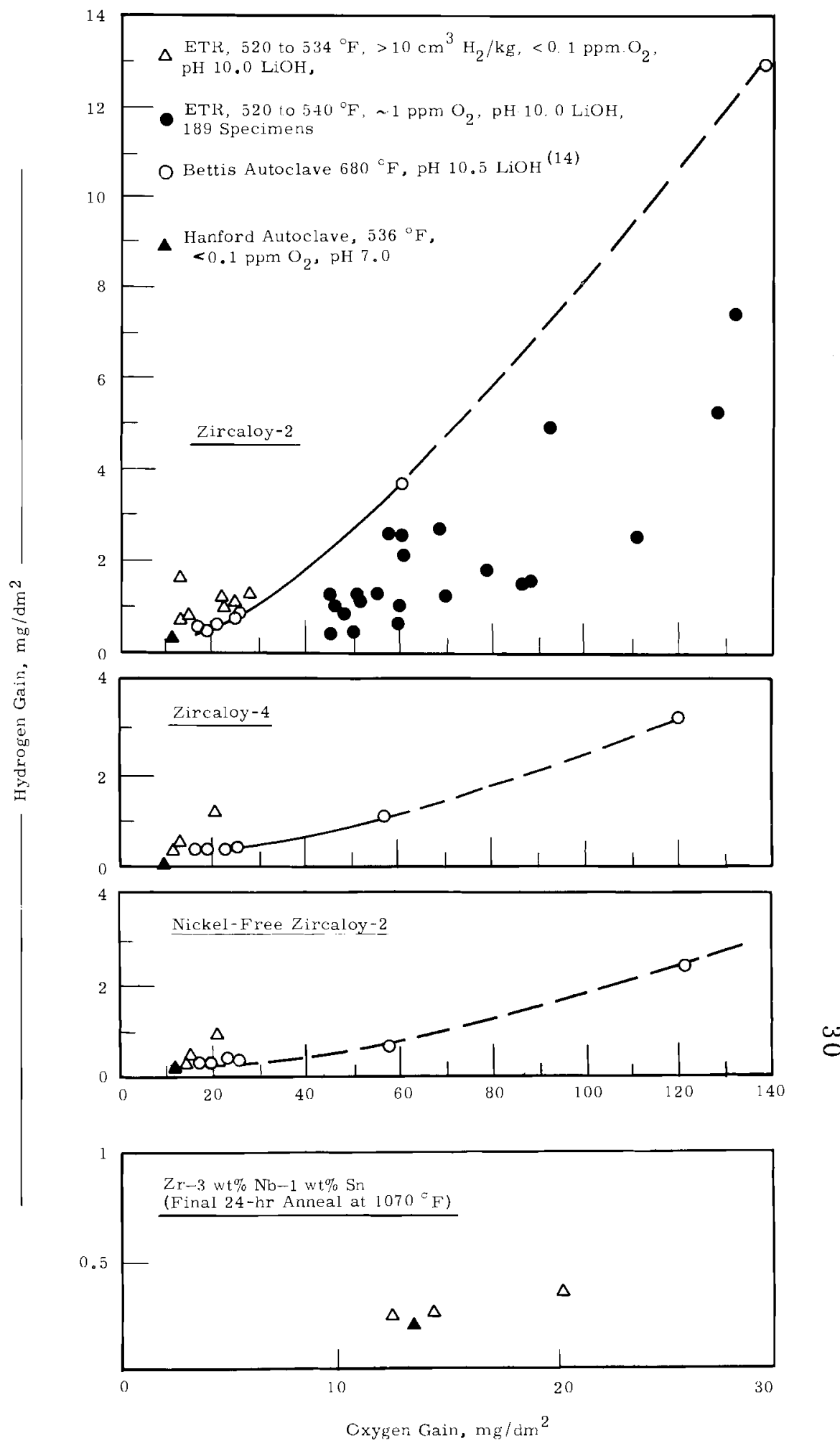

FIGURE 10

Comparison of In- and Out-of-Reactor Corrosion of Zirconium Alloys

FIGURE 9

Comparison of In- and Out-of-Reactor Corrosion of Zirconium Alloys in Low-Oxygen Water

Comparison of In- and Out-of-Reactor Hvdrogen Picksup Behag,vior

\section{FIGURE 10}

Comparison of In- and Out-of-Reactor Hydrogen Pickup Behavior of Zirconium Alloys 
two different sources and which were exposed simultaneously at the same location in the reactor and both in the preautoclaved and bright-etched condition.

It can be noted that the increased weight gain attributable to inreactor exposure is approximately the same for etched and preautoclaved specimens, and only slightly different for the two materials. The average indicated rate increase is near $1 \mathrm{mg} / \mathrm{dm}^{2} /$ day. This rate is less than that for samples exposed for comparable periods of time in ETR G-7 loop water containing $\sim 1$ ppm oxygen, but simila $r$ to rates observed in oxygencontaining ETR water following long exposure at comparable flux levels.

It is also of interest to note that in-reactor hydrogen pickup fractions are greater for etched specimens, indicating a strong protective effect of the out-of-reactor-grown preautoclave film.

Specimens of NPR $86 \%$ cold-worked material in the bright-etched condition were also exposed to the low-oxygen water in-and out-of-reactor, and it is interesting to compare the results of exposing etched versus preautoclaved specimens at different flux levels and in different water environments (Table VII).

TAB - BLE VII

EFFECT OF PREA UTOCLAVED OXIDE FILM, NEUTRON IRRADIATION, AND WATER OXYGEN ON WEIGHT GAIN AND HYDROGEN PICKUP FOR ZIRCA LOY - 2

\begin{tabular}{|c|c|c|c|c|c|c|c|}
\hline \multirow{2}{*}{$\begin{array}{l}\text { Neutron Flux } \\
(>1 \text { MeV), nv }\end{array}$} & \multirow{2}{*}{$\begin{array}{c}\text { Specimen } \\
\text { Type }\end{array}$} & \multirow{2}{*}{$\begin{array}{l}\text { Exposure } \\
\text { Time, } \\
\text { Days }\end{array}$} & \multirow{2}{*}{$\begin{array}{l}\text { Water } \mathrm{O}_{2} \\
\quad \mathrm{ppm}\end{array}$} & \multicolumn{2}{|c|}{ Weight Gain, $\mathrm{mg} / \mathrm{dm}^{2}$} & \multicolumn{2}{|c|}{$\begin{array}{l}\text { Hydrogen Gain, } \\
\% \text { Theoretical }\left(b^{\prime}\right)\end{array}$} \\
\hline & & & & Preautoclaveo & Etched & Preautoclaved & Etched \\
\hline 0 & $N P R^{86}$ & 49 & -1 & $1.2^{(c)}$ & 11 & 17 & 15 \\
\hline $6.1 \times 10^{13}$ & $\mathrm{NPR}^{86}$ & 49 & $\sim 1$ & $13^{(c)}$ & 24 & 25 & 12 \\
\hline 0 & 6515 & 49 & $\sim 1$ & 1. $3^{(\mathrm{c})}$ & 11 & 14 & 22 \\
\hline $6.1 \times 10^{13}$ & 6515 & 49 & $\sim 1$ & $50^{(\mathrm{c})}$ & 45 & 35 & 23 \\
\hline 0 & NPR 86 & 16.5 & $<0,1$ & 2.7 & 11 & 53 & 43 \\
\hline$<6.0 \times 10^{12}$ & $\mathrm{NPR}^{86}$ & 16.5 & $<0.1$ & 3. 1 & 12 & 94 & 104 \\
\hline$<6.6 \times 10^{12}$ & $N P R^{86}$ & 16.5 & $<0.1$ & 5.5 & 10 & 68 & 101 \\
\hline 0 & 6515 & 16.5 & $<0.1$ & 2.9 & 9.8 & 33 & 14 \\
\hline $6.6 \times 10^{13}$ & 6515 & 16.5 & $<0.1$ & 20 & 26 & 38 & 43 \\
\hline 0 & Bettis & 16.5 & $<0.1$ & 2.5 & 10 & 23 & 11 \\
\hline $6.6 \times 10^{13}$ & Bettis & 16.5 & $<0.1$ & 17 & 24 & 29 & 38 \\
\hline
\end{tabular}

(a) All weight gains are in addition to the preautoclave film, if any.

(b) Based on theoretical hydrogen associated with total weight gain.

(c) Preautoclaved film approximately $11 \mathrm{mg} / \mathrm{dm}^{2}$; all others approximately $8 \mathrm{mg} / \mathrm{dm}^{2}$. 
These data show that in high-oxygen water out-of-reactor, a prior thin film of oxide has the effect of reducing the fractional pickup of hydrogen, whereas the reverse is true in low-oxygen water. For specimens in the neutron flux in high-oxygen water, the prefilm acts to cause a higher fractional pickup, whereas in low-oxygen water in-reactor the prefilm reduces the hydrogen pickup. Of course these data pertain for the most part to the pretransition stage of oxidation and they represent the behavior of only one or two specimens in each environment, but they do suggest a barrier effect attributable either to the nature of out-of-reactor-formed preautoclave film which was formed in each case in low-oxygen water, or to an influence of oxide thickness alone, or both. Apparently this barrier acts either to prevent ready access of bulk coolant in its oxidizing or reducing state to the metal-oxide interface or it acts as a trap for products of radiolytic dissociation and corrosion hydrogen generated within the film.

Yeniscavich and co-workers have shown previously that hydrogen pickup in-reactor in low-oxygen water is inhibitied by an oxide prefilm.

All of the specimens which had been exposed in quadrants positioned in the perturbed flux at the fringe of the active zone were sectioned into six $1 / 2$ by $1 \mathrm{in.}$ strips for hardness testing, hydrogen analysis, and metallographic determination of oxide thickness. The effective fast flux at the location of each section was determined by analysis of corresponding sections of the attached vertical and horizontal flux wires. No significant or consistent variations of hardness or hydrogen content were observed from section to section along the length of any of the specimens, although the flux varied from about 2.0 to $6.6 \times 10^{12} \mathrm{nv}(>1 \mathrm{MeV})$.

Samples from the center of each of the six sections cut from two Zircaloy-2 specimens were mounted and polished for oxide metallography at $1000 \mathrm{X}$. Averages of more than 20 measurements on each sample are shown in Table VIII.

The total film thickness following such short exposure at low flux was too thin to avoid considerable scatter due to a combination of measurement error and normal, minor variations in film thickness. This was 
TABLE VIII

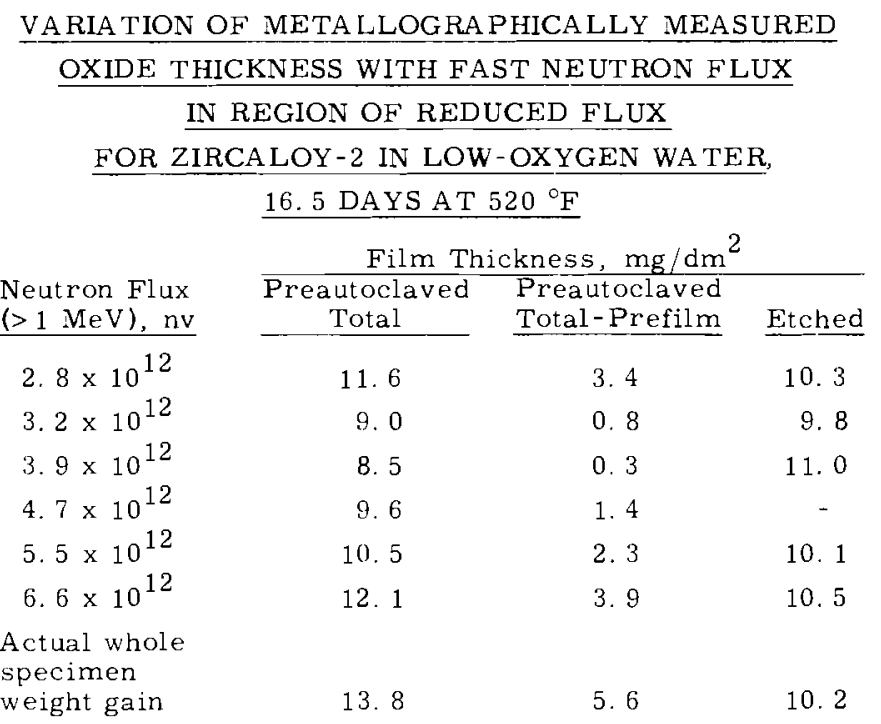

particularly true for the preautoclaved specimen, where a relatively large average prefilm thickness had to be subtracted. The results for the material exposed in the etched condition a re therefore more indicative of flux effects on rate of film growth.

In view of the inherent difficulty in the optical measurement of such thin oxide films, it is possible that any small dependence of oxidation rate on flux at these low levels of flux would be masked. Even so, the fast flux varied by more than a factor of two, and these metallographic measurements show no evidence of either any consistent increase in film thickness with flux or an overall increase approaching the approximately $50 \%$ which might have been expected on the basis of results at higher flux levels (Table V). Therefore, pending the development of improved methods of film thickness measurement and the examination of more specimens, it is reasonable to conclude that in low-oxygen water the influence on pretransition oxidation rate of variations in fast flux in the region below $1 \times 10^{13} \mathrm{nv}$ is not as great as in the region between $1 \times 10^{13} \mathrm{nv}$ and $1 \times 10^{14} \mathrm{nv}$.

In general, results of exposure of Zircaloy-2 in a low-oxygen environment in the ETR G-7 loop are quite different from results of examination of PWR components where no abnormal hydrogen pickup nor excessive oxide thickness has been observed for the jackets of PWR fuel and 
blanket rods and other components, $(16-18)$ and where close agreement has been obtained between actual oxide thicknesses and predictions based on out-of-reactor exposure. ${ }^{(19)}$

On the other hand, the results of investigations at other sites support the Hanford findings to some degree. Early investigations of irradiation effects on Zirconium-steam reactions at Harwell indicated increases in post-transition corrosion rates and decreases in time to transition by about eight-fold at $644{ }^{\circ} \mathrm{F}$. These experiments were performed in DIDO and PLUTO in hollow fuel elements supplied with flowing steam. Radiation levels were $\sim 3 \times 10^{13} \mathrm{nv}(>1 \mathrm{MeV})$ and $10^{8}$ to $10^{9} \mathrm{r} / \mathrm{hr}$ of $\gamma$ radiation. These experiments showed no effect of irradiation on the fraction of corrosion hydrogen absorbed by the metal, thereby indicating increases in hydriding rates proportional to the increased corrosion. Hydrogen findings of the present Hanford experiments are somewhat different, with the preponderance of data showing reduced pickup in oxygen-bearing water and increased pickup in low-oxygen water mainta ined under an over-pressure of hydrogen. However, it must be recognized here that the environments are not the same (vapor versus liquid) and both temperature differences and concentration effects could alter diffusion-controlled processes involved in hydrogen pickup behavior.

A 3- to 10-fold increase in corrosion as compared with out-ofreactor rates and absorption of approximately $50 \%$ of the corrosion hydrogen ${ }^{(21)}$ was revealed by metallographic examination of Zircaloy-2 safety rod guide tubes from the Heavy Water Components Test Reactor (HWCTR) following 250 days in-core operation in a fast flux of $3 \times 10^{12} \mathrm{nv}(>1 \mathrm{MeV})$ and in $390{ }^{\circ} \mathrm{F}, \mathrm{pH} 10.5$ (LiOH) water containing 10 to $25 \mathrm{~cm}^{3} \mathrm{D}_{2} / \mathrm{kg}$. While the cited corrosion rates are somewhat greater than the present ETR results would indicate for hydrogen-bearing water at the indicated flux levels, the hydrogen pickup results are reasonably comparable. It should be noted also that the ETR irradiations are conducted at a considerably higher temperature, and there is reason to believe that some suppression of the accelerating effects of radiation on the corrosion process may be expected at higher temperatures as indicated below. 
British in-reactor experiments in the thin-film region $(10$ to $15 \mathrm{mg} / \mathrm{dm}^{2}$ weight gain) demonstrated that oxidation of Zircaloy-2 in steam in this region was greatly accelerated by radiation, although the effect was not consistently reproducible and there were indications that the accelerating effect might be due to $y$ radiation. (22) Their post-transition data showed no increase in rate of oxidation in neutron flux intensities of $5 \times 10^{10}$ and $1 \times 10^{11} \mathrm{nv}(>1 \mathrm{MeV})$ at temperatures ranging from 572 to $842^{\circ} \mathrm{F}$, acceleration at $572^{\circ} \mathrm{F}$ only (not at higher temperatures) in a fast flux of $2 \times 10^{12} \mathrm{nv}$, and only at 752 and $644^{\circ} \mathrm{F}$ in a fast flux of $3 \times 10^{13}$ (not at 572 or $842^{\circ} \mathrm{F}$ ). In all cases where irradiation effects were found, the acceleration factors were lower at the more elevated temperatures. Percent hydrogen absorption was unaffected by radiation over the range of temperatures investigated.

The results of recent Canadian experiments involving pure zirco: nium and several binary zirconium alloys in the $\mathrm{X}-2$ loop of the NRX Reactor $\left[\sim 10^{12} \mathrm{nv}(>1 \mathrm{MeV}), 493^{\circ} \mathrm{F} \mathrm{pH} \sim 10(\mathrm{LiOH}), 13\right.$ to $\left.37 \mathrm{~cm}^{3} \mathrm{H}_{2} / \mathrm{kg}\right]$ have shown increases in average oxidation rates from $50 \%$ to more than a factor of two for the alloys and a factor of eight for the pure metal as compared with out-of-reactor behavior. (23) These studies also indicate an influence of flux intensity on the corrosion process. The data are reasonably consistent. with ETR low-oxygen-water findings reported herein.

Significant corrosion effects which could be attributed to fast neutrons was shown by work performed on Zircaloy-2 at Oak Ridge by use of LITR and MTR facilities and autoclaves containing oxygenated solutions of $\mathrm{U}^{2} 3 \underline{5}$ depleted $\mathrm{UO}_{2} \mathrm{SO}_{4}, \mathrm{D}_{2} \mathrm{O}$, and dilute acid in the temperature range 482 to $572^{\circ} \mathrm{F}$. Limited testing in hydrogen-bearing water also showed significant increases in corrosion rates (about a factor of two greater than expected in absence of radiation) but less than for oxygenated solutions. Fast neutron flux intensity varied from 1 to $7.5 \times 10^{12} \mathrm{nv}$ and exposure times from 190 to $1610 \mathrm{hr}$. 
5. 2. 3 Weight Gain and Hydrogen Pickup for Zircaloy-4, NickelFree Zircaloy -2 and $\mathrm{Zr}-3 \mathrm{wt} \% \mathrm{Nb}-1 \mathrm{wt} \% \mathrm{Sn}$

An extensive review of the development, treatment, and out-ofreactor environmental behavior of Zircaloy-4 and nickel-free Zircaloy-2 has been given by Kass, $(25,26)$ and a continuing project has been aimed at establishing the long-term effects of various processing treatments on the corrosion and hydrogen pickup characteristics of these alloys as well as Zircaloy-2. (14) In-reactor performance data on the nickel-free alloys is scanty, however.

Zirconium-niobium alloys have shown promise of improved hightemperature strength, reduced absorption combined with increased solubility for hydrogen*, and more favorable distribution and orientation of hydride, with the net effect of reducing the susceptibility of these alloys to corrosion hydrogen embrittlement. The environmental behavior of zirconium-niobium binary alloys and ternary alloys (primarily additions of tin and copper) has been studied fairly extensively out-of-reactor, where corrosion performance has been found very sensitive to nitrogen contamination, heat treatment, niobium content, and the nature and amount of the ternary alloying constituent. $(27-34)$ However, only a very limited a mount of work has been or is being done on the behavior of these alloys under irradiation. $(22,34,35)$

$\mathrm{Zr}-3 \mathrm{wt} \% \mathrm{Nb}-1 \mathrm{wt} \% \mathrm{Sn}$ was selected for testing at this laboratory because of its immediate availability in sufficient quantities for thorough evaluation of mechanical as well as physical-chemical behavior. Additionally, this particular alloy is being evaluated with respect both to mechanical effects and environmental reactions in-and out-of-reactor by Metallgesellschaft A. G. of Frankfurt/Main, Germany, on a cooperative contract between Euratom and the United States. Irradiations are being carried out in the GKSS reactor near Hamburg. It is recognized, however,

* Currently subject to question in view of recent findings reported by A. Sawatzky in Canadian Materials Newsletter, no. 20, FD-34-20, October, 1964. 
that both the niobium and tin content may be in excess of the optimum amounts for corrosion resistance in water at the lower temperatures employed in the ETR.

Weight gain results for these alloys are shown in Figure 9 in comparison with out-of-reactor data obtained elsewhere ${ }^{(14)}$ at higher temperatures and at $536{ }^{\circ} \mathrm{F}$ in autoclave facilities at this laboratory. It appears that irradiation at $6.2 \times 10^{13} \mathrm{nv}(>1 \mathrm{MeV})$ in $534^{\circ} \mathrm{F}$ hydrogen-bea ring, low oxygen $(<0.1 \mathrm{ppm})$ water results in oxidation rates greater than for out-ofreactor exposure to $680^{\circ} \mathrm{F}$ water.

$\mathrm{Zr}-2.5 \mathrm{wt} \% \mathrm{Nb}$ alloys are reported very sensitive to low concentrations of $\mathrm{LiOH}$ in water $(\mathrm{pH} 10)$. The oxide formed has been found to contain lithium ions, which appeared to have an adverse effect upon the corrosion resistance. (36) However, the Hanford in-reactor experiment with the $\mathrm{Zr}-3 \mathrm{wt} \% \mathrm{Nb}-1 \mathrm{wt} \% \mathrm{Sn}$ alloy in $\mathrm{pH} 10$ (LiOH) water showed no adverse effects attributable to lithium ions when compared with in- and out-ofreactor behavior of this and the other zirconium alloys (Table V).

Hydrogen pickup results for the Zircaloy-2, Zircaloy-4, and nickelfree Zircaloy-2 alloys of this experiment are shown in Figure 10 in comparison with out-of-reactor data obtained elsewhere at higher temperatures. (14) Hydrogen pickup data for a $\mathrm{Zr}-\mathrm{Nb}-\mathrm{Sn}$ alloy of a composition and heat treatment and in an environment approximating that of the present experiment could not be found in the available literature for comparison purposes. However, data obtained elsewhere in steam, moist air, and water for alloy compositions varying to $21 / 2 \mathrm{wt} \% \mathrm{Nb}$ and to $11 / 2 \mathrm{wt} \% \mathrm{Sn}$ and for usually much longer exposure times show low hydrogen pickupusually less than $10 \%$-at the lower temperatures and particularly at small weight gains. $(28-30)$ The $\mathrm{Zr}-3 \mathrm{wt} \% \mathrm{Nb}-1 \mathrm{wt} \%$ Sn alloy showed no significant difference in pickup fraction between out-of-reactor controls and irradiated materials and exhibited the lowest in-reactor pickup fraction of the test group: $\sim 16 \%$. The microstructure of this alloy was extremely finegrained, and although the specimens contained hydrogen at the level of about 20 ppm, no hydride platelets could be observed. Typical photomicrographs of irradiated and unirradiated specimens are shown in Figure 11. 

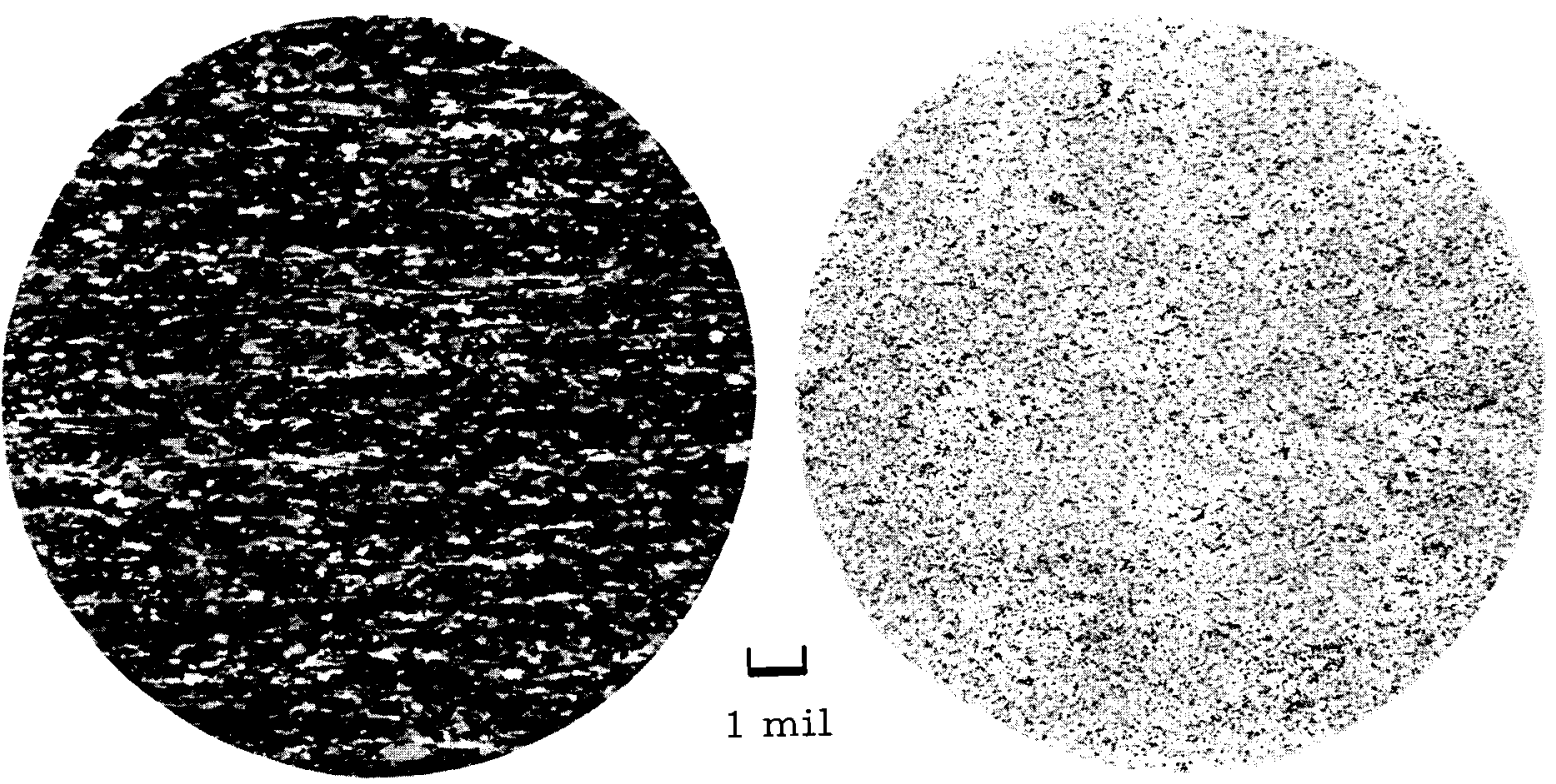

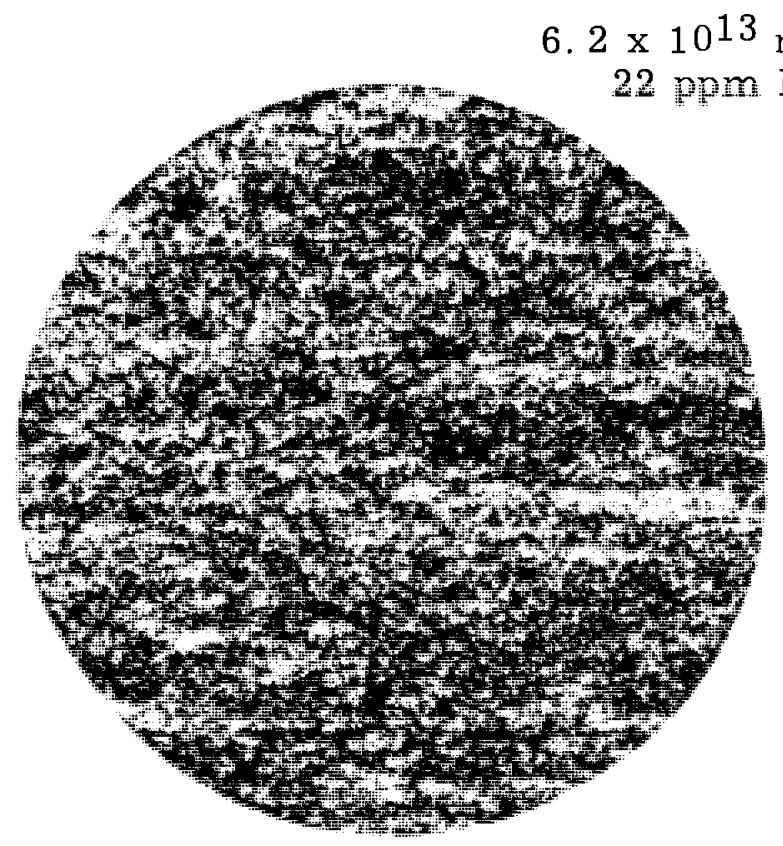

Hydride Etch, Polarized Light $\mathrm{nv}(>1 \mathrm{MeV})$ Hydrogen
Hydride Etch, Bright Field

Unirradiated,

15 ppm Hydrogen

\section{FIGURE 11}

Microstructure of $\mathrm{Zr}-3 \mathrm{wt} \% \mathrm{Nb}-1 \mathrm{wt} \% \mathrm{Sn}$ After Exposure to $534^{\circ} \mathrm{F}$ Low-Oxygen Water for 16. 5 Days $250 \mathrm{X}$

Neg. 465117D, 465117C, 46547B, 46547A 
Up to $750^{\circ} \mathrm{F}$ out-of-reactor the hydrogen pickup of Zircaloy-4 and nickel-free Zircaloy-2 has been found less than that of Zircaloy-2, with nickel-free Zircaloy-2 absorbing the least hydrogen. Corrosion rates are similar to Zircaloy-2. (26) alloys, based upon limited ETR exposure data available to date, indicates that radiation has no influence on the relative rankings established for hydrogen pickup in out-of-reactor environments. Neutron acceleration of oxidation is similar to that observed for Zircaloy-2.

At the Savannah River Laboratory, recent metallographic examinations of a low-nickel Zircaloy-2 HWCTR driver housing which had been irradiated under low-oxygen environmental conditions at a flux of $6 \times 10^{12}$ $(>1 \mathrm{MeV})$ showed an approximate 6 -fold higher corrosion rate than expected, but only about $12 \%$ of the corrosion hydrogen was absorbed. ${ }^{(37)}$ While such marked corrosion acceleration for this alloy would not be indicated on the basis of the recent ETR results, the possible effect of the rather large difference in irradiation temperatures must be considered. The reported hydrogen gains, however, are in reasonable agreement with ETR results.

\section{3 Postirradiation Effects}

Improved characterization of irradiation effects on environmental reactions requires some knowledge of the separate contributions from (1) damage within the oxide film, (2) damage within the metal lattice, and (3) radiolytic changes in the reacting environment near the metal or oxide surface. Hanford experiments have shown differences in the overall inreactor effects on oxidation and hydriding of particular zirconium alloys due to changes in the dissolved gas content of the water environment, and they have given an indication of an in-core effect due to radiolytic changes in the coolant. The results of the previous scouting studies suggest the need for more sophisticated experiments along lines which will provide a better insight into cause and effect relationships.

To gain some knowledge of the possible contributions of damage within the metal and damage within the oxide to the overall effects, specimens of irradiated and unirradiated metal were exposed to steam in an 
out-of-reactor autoclave. The selected specimens had been irradiated in high-oxygen water, but it is unlikely that any radiation damage to the metal or oxide would be influenced by this factor.

Coupons measuring approximately 1 by $1 / 2$ in. were cut from specimens previously exposed to weight gains of approximately $50 \mathrm{mg} / \mathrm{dm}^{2}$ and from corresponding specimens of the same material which had been exposed out-of-reactor to $750^{\circ} \mathrm{F}$ steam or $680^{\circ} \mathrm{F}$ water to form a comparable thickness of oxide. Some of these coupons were exposed with oxide films intact, except for the cut edges (approximately $10 \%$ of the surface area). The oxide was abraded from the surface of others and these were in turn given a 2-mil per surface etch. The irradiated specimens had been discharged from the reactor a little more than $1 \mathrm{yr}$ before this experiment, and the radiation levels from the coupon rack assembly in the autoclave were only moderate, less than $200 \mathrm{mr} / \mathrm{hr}$ at $1 \mathrm{ft}$ through air. Consequently, in view of the combination of a low level of radiation intensity and the use of a steam atmosphere with a low coefficient of energy transfer in comparison with liquid water, any significant effects noted would be primarily and reasonably attributable to previously existing damage within the metal or oxide rather than the result of radiation-induced decomposition and ionization of the oxidant. Of course, enhancement of electron transfer within the oxide film could still not be ruled out as a major contributing factor. The effect of reactor irradiation in decreasing the electrical resistance of Zircaloy-2 corrosion films has been demonstrated by Shannon, ${ }^{(38)}$ but the recent work of Harrop and Wanklyn tends to discount the probability of any significant effects of intense $\gamma$ irradiation on the conductivity of Zircaloy-2 corrosion films. (39)

Table IX gives the results of the simultaneous exposure of these coupons to $750^{\circ} \mathrm{F}, 1500 \mathrm{psi}$, nondeaerated refreshed steam for 39 days with intermediate weighings at 14 and 28 days. The coupons bearing in-reactorformed oxide behaved erratically. Except for one or two specimens which showed near-normal rates of weight gain, the majority showed greatly 


\section{TABLE IX}

EFFECT OF POST-IRRADIA TION EXPOSURE OF ZIRCA LOY - 2

TO $750^{\circ} \mathrm{F}, 1500 \mathrm{psi}$, REFRESHED STEAM

\begin{tabular}{|c|c|c|c|c|c|c|c|}
\hline Plate & $\begin{array}{c}\text { Cold } \\
\text { Work, } \\
\% \\
\end{array}$ & $\begin{array}{c}\text { Prior } \\
\text { Integrated } \\
\text { Flux } \\
\text { nvt } \times 10^{-19} \\
\end{array}$ & $\begin{array}{l}\text { Initial } \\
\text { Oxide, } \\
\mathrm{mg} / \mathrm{dm}^{2} \\
\end{array}$ & $\frac{\text { Weight }}{14 \text { Days }}$ & $\underline{\text { in, } \Delta W,}$ & $\frac{\mathrm{mg} / \mathrm{dm}^{2}}{39 \text { Days }}$ & $\Delta \mathrm{H},{ }^{(\mathrm{b})} \mathrm{ppm}$ \\
\hline $\begin{array}{l}6497 \\
6497\end{array}$ & $\begin{array}{l}0 \\
0\end{array}$ & $\begin{array}{l}0 \\
6.2\end{array}$ & $\begin{array}{l}44 \\
56\end{array}$ & $\begin{array}{l}24 \\
(\operatorname{loss})\end{array}$ & $\begin{array}{l}+18 \\
\quad+2.7\end{array}$ & $\begin{array}{l}+18 \\
+5.4\end{array}$ & $\begin{array}{l}43^{(c)} \\
11\end{array}$ \\
\hline $\begin{array}{l}6497 \\
6497\end{array}$ & $\begin{array}{l}10 \\
10\end{array}$ & $\begin{array}{l}0 \\
6.2\end{array}$ & $\begin{array}{l}44 \\
53\end{array}$ & $\begin{array}{l}26 \\
(\operatorname{loss})\end{array}$ & $\begin{array}{l}+21 \\
\quad+8.2\end{array}$ & $\begin{array}{l}+22 \\
+12\end{array}$ & $\begin{array}{l}47^{(\mathrm{c})} \\
15\end{array}$ \\
\hline $\begin{array}{l}6497 \\
6497\end{array}$ & $\begin{array}{l}10 \\
40\end{array}$ & $\begin{array}{l}21 \\
21\end{array}$ & $\begin{array}{l}54 \\
47\end{array}$ & ${ }_{6}{ }_{6}^{(d)}(d)$ & - & - & - \\
\hline $\begin{array}{l}6515 \\
6515\end{array}$ & $\begin{array}{l}0 \\
0\end{array}$ & $\begin{array}{l}0 \\
7.8\end{array}$ & $\begin{array}{l}54 \\
40\end{array}$ & $\begin{array}{l}28 \\
22\end{array}$ & $\begin{array}{l}+13 \\
+18\end{array}$ & $\begin{array}{l}+17 \\
+17\end{array}$ & $\begin{array}{l}57^{(c)} \\
15\end{array}$ \\
\hline $\begin{array}{l}6515 \\
6515\end{array}$ & $\begin{array}{l}10 \\
10\end{array}$ & $\begin{array}{l}0 \\
7.8\end{array}$ & $\begin{array}{l}48 \\
37\end{array}$ & $\begin{array}{l}23 \\
\text { (loss) }\end{array}$ & $\begin{array}{l}+20 \\
+14\end{array}$ & $\begin{array}{l}+23 \\
+18\end{array}$ & $\begin{array}{l}61^{(c)} \\
22\end{array}$ \\
\hline $\begin{array}{l}6515 \\
6515\end{array}$ & $\begin{array}{l}20 \\
20\end{array}$ & $\begin{array}{l}0 \\
7.8\end{array}$ & $\begin{array}{l}58 \\
47\end{array}$ & $\begin{array}{r}16 \\
4\end{array}$ & $\begin{array}{l}+21 \\
+2.8\end{array}$ & $\begin{array}{r}+26 \\
+2.8\end{array}$ & $\begin{array}{l}58^{(c)} \\
20\end{array}$ \\
\hline $\begin{array}{l}6515 \\
6515\end{array}$ & $\begin{array}{l}40 \\
40\end{array}$ & $\begin{array}{l}0 \\
7.8\end{array}$ & $\begin{array}{l}57 \\
44\end{array}$ & $\begin{array}{l}25 \\
1.4\end{array}$ & $\begin{array}{l}+13 \\
+8.2\end{array}$ & $\begin{array}{l}+13 \\
+4.1\end{array}$ & $\begin{array}{l}48^{(c)} \\
14\end{array}$ \\
\hline $\begin{array}{l}6497 \\
6497\end{array}$ & $\begin{array}{l}0 \\
0\end{array}$ & $\begin{array}{l}0 \\
6.2\end{array}$ & $\begin{array}{l}0 \\
0\end{array}$ & $\begin{array}{l}31 \\
50\end{array}$ & $\begin{array}{l}+13 \\
+10\end{array}$ & $\begin{array}{l}+27 \\
+21\end{array}$ & $\begin{array}{l}30 \\
26\end{array}$ \\
\hline $\begin{array}{l}6497 \\
6497\end{array}$ & $\begin{array}{l}10 \\
10\end{array}$ & $\begin{array}{l}0 \\
6.2\end{array}$ & $\begin{array}{l}0 \\
0\end{array}$ & $\begin{array}{l}28 \\
48\end{array}$ & $\begin{array}{l}+12 \\
+18\end{array}$ & $\begin{array}{l}+23 \\
+19\end{array}$ & $\begin{array}{l}31 \\
36\end{array}$ \\
\hline $\begin{array}{l}6515 \\
6515\end{array}$ & $\begin{array}{l}0 \\
0\end{array}$ & $\begin{array}{l}0 \\
7.8\end{array}$ & $\begin{array}{l}0 \\
0\end{array}$ & $\begin{array}{l}30 \\
44\end{array}$ & $\begin{array}{r}+7 \\
+14\end{array}$ & $\begin{array}{l}+18 \\
+18\end{array}$ & $\begin{array}{l}17 \\
12\end{array}$ \\
\hline $\begin{array}{l}6515 \\
6515\end{array}$ & $\begin{array}{l}10 \\
10\end{array}$ & $\begin{array}{l}0 \\
7.8\end{array}$ & $\begin{array}{l}0 \\
0\end{array}$ & $\begin{array}{l}33 \\
47\end{array}$ & $\begin{array}{r}+6 \\
+15\end{array}$ & $\begin{array}{l}+17 \\
+18\end{array}$ & $\begin{array}{l}24 \\
38\end{array}$ \\
\hline
\end{tabular}

\footnotetext{
(a) Because of erratic weight gains during the first 14-day period for some oxide-coated specimens, it is more meaningful to refer subsequent weighings to the 14-day weight.

(b) Final hydrogen minus hydrogen in specimens at start of 39-day period.

(c) Exposed to $750{ }^{\circ} \mathrm{F}$ steam to form initial oxide

(d) For 11-day exposure only.
} 
reduced rates. About all that can be concluded from the behavior of the oxide-coated specimens is that the physical condition of oxide formed inreactor apparently is not responsible for the excessive oxidation rates observed, although Davis has found evidence of inferior "leaky" film formation during the early stages of oxidation of irradiated specimens. course this is not to say that concurrent neutron and/or intense beta-gamma radiation effects on the oxide or on coolant within the oxide in-reactor are not responsible for at least a portion of the observed increase in rates. However, beta-gamma effects can probably be largely discounted in view of the reports of a lack of any effect of intense beta radiation on the oxidation of zirconium, iron, and stainless steel ${ }^{(41)}$ and of a lack of any significant effect of intense gamma radiation on the conductivity of corrosion films on Zircaloy -2 . (39)

Results for the bare metal coupons showed what appeared to be a $50 \%$ increase in oxidation rate during the initial 2 wh period only. The most likely cause of rapid decrease of a high initial oxidation rate for irradiated metal would be annealing of radiation damage. Recovery of irradiation damage as evidenced by decreases in hardness and electrical resistivity during postirradiation annealing is known to take place rapidly, depending upon the annealing temperature. At $750^{\circ} \mathrm{F}$, essentially complete recovery could be expected within about $8 \mathrm{hr}$.

To test this most likely cause of a rapid decrease in high initial oxidation rates for irradiated etched metal, specimens were subjected to a $24 \mathrm{hr}, 750^{\circ} \mathrm{F}$ dynamic vacuum anneal and then exposed simultaneously to $750^{\circ} \mathrm{F}$ steam as before. All specimens, one coupon from each of five pairs of etched irradiated specimens and unirradiated controls and from one oxidized, irradiated pair, were weighed at the end of $24 \mathrm{hr}$ and again following 14 days of exposure. The results are shown in Table X.

No really significant or consistent differences in oxidation rates between annealed and as-received specimens were noted. In general, all of the 1-day weight gains for etched specimens a re higher by 30 to $100 \%$ 
TABLE X

EFFECT OF $24 \mathrm{hr}, 750^{\circ} \mathrm{F}$ VACUUM ANNEAL ON OXIDATION BEHAVIOR OF PREIRRADIATED ZIRCALOY - 2 IN $750^{\circ} \mathrm{F}, 1500$ psi, REFRESHED STEAM

\begin{tabular}{|c|c|c|c|c|}
\hline Plate & $\begin{array}{l}\text { Neutron Flux, } \\
(>1 \mathrm{MeV}) \text {, nvt }\end{array}$ & $\begin{array}{l}\text { Initial Oxide, } \\
\mathrm{mg} / \mathrm{dm}^{2}\end{array}$ & $\frac{\text { Weight }}{\underline{1 \text { Day }}}$ & $\frac{\text { Gain, } \mathrm{mg} / \mathrm{dm}^{2}}{\underline{14 \text { Days }}}$ \\
\hline 6515 & 0 & 0 & 17 & 42 \\
\hline 6515 * & 0 & 0 & 15 & 37 \\
\hline $\begin{array}{l}6515 \\
6515 *\end{array}$ & $\begin{array}{l}\text { 7. } 8 \times 10^{20} \\
7.8 \times 10^{20}\end{array}$ & $\begin{array}{l}0 \\
0\end{array}$ & $\begin{array}{l}17 \\
18\end{array}$ & $\begin{array}{l}41 \\
38\end{array}$ \\
\hline $\begin{array}{l}6497 \\
6497 *\end{array}$ & $\begin{array}{l}0 \\
0\end{array}$ & $\begin{array}{l}0 \\
0\end{array}$ & $\begin{array}{l}20 \\
13\end{array}$ & $\begin{array}{l}35 \\
34\end{array}$ \\
\hline $\begin{array}{l}6497 \\
6497 *\end{array}$ & $\begin{array}{l}6.2 \times 10^{20} \\
6.2 \times 10^{20}\end{array}$ & $\begin{array}{l}0 \\
0\end{array}$ & $\begin{array}{l}17 \\
13\end{array}$ & $\begin{array}{l}43 \\
32\end{array}$ \\
\hline $\begin{array}{l}6497 \\
6497 *\end{array}$ & $\begin{array}{l}6.2 \times 10^{20} \\
6.2 \times 10^{20}\end{array}$ & $\begin{array}{l}49 \\
49\end{array}$ & $\begin{array}{l}14 \\
15\end{array}$ & $\begin{array}{l}19 \\
35\end{array}$ \\
\hline $\begin{array}{l}6497 \\
6497 *\end{array}$ & $\begin{array}{l}21.0 \times 10^{20} \\
21.0 \times 10^{20}\end{array}$ & $\begin{array}{l}0 \\
0\end{array}$ & $\begin{array}{l}16 \\
17\end{array}$ & $\begin{array}{l}31 \\
37\end{array}$ \\
\hline
\end{tabular}

than would normally be expected, but the 14-day gains are reasonably close to expected levels. On the basis of this supplementary scouting experiment, it appears that irradiation-damage annealing effects were not responsible for the weight-gain behavior of irradiated etched specimens previously tested.

It should be mentioned that following the vacuum anneal, portions of the surfaces of all specimens had lost their lustre and several others had areas of bluish discoloration, especially where surfaces had been in contact. Obviously some small amount of oxidation had occurred, and therefore all of the etched specimens, including nonannealed controls, were reetched simultaneously. For the prior experiment, the irradiated specimens were etched separately. Thus it is possible that the initial-period differences in weight gain observed during the first experiment were indeed caused by some surface impurity, in spite of precautions taken to ensure identical treatment.

The results shown in Table $\mathrm{X}$ show that long-term neutron irradiation damage within the metal substrate, which is not self-healing during 
short periods (less than $60 \mathrm{~min}$ ) between 540 and $200^{\circ} \mathrm{F}$ (G-7 loop cooldown time) followed by long periods ( $1 \mathrm{yr}$ ) at room temperature, probably does not contribute to the increased reaction rate observed in-reactor. Examples of such damage would be interstitial atoms, vacancies, electron scattering centers in general, migration and precipitation of second-phase intermetallics (if influenced by radiation), lattice strain energy, and the bulk of element transmutations. If any such "permanent" damage does contribute it is of an extremely fast healing type at $750{ }^{\circ} \mathrm{F}$, and a repetition of this experiment out-of-reactor at a considerably lower temperature should yield more conclusive evidence.

Other conceivable mechanisms by which neutron irradiation of the metal substrate could be an important factor in increasing reaction rates would be (1) the generation of numerous hot spots (thermal spikes) along the paths of knock-ons near the metal-oxide interface, and (2) the ejection both of neutral and ionized metal atoms into the oxide at the interface, or the creation of ionized atoms at the interface. These mechanisms would be tantamount to increasing the availability of the metal reactant (surface area effect) while at the same time causing an increase in the fraction of atoms having the necessary activation energy. Such effects should be extremely short-lived and observable only simultaneously with irradiation. In addition, they should be dependent upon both neutron energy and flux, but modified by any reactant transport barrier effects caused by the nature of the oxide film or its thickness.

Preirradiation, irradiation-temperature, and exposure-temperature effects have been reported by a number of investigators. Some years ago Rockwell and Cohen presented data showing the results of deuteron bombardment of zirconium in degassed water at $599^{\circ} \mathrm{F}$. Although oxidation rates were increased tenfold during irradiation, there was no postirradiation effect. (43)

Studies of the postirradiation corrosion of etched and prefilmed Zircaloy-2 in steam-oxygen mixtures at $572{ }^{\circ} \mathrm{F}$ have been conducted by 
Davis at the Oak Ridge National Laboratory. Specimens were irradiated at $\sim 1 \times 10^{13} \mathrm{nv}(>1 \mathrm{MeV})$ in helium atmospheres at temperatures of 212 and $572{ }^{\circ} \mathrm{F}$ for periods up to 10 days before exposure to steam-oxygen. Some specimens showed erratic weight-gain behavior (initial losses and early rates lower than controls), but over a period of about $5 \mathrm{wk}$, weight gains for preirradiated specimens were found to be generally greater than for unirradiated controls by up to a factor of two. He concludes that the increased corrosion rates are caused by increased chemical reactivity of the metal due to irradiation damage in the metal. (40)

Tobin has shown that preirradiation of copper to an integrated fast neutron exposure of $1 \times 10^{19} \mathrm{nvt}(>1 \mathrm{MeV})$ in $\mathrm{O}_{2}$ at $392^{\circ} \mathrm{F}$ but at $\sim 10^{12} \mathrm{nv}$ caused no observable change in the oxidation behavior, but other postirradiation effects (etch rates, etc.) indicate altered chemical reactivity of the metal. (44)

Along with unirradiated controls, samples of the irradiated fuel alloy core from the EBWR (U-5 wt $\mathrm{Zr}-1.5 \mathrm{wt} \% \mathrm{Nb}$ ) were corrosion-tested in water at 500 to $518^{\circ} \mathrm{F}$. The results showed a decrease in corrosion rate with extent of burnup and a minimum around 0.024 to 0.09 at. \% burnup.

Following exposure of specimens of irradiated Hanford KER Zircaloy2 process tubing to $572{ }^{\circ} \mathrm{F} \mathrm{pH} 10$ ( $\mathrm{LiOH}$ ) water, Maffei concluded that the high initial corrosion rate exhibited by one specimen was caused by a corrosion-prone, localized surface condition. Weight gains for another irradiated specimen were not different from those of controls.

At best, the picture of postirradiation corrosion effects is somewhat cloudy, but there is a notable absence of any indication of a large effect.

\section{CONCLUSIONS}

The preponderance of experimental results described or referenced in this report reflect certain patterns of in-reactor corrosion behavior which may be expected of zirconium and its alloys. These patterns, broadly identified in the following list, permit tentative conclusions about the governing mechanisms. 
- Oxygen content of the water environment has a marked influence on in-reactor corrosion rates. Corrosion rates are significantly higher in high-oxygen water than in low-oxygen water.

- Posttransition oxidation rates in-reactor in high-oxygen water correspond with pretransition rates in low-oxygen water.

- The fast neutron component of reactor radiation is primarily responsible for the acceleration of corrosion.

- Oxidation rates are more sensitive to fast flux magnitude in the thinfilm region.

- Acceleration effects of fast flux on oxidation are more pronounced above $10^{13} \mathrm{nv}$, and a practical threshold level near $10^{11}$ is probable.

- Oxygen-hydrogen content of the water environment influences inreactor sorption of corrosion hydrogen. Hydrogen pickup fractions are higher in low-oxygen water than in high-oxygen water.

- Hydrogen pickup fraction is not influenced by changes in the fast flux above the threshold for oxidation effects.

- Hydrogen pickup fraction is influenced by film thickness. It increases with increasing film thickness in high-oxygen water. It decreases with increasing film thickness in low-oxygen water.

- Heat treatment and texture effects are important variables in inreactor corrosion behavior.

- For any of the alloys tested at this laboratory, there is no indisputable evidence for direct pickup of hydrogen from the water environment.

- At low magnification, the physical appearance of the surface and cross sections of oxide films formed in-reactor are similar to those of films formed in the absence of radiation.

- Electron microscopy has disclosed a markedly higher population of microcracks in cross sections of in-reactor formed oxide as compared with unirradiated oxide. 
When viewed together, some of these behavior patterns appear to be consistent with a relatively simple conception of the in-reactor corrosion process. The essential features of the corrosion process which correlate the various observations on in-reactor corrosion and hydrogen pickup fractions are described below.

Zirconium metal exposed in high-temperature water or steam characteristically corrodes by a cubic oxidation process followed by oxide breakaway at about 30 to $40 \mathrm{mg} / \mathrm{dm}^{2}$ weight gain (transition). A sharp increase in rate occurs at breakaway, indicating a failure of the protective oxide filmprobably of a mechanical nature. Either thermal cycling or mechanical flexure of the corroding specimen can induce premature breakaway. A detailed investigation of weight gain versus time for individual samples by B. Griggs, et al, has shown that repetitive cycles of oxide formation and failure occur which can be identified metallographically with a layer structure in the oxide, in some cases at least. (47) Electron and light micrographs of this layered structure are shown in Appendix B. Judging from this kinetic and physical evidence, the layer of oxide at the oxide-metal interface must control the rate of the oxidation process. Because of cracks, voids, or pores, the bulk exterior oxide layers contribute little or nothing as a barrier to further oxidation in high-pressure water or steam environments. In summary, the zirconium corrosion product is visualized as a compact protective inner layer of oxide plus a porous bulk oxide which the oxidizing environment can more or less readily penetrate.

During oxidation of zirconium alloys in high-temperature water or steam, a fraction of the hydrogen produced by corrosion dissolves in the zirconium metal substrate. The fraction of corrosion-product hydrogen absorbed is influenced by alloy composition and possibly pressure and surface condition, and certainly by the availability (concentration) of the hydrogen at the metal-oxide interface. Of concern here are the effects of dissolved oxygen and hydrogen in the water or steam, oxide thickness, and the fast neutron flux. 
Considering first the effect of dissolved hydrogen in water, there is a gradual linear increase in hydrogen pickup with hydrogen partial pressure. Hillner draws a straight line from about $35 \%$ pickup at zero dissolved hydrogen in water to $150 \%$ in water containing 2500 psi $\mathrm{H}_{2}$ overpressure for Zircaloy-2 at $650^{\circ} \mathrm{F}$ and arbitrary weight gain $\left(\mathrm{O}_{2}\right)$ of $20 \mathrm{mg} / \mathrm{dm}^{2}$. (48) At low partial pressures the dependence is sufficiently small that hydrogen pickup fractions in degassed water and in water containing $50 \mathrm{~cm}^{3}$ hydrogen/ $\mathrm{kg}$ water are indistinguishable. Oxidation rates a re insensitive to hydrogen concentration out-of-reactor. (49)

With regard to the effect of dissolved oxygen, in- and out-of-reactor experiments at this laboratory and elsewhere ${ }^{(24,36)}$ have shown that even very small concentrations of oxygen ( 3 to $4 \mathrm{ppm}$ ) dissolved in water can significantly reduce hydrogen pickup by zirconium alloys. Little if any further reduction in hydrogen pickup fraction is observed with higher concentrations of oxygen, even of several orders of magnitude. Most observations of this effect have referred to pretransition corrosion and hydrogen pickup processes, but Maffei and other Hanford observers found a marked increase in hydrogen pickup at transition for specimens exposed to water containing 3 to 4 ppm oxygen. ${ }^{(50)}$ In fact, post-transition hydrogen pickup fractions for Zircaloy-2 are essentially indistinguishable in static systems, in refreshed degassed water, and in refreshed water containing 3 to $4 \mathrm{ppm} \mathrm{O}_{2}$ at $750^{\circ} \mathrm{F}$. Increases have also been observed in hydrogen pickup fractions following extended out-of-reactor exposure of zirconium alloys to high weight gains in steam。 ${ }^{(51,52)}$ The implication here is that subsequent to the transition-cracking modification of the oxide, a change occurs in the effective corrosion environment.

In addition to its well-established effect on pretransition hydrogen pickup out-of-reactor, oxygen appears to have an important effect on inreactor corrosion rates of Zircaloy, contrary to the insensitivity of this process to dissolved oxygen out-of-reactor. (18) There is no evidence that small concentrations of oxygen in water or steam appreciably alter out-ofreactor corrosion rates, but in-reactor Zircaloy corrosion rates in water 
containing dissolved oxygen are predictably higher than in water where free oxygen is suppressed by hydrogen or ammonia additions. Presumably, radiolytic decomposition of water is independent of small dissolved gas concentrations, but the liquid-phase rate of recombination of oxygen with a considerable excess of hydrogen is sufficiently fast to reduce free oxygen to negligible proportions. Vapor-phase kinetics are quite different,and B. Cox has brought to our attention observations that effective elimination of free oxygen by additions of hydrogen to gas-phase mixtures of oxygen and water vapor in a reactor flux field is not possible. (53) Thus, no marked differences may be expected in in-reactor corrosion rates for high- and lowoxygen vapor-phase environments.

For comparable (high) magnitudes of fast neutron flux, average posttransition (thick-film) oxidation rates in-reactor have been shown to approximate pretransition rates in low-oxygen water. In-reactor hydrogen pickup fractions in the thin-film region (etched specimens) in high-oxygen water were shown to be low in comparison with preautoclaved specimens or those exposed to high weight gains, while the converse was generally true of specimens exposed in low-oxygen water.

Such behavior suggests the possibility of an oxide barrier-entrapment effect of the post-transition bulk oxide which acts to isolate the water-oxygenhydrogen components of the corrosion system from the bulk coolant. This entrapment would shift the corrosion environment from the bulk coolant and permit the establishment of a dynamic equilibrium within the bulk oxide, with oxidants and kydrogen being generated and removed by radiolysis and reaction with the metal substrate and by high-impedance interchange with the bulk coolant.

In high-oxygen water it is conceivable that this mechanism would result in high oxidatior rates and low hydrogen pickup initially, followed at transition by a reduction in the rate of oxidation and an increase in the rate of hydriding as a consequence of the buildup of an excess of corrosion hydrogen and depletion of oxidants in the corrosion environment of the bulk oxide. 
In low-oxygen water with an excess of dissolved hydrogen, relatively low initial oxidation rates and moderate hydrogen pickup would be expected in the thin-film stage. At transition in this case, little change in the oxidation rate might be expected, although a reduction in the pickup of hydrogen might well result. This is because oxygen and radiolytically generated oxidants in the isolated environment would tend to remain at levels not greater than in the bulk coolant, provided hydrogen absorption by the metal substrate is not more than $\sim 100 \%$ of the corrosion hydrogen. A slight reduction in hydrogen pickup is conceivable on the basis of either a transportbarrier effect of the inner layer of compact, protective oxide or a reduction of dissolved molecular hydrogen in the isolated environment (resulting from reaction with radiolytically generated oxidants) as compared with the bulk water.

Of course this simple explanation completely disregards effects due to higher temperatures and temperature variations in the corrosion environment as a function of power level, increasing thickness of oxide, and bulk water temperature. Such increases in temperature can greatly complicate the simple in-reactor corrosion picture by introducing phase changes into the corrosion environment, especially where high rates of heat transfer are involved-as with fuel-element jackets. In addition, it is conceivable that interruption of the steady-state equilibria in the isolated corrosion environment within the bulk oxide and reestablishment of bulk water conditions would occur at every reactor shutdown, thus changing post-transition behavior to a degree dependent upon the frequency and/or total number of such shutdowns. 
7. ACKNOWLEDGMENTS

The many helpful suggestions of R. L. Dillon throughout the course of these investigations and his comments and contributions relative to the interpretation of the experimental results are greatly appreciated. It is also a pleasure to acknowiedge the assistance of $\mathrm{J}$. E. Irvin of the Reactor Metals Research staff and E. N. Heck and J. H. Johnson of Fuel Design who provided many of the metal specimens and all of the in-reactor data necessary for this investigation. Special thanks go to J. D. Berger of Fuels Design for providing excellent control of water quality under difficult conditions during the low - oxygen runs and to Mrs. I. R. Robertson of the Metaliography Laboratory for excellent meallography of many irradiated and unirradiated specimens of the various alloys. 
8. APPENDIXES 
3.1. 1 TABLE A-I

ZIRCONIUM ALLOY SPECIMEN COMPOSITIONS

Average Analysis of Ingot or Plate

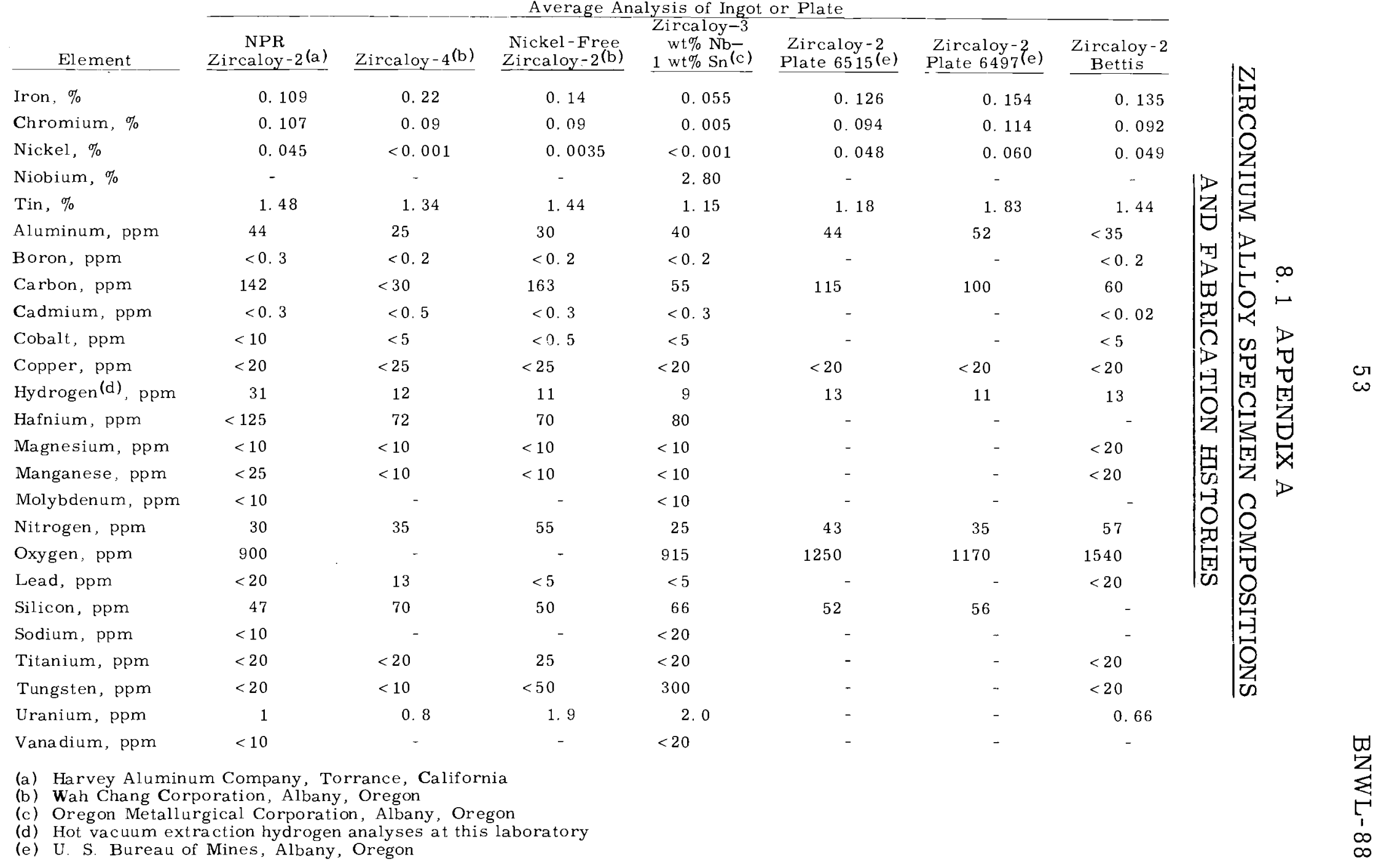




\section{1.2 TABLE A-II}

\section{ZIRCONIUM ALLOY SPECIMEN FABRICATION HISTORY}

\section{NPR Zircaloy -2}

Tube drawn at $1550^{\circ} \mathrm{F}$ to $0.4-$ in. wall thickness, followed by colddraw to nominal 0.25 -in. wall. Tube wall section rolled at $<900^{\circ} \mathrm{F}$ to 0. 072-in. thickness followed by cold-rolling to 0.050-in. specimen thickness. Annealed specimens heated in vacuo $8 \mathrm{hr}$ at $1400^{\circ} \mathrm{F}$.

\section{$\underline{\text { Zircaloy }-4 \text { and Nickel -Free Zircaloy }-2}$}

Ingot forged at $1800^{\circ} \mathrm{F}$ tó 4 -in. slab, followed by hot-rolling at $1800^{\circ} \mathrm{F}$ to $2-\mathrm{in}$. slab. Strip hot-rolled at $1450^{\circ} \mathrm{F}$ to $0.1-\mathrm{in}$. thicknoss, followed by cold-rolling to nominal 0.030-in. thickness. Strip vacuum annealed $1 \mathrm{hr}$ at $1450^{\circ} \mathrm{F}$.

$\underline{\mathrm{Zr}-3} \times 1 \% \mathrm{Nb}-1 \mathrm{wt} \% \mathrm{Sn}$

Arc cast ingot button, 1/2-in. thick, rolled to $0.060-$ in. thickness at 1200 to $1300^{\circ} \mathrm{F}$ with intermediate anneal at 1400 to $1475{ }^{\circ} \mathrm{F}$ following each $40 \%$ reduction. Strip cold-rolled from 0.060 to 0.040 in. Specimens cut and annealed in vacuo at $1070^{\circ} \mathrm{F}$ for $24 \mathrm{hr}$. No fabrication abnormalities, embrittlement, or edge-splitting of rolled strip were observed.

\section{Zircaloy-2 Plate Materials 6515 and 6497}

Double-vacuum-melted ingots heated to $1740^{\circ} \mathrm{F}$ in $2-1 / 2 \mathrm{hr}$ and forged to a 5 -in. billet, finishing at $1485{ }^{\circ} \mathrm{F}$. Billet rolled to $3 / 4$-in. plate, starting at $1670^{\circ} \mathrm{F}$ and finishing at $1450^{\circ} \mathrm{F}$. Final hot-rolling performed at $1620^{\circ} \mathrm{F}$ to a 0.275 -in. thickness, followed by air annealing at $1550^{\circ} \mathrm{F}$. Plate was subsequently given 25 to $40 \%$ cold work with intermediate anneals for $1 \mathrm{hr}$ at $1382^{\circ} \mathrm{F}$ to arrive at the final 0.050 -in. thickness with 10,20 , or $40 \%$ cold work. 


\section{2 APPENDIX B}

\section{METALLOGRAPHIC OBSERVA TIONS}

\section{2. 1 Hydride Platelet Gradients}

A number of cases of decreasing concentration of platelets from surface to center of the specimen were noted during metallographic studies of precipitated hydride in relatively thick (0. 1 in. ) tensile test specimens. These platelet gradients were observed only in annealed material exposed to high weight gains. Typical micrographs a re shown in Figure B-1.

Whether a hydrogen concentration gradient exists corresponding to the platelet gradient is not known. The platelet gradient does not appear to be dependent upon total hydrogen content in excess of the solubility limit $\left(\sim 88\right.$ ppm at $\left.545^{\circ} \mathrm{F}\right)$ because of two specimens containing approximately the same amount of hydrogen $(\sim 180 \mathrm{ppm})$, a 144 -day exposed annealed specimen showed a gradient while a 264-day, 40\% cold-worked specimen did not. It is also unlikely that temperature gradients in the specimens were responsible, since these are minor and comparisons involved specimens exposed at the same position in the reactor (approximately equal heat-generation rates). In addition, the oxide film thickness was considerably thinner on the $40 \%$ cold-worked specimens, thus indicating the possibility of a steeper temperature gradient for the specimens which did not show a variation in hydride concentration.

During the examination of these specimens, an occasional oxide "spike" was observed to be penetrating rather deeply into the underlying metal. That these "spikes" were not the result of oxidation of the exposed surfaces of a preexisting microcrack is indicated by the orientation of growth cracks in the spike oxide and the lack of any indication of a joint line between two layers of oxide growing on opposite surfaces. The largest observed spike is shown as an inset at 500X in the hydride photomicrograph (Figure B-1). This particular spike had penetrated over four times the a mount of metal that had been penetrated by the average oxide layer on either side. 


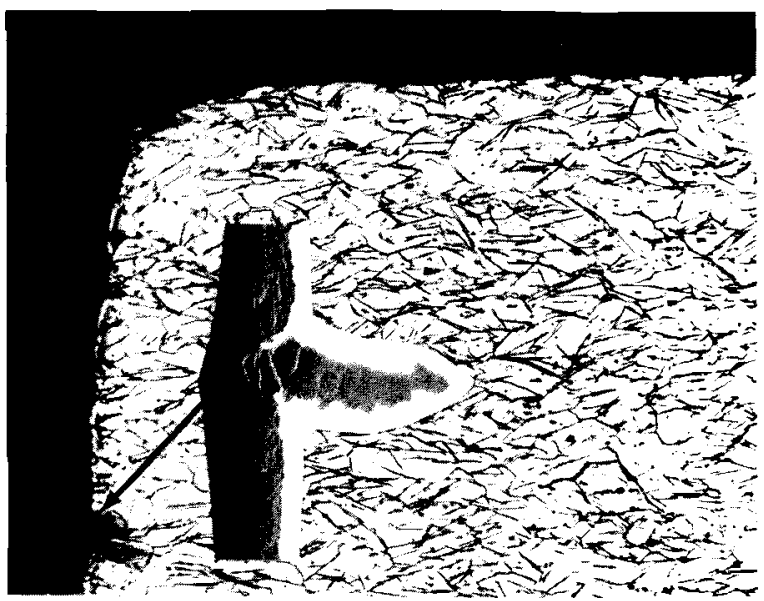

Edge

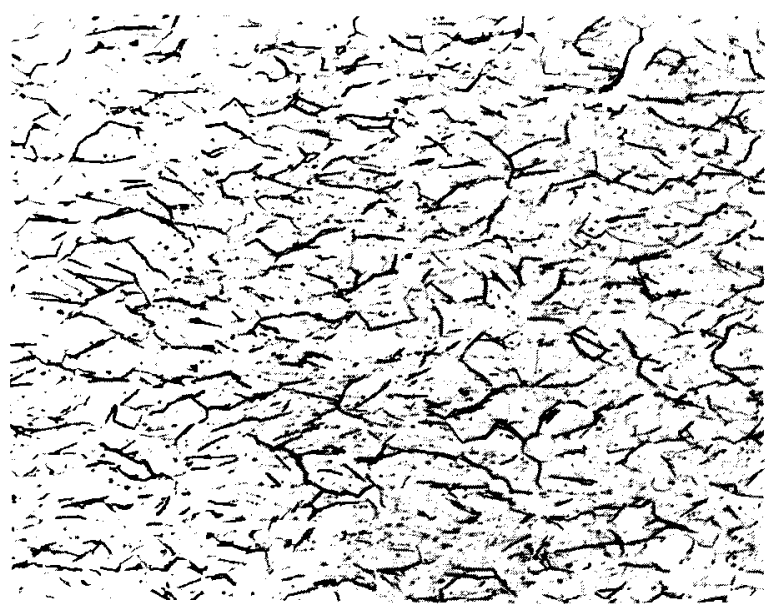

Center
264 days, $540^{\circ} \mathrm{F}, 8.2 \times 10^{13} \mathrm{nv}(>1 \mathrm{MeV}), 450 \mathrm{ppm} \mathrm{H}$
View transverse to rolling direction; inset shows oxide spike.

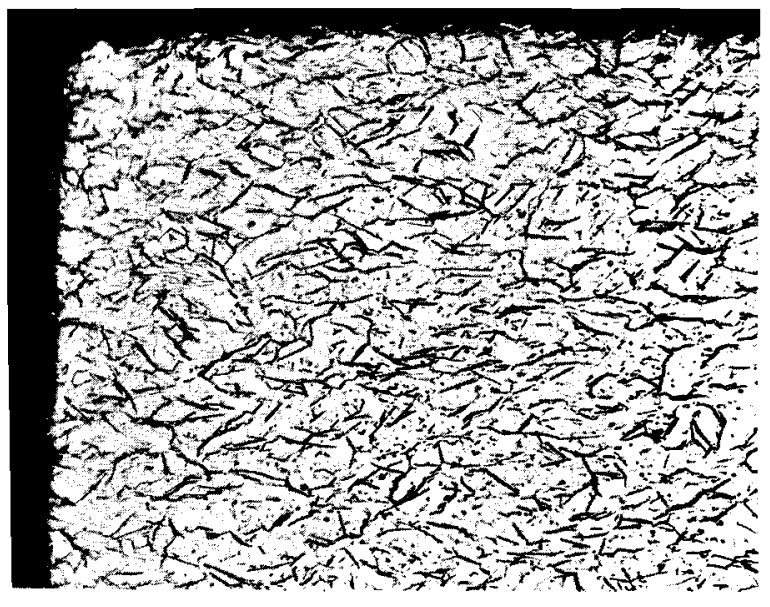

Edge

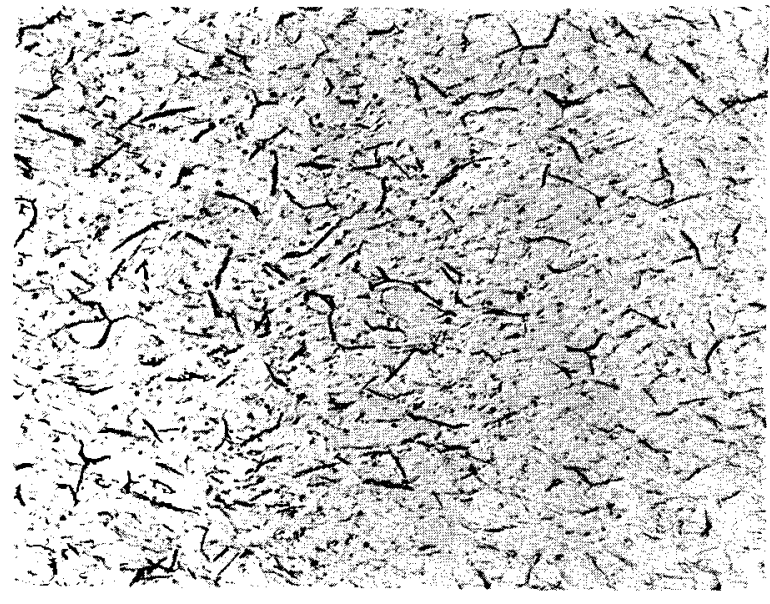

Center

144 days, $540{ }^{\circ} \mathrm{F}, 8.7 \times 10^{13} \mathrm{nv}(>1 \mathrm{MeV}), 176 \mathrm{ppm}_{2}$
View in rolling direction

FIGURE B-1

Variation of Hydride Platelet Concentration in Annealed Irradiated Zircaloy-2 Tensile Specimens

( $250 \mathrm{X}$ reduced $\sim 25 \%$ ) 
The large amount of hydride in the metal of some of these longerexposure specimens and the concentration of platelets near the surface may be a major cause both of oxide "spikes" and the higher-than-normal inreactor average corrosion rates observed for some of these specimens. Schwartz and Vaughn observed some years ago that hydrogen absorption leads to considerable lattice distortion, indicating significant structural damage to the surface, ${ }^{(54)}$ and this is borne out by the photomicrographs of Figure B-1.

\section{2. 2 Anisotropic Effects}

Repeated evidence of thicker oxide formation on roll-plane surfaces of irradiated, machined tensile specimens was noted in the course of metallographic studies. This effect was found for each of six specimens examined, and the ratio of oxide thickness on roll-plane surfaces to that on transverse surfaces varied from 1.2 to 1 to 2.1 to 1 . The greatest difference in thickness was observed on a $40 \%$ cold-worked specimen which also showed a markedly thinner oxide than an annealed specimen which was exposed in the same quadrant. Photomicrographs of the oxide on some of these specimens are shown in Figure B-2.

To determine in a short time whether the anisotropic oxidation rates were generally operative following exposure to high weight gains irrespective of irradiation, temperature, and atmosphere, five pairs of tensile specimens of the same material in the annealed and $40 \%$ cold-worked condition were oxidized in $842^{\circ} \mathrm{F}$ steam to achieve weight and hydrogen gains similar to those of the irradiated specimens. Results were inconclusive with regard to oxidation behavior. Two sets showed thicker films on the roll-plane surfaces both of annealed and cold-worked specimens while one set showed the reverse. The remaining two sets showed thicker films on roll-plane surfaces for cold-worked material but thinner for the roll-plane surfaces on annealed material. No hydride gradients were observed in any of the out-of-reactor specimens either; however, the solubility limit of of hydrogen was not exceeded at the exposure temperature $\left(842^{\circ} \mathrm{F}\right)$. Consequently, about all that can be gleaned from this experiment about hydride 

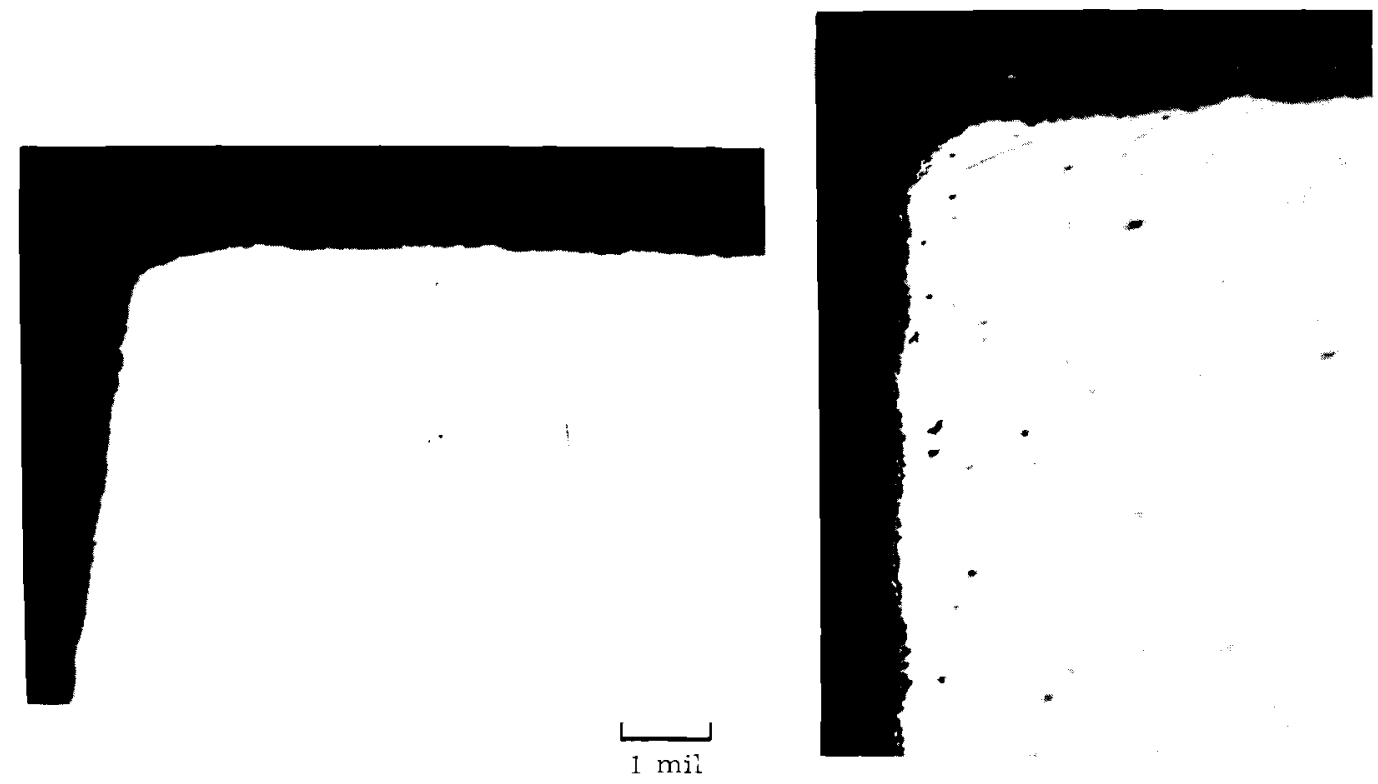

Top (roll plane): $\left.120 \mathrm{mg} / \mathrm{dm}^{2}\right\}$ $\left.\begin{array}{r}\text { Top (roll plane): } \begin{array}{r}120 \mathrm{mg} / \mathrm{dm}^{2} \\ \text { Side: }\end{array} \quad 13 \mathrm{mg} / \mathrm{dm}^{2}\end{array}\right\} 1.3 / 1$ 43 days, $540{ }^{\circ} \mathrm{F}, 6.3 \times 10^{13} \mathrm{nv}$,

$60 \mathrm{ppm} \mathrm{H}_{2}$, annealed

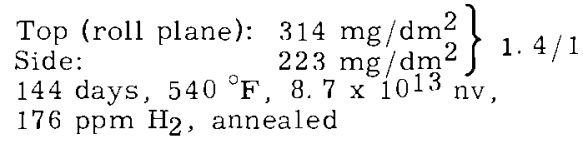
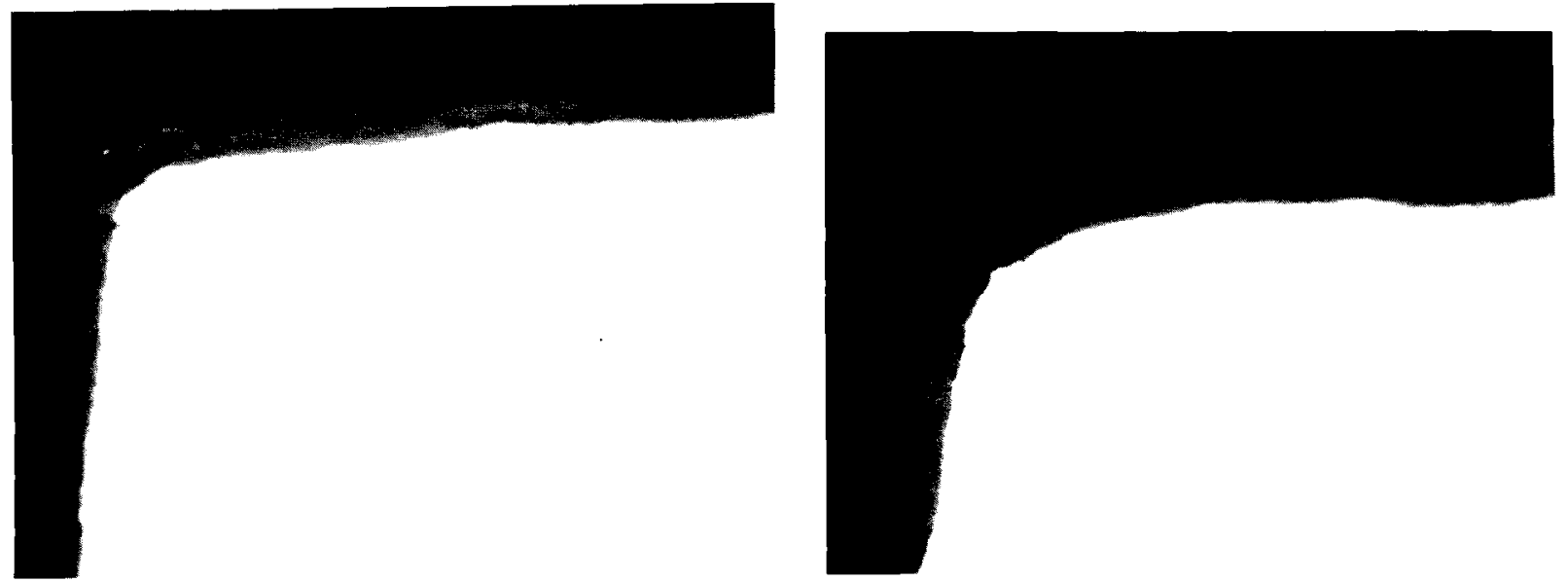
$\left.\begin{array}{ll}\text { Top (roll plane): } & 239 \mathrm{mg} / \mathrm{dm}^{2} \\ & 113 \mathrm{mg} / \mathrm{dm}^{2}\end{array}\right\} 2.1 / 1$

264 days, $540^{\circ} \mathrm{F}, 8.2 \times 10^{13} \mathrm{nv}$,

$180 \mathrm{ppm} \mathrm{H}_{2}, 40 \% \mathrm{cw}$

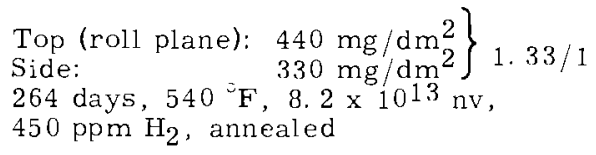

(500X reduced $\sim 30 \%$ )

\section{FIGURE B-2}

Anistropic Oxide Formation

on Irradiated Zircaloy-2 in High-Oxygen Water

Neg. 421547A, 421453C, 72123C, 421251D 
platelet gradients is that hydrogen absorption in excess of the solubility limit at the exposure temperature is very probably required.

It is, of course, well known that rolling leaves zirconium alloy sheet material with a texture which can cause minor anisotropy in some physical properties such as thermal expansion. The observation of anisotropic oxidation behavior for zirconium single crystals and alloys is not new.

Bibb has made some extensive comparisons of oxidation rates on different faces of large zirconium crystals in $680^{\circ} \mathrm{F}$ water and has studied the epitaxial relationships between metal substrate and oxide in some detail. He found lowest oxidation rates on the 0001 and $21 \overline{3} 0$ crystal faces and the highest on $10 \overline{1} 4$ and $21 \overline{3} 1$ faces. ${ }^{(55)}$ Bibb also quoted some findings of Pemsler which indicated:

- A minimum oxidation rate for zirconium when the " $C$ " axis of the metal substrate is parallel to the surface of the specimen

- A maximum rate for " $\mathrm{C}$ " axis inclined $20^{\circ}$ from the surface

- A subsequent decrease for higher inclinations.

Douglas and Dearing, in studying a $\mathrm{Zr}-2$ at. $\% \mathrm{Nb}-2$ at. $\% \mathrm{Sn}$ alloy, concluded that the basic differences in corrosion between annealed and slowly cooled samples or quenched samples may be attributed to different crystallographic orientation of the substrate and a resultant different epitaxial relation between oxide and metal. For this alloy, greatest corrosion resistance was achieved for a 0001 texture. (31)

Most pertinent to present observations of oxide growth on rolled Zircaloy-2 tensile specimens, however, are electrochemical measurements made on unirradiated rolled sheet by Swedish investigators. Corrosion current on the roll-plane surface was found to be higher by a factor of 1.2 to 1. 4 than that on a transverse section, and there was a corresponding difference of $13 \mathrm{mv}$ in the rest potential. Their examination of the microstructure under polarized light showed that the electrochemical differences could be related to texture. (56) 
It is not at all unlikely that an influence of plate texture on hydrogen uptake may also be found. Indeed, Bibb has found a marked decrease in fractional hydrogen pickup from $680^{\circ} \mathrm{F}$ water for those zirconium single crystal faces which exhibited lowest weight gains (0001 and 2130). Earlier work at Hanford ${ }^{(1)}$ also produced data indicating a possibility of reduced hydrogen pickup for $10 \%$ cold-worked material (predominant 0001 texture), but this has not been confirmed by subsequent test results.

With regard to the influence of fast neutron irradiation on anisotropic corrosion behavior, some information of value has been generated by Piercy and Tuxworth. (58) These investigators made a study of density and lattice parameter changes and $X$-ray line broadening for nine metals following $122^{\circ} \mathrm{F}$ exposure to an integrated fast neutron flux of $1.4 \times 10^{20} \mathrm{nvt}$ $(>0.5 \mathrm{keV})$ in the NRX reactor. Zirconium showed no change in density nor " $\mathrm{C}$ " lattice parameter nor any large change in integral line breadth, but it did show a significant increase in the "A" lattice parameter. It was concluded that interstitials in the form of two-dimensional platelets had formed in planes parallel to the ' $\mathrm{C}$ ' axis and preferentially on the crystallographic plane having the lowest interplanar cohesion-the $10 \overline{1} 0$ slip plane. Early work by McGeary and Lustman on rolled crystal bar zirconium has shown a texture with the $10 \overline{1} 0$ direction parallel to the rolling direction, ${ }^{(59)}$ and $X$-ray reflection-diffraction pole figure data obtained at Hanford on the Zircaloy-2 plate materials under study has shown a predominantly 0001 texture (Figure B-3). ${ }^{(60)}$ Consequently, if the accelerated, oxidative attack in-reactor is by way of interstitial da mage sites it might be expected that the paths for penetration would be more direct in a direction normal to the roll-plane surface than elsewhere. Thus it is conceivable that in-reactor oxidation rates could be highest on those plate surfaces which out-of-reactor single crystal studies have shown to be most resistant to oxidation.

Further studies of the relationships among crystallographic orientation and chemical and mechanical behavior may well establish optimum textures for zirconium alloys for given service conditions. Picklesimer has 
Annealed

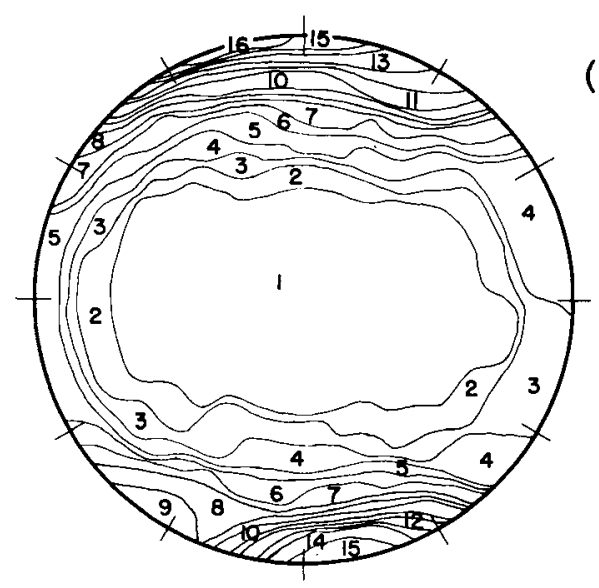

(0002)
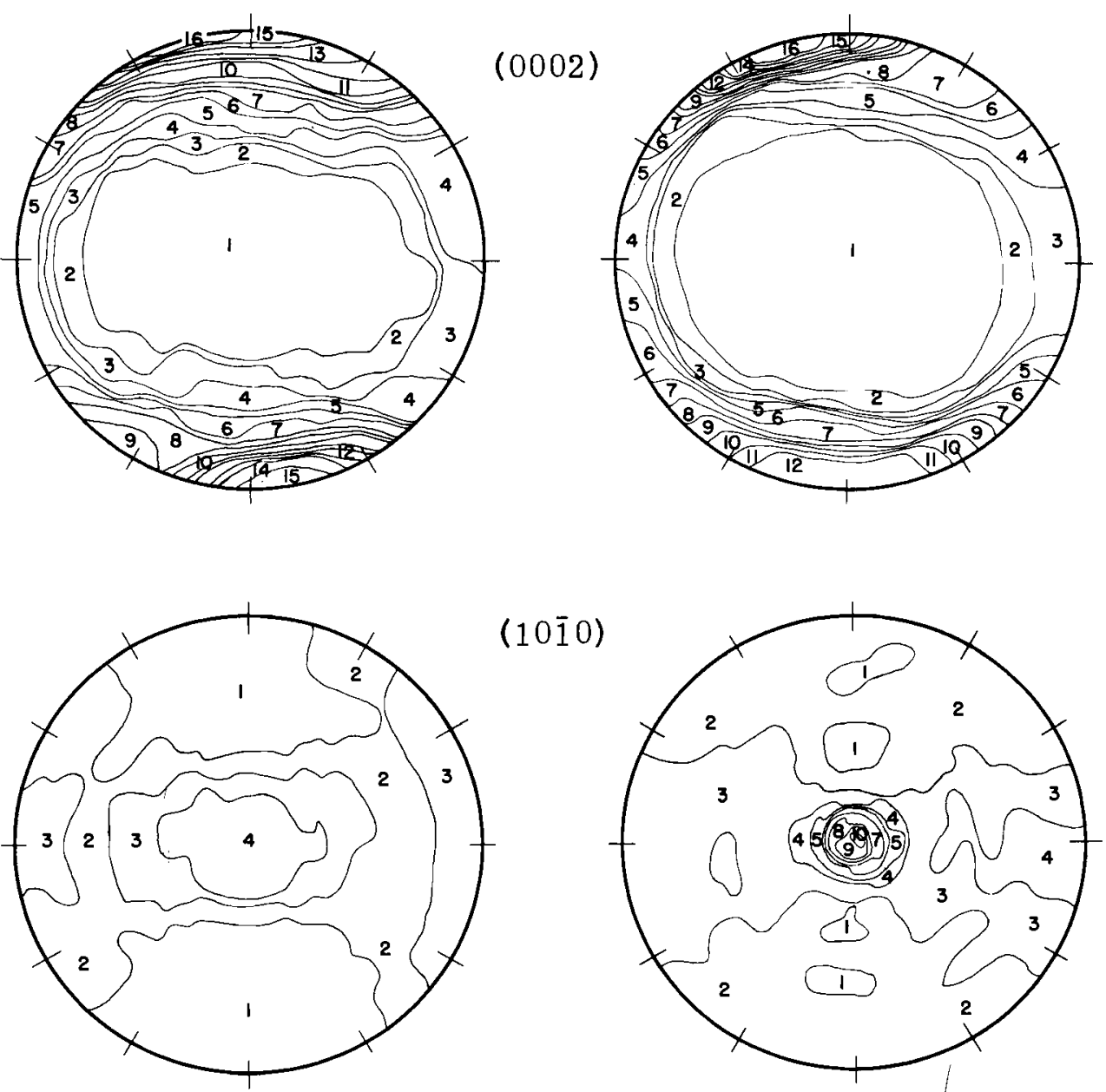

(10̄10)
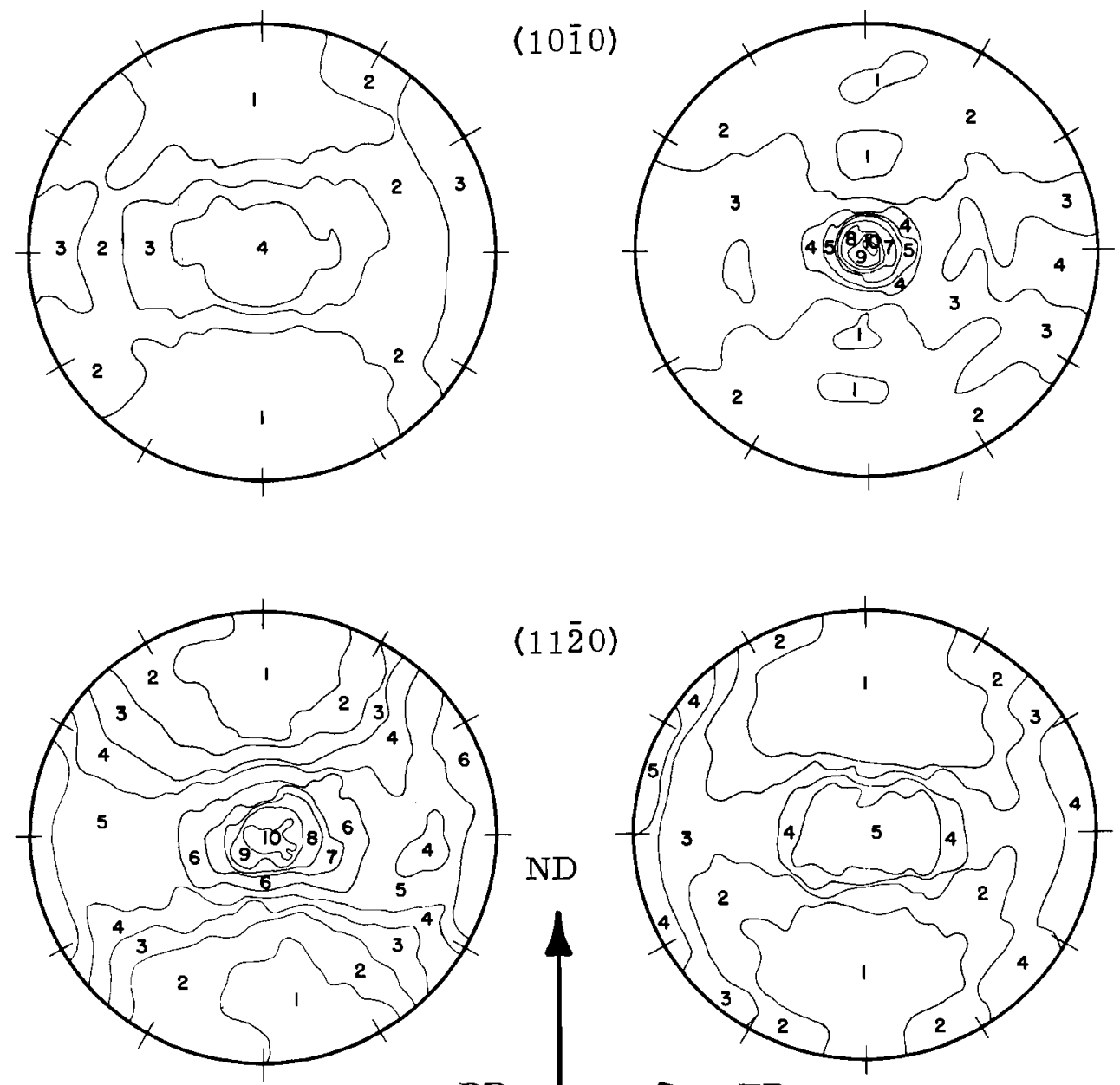

$\mathrm{RD}$

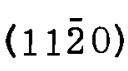

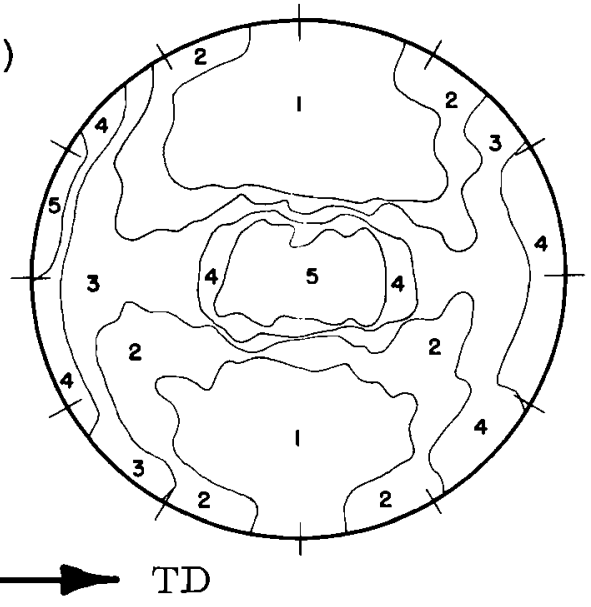

FIGURE B-3

Texture of Annealed and Cold-Rolled Zircaloy-2

Neg. 0650486 ( 1 = minimum pole density) 
analyzed a number of problems related to the development and control of texture in Zircaloy-2 during manufacture and has proposed several advantageous applications of anisotropy. (61)

\section{2.3 Heat Treatment and Radiation Effects on Microstructure and Second- Phase Agglomerates}

Metallographic studies of irradiated specimens in bright field and in polarized light showed what appeared to be an increase in the population of second-phase precipitates and/or a growth of previously existing secondphase deposits. However, the "before and after" observations were being made on different specimens which, although cut from the same plate of material, may have been representative of regions separated by many feet and therefore not identical either in composition or treatment history, or both. Increases in the concentration of second-phase intermetallics at the reacting surface, if induced by some process operative only under fast neutron irradiation, could be a contributing factor in causing the observed higher in-reactor oxidation rates.

To observe such effects with reasonable certainty, it would of course be desirable to obtain micrographs of the same grains and grain boundaries before and after exposure. However, this could only be done by encapsulating the specimens in an inert environment to protect the prepared surfaces. A more expedient, though less ideal, approach would be to take photomicrographs of a marked region on a corrosion specimen before and after exposure. Thus while the same grains would not be observed, careful mounting and polishing following exposure would ensure that the regions being compared were separated by not more than $1 \mathrm{~mm}$. This was done for several of the in- and out-of-reactor specimens included in the heat treatment effects studies discussed in Section 5.1.2. Results are shown in Figures B-4 and B -5.

As can be seen in the figures, the most striking effects appear in the beta grain structure, and while the bright field photomicrographs of the $651510 \%$ cold-worked material show little or no change in the "spot" population, the differences were more apparent upon direct visual observation 


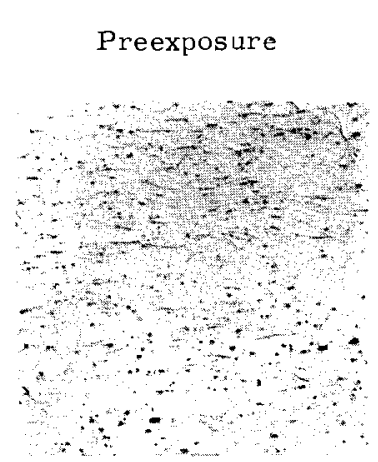

Post In-Reactor Exposure

Post

Out-of-Reactor Exposure
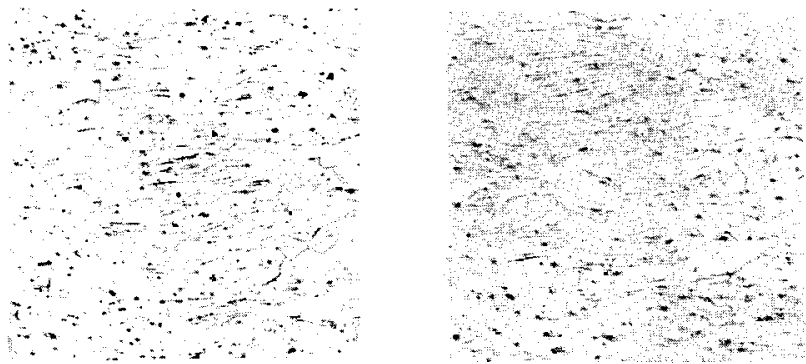

B Etched

Bright

Field

Plate 6515 Zircaloy-2, 10\% Cold Work
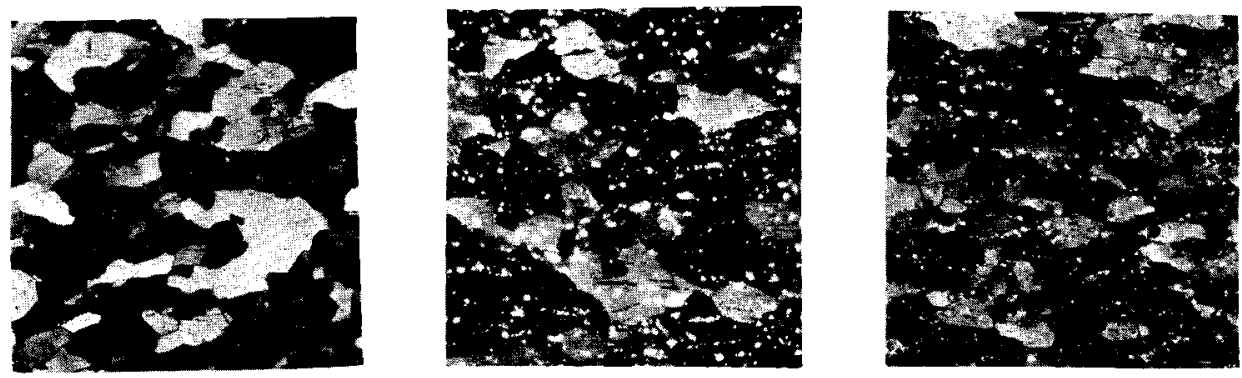

B Etched

Anodized

Polarized

Light

Plate 6515 Zircaloy-2, 10\% Cold Work
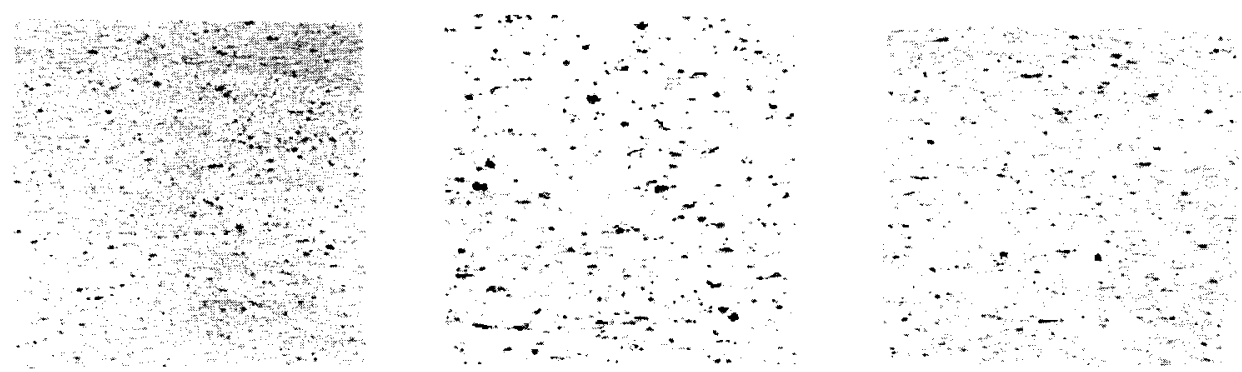

B Etched

Bright

Field

NPR Zircaloy-2, 86\% Cold Work

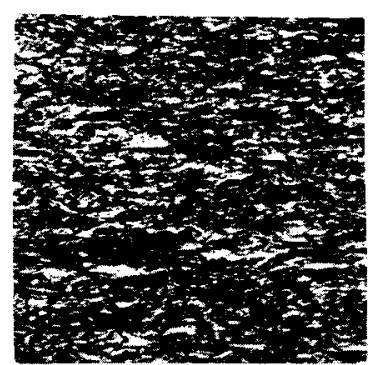

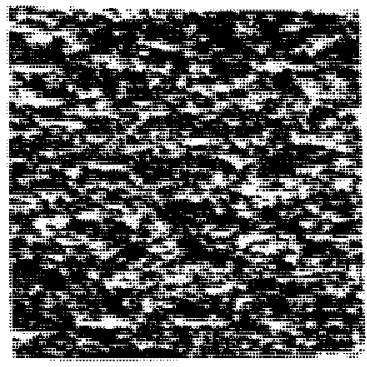

NPR Zircaloy-2, 86\% Cold Work

FIGURE B-4

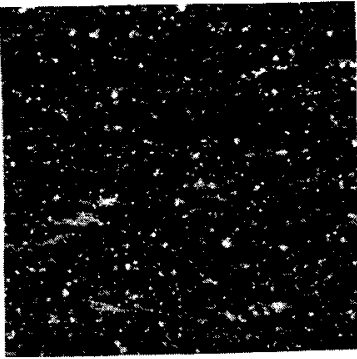

B Etched

Anodized

Polarized

Light

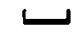

(250X reduced $\sim 30 \%$ )

Comparison of the Microstructure

of Cold-Worked Zircaloy-2

Before and After 49-Day Exposure

In- and Out-of-Reactor at $540{ }^{\circ} \mathrm{F}$ 


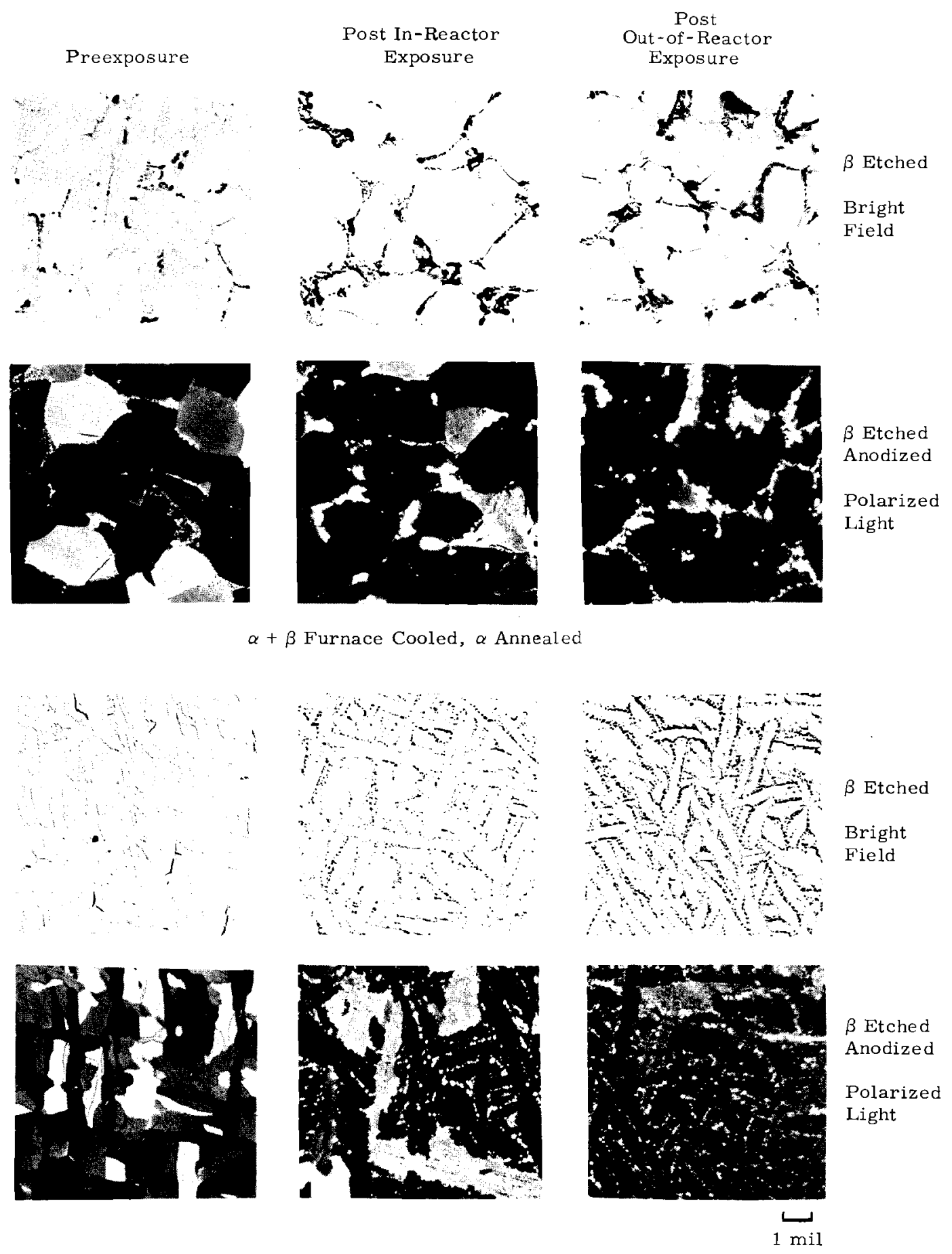

$\alpha+\beta$ Furnace Cooled, $\beta$ Quenched, $\alpha$ Annealed

\section{FIGURE B-5}

(250X reduced $\sim 30 \%$ )

Comparison of the Microstructure

of Heat-Treated Zircaloy-2

Before and After 49-Day Exposure

In- and Out-of-Reactor at $540^{\circ} \mathrm{F}$ 
of the surfaces. On the other hand, little or no difference could be dis cerned for the heavily cold-worked NPR tube material. Another observation is that the change is not solely or even primarily related to in-reactor exposure, but rather is an apparent effect of (prolonged) heating at moderate temperature ( 49 days at $540^{\circ} \mathrm{F}$ ) as shown by the extreme right-hand columns of the photomicrographs in the figures. The effects of other combinations of time and temperature were not studied. That changes in the hydrogen or oxygen content of the metal is not a factor was shown by examining some of the specimens following use of a hydride etchant* and following the heating of other specimens out-of-reactor in sealed, heliumpurged and evacuated ampoules. The dark "spots" in bright field and bright "spots" in polarized light are predominantly something other than hydride.

Great care was exercised to ensure that etchant and anodizing solutions and techniques were duplicated, but the possibility still remains that what has been observed is not at all an increase in the amount of precipitated intermetallics but rather an increased sensitivity of certain compounds to the etchant caused by heat and with a possible contribution from irradiation.

A number of reports have appeared in the literature indicating evidence both for and against changes in microstructure of metals as a consequence of neutron irradiation. Most of the supporting evidence has been associated with the sub-grain structure as deduced from $\mathrm{X}$-ray scattering and lattice parameter measurements, which have indicated the probable existence of lattice distortions。 $(58,62)$

Indications of neutron-induced alterations in the grain structure of a number of annealed metals, including zirconium, were reported by Konobeyevskii, et a1. ${ }^{(63)}$ Subsequent studies by Bruch and co-workers of relatively pure metals, including the same metals reported by the Russian workers, were specifically designed to detect such changes but none were

* Etchant: 45 parts by volume $30 \% \mathrm{H}_{2} \mathrm{O}_{2}, 45$ parts by volume $70 \% \mathrm{HNO}_{3}$, 7 parts by volume $48 \% \mathrm{HF}$. 
found. ${ }^{(64)}$ Exposures were to an integrated flux of 1.9 to $6.9 \times 10^{19} \mathrm{nvt}$ $(>1 \mathrm{MeV})$ and at 158 to $203{ }^{\circ} \mathrm{F}$. The Bruch report also summarizes the investigations of Chang on copper and nickel irradiated at $-292{ }^{\circ} \mathrm{F}$ to an integrated fast flux of $2 \times 10^{18} \mathrm{nvt}$, wherein no change in the grain size of copper was observed and a small indicated increase in the grain size of nickel was judged to be within experimental error. They conclude that the differences between their own and the Russian work may be the result of either or both the higher integrated neutron exposure and higher temperature of the Russian experiment: $2 \times 10^{20}$ nvt (fast component unknown), and 365 to $572{ }^{\circ} \mathrm{F}$. Arguments against a neutron effect are presented.

On the other hand, in addition to lattice distortions, there is ample evidence of phase transformations in metals and non-metals as a consequence of neutron irradiation, and mechanisms for formation of crystal nucleation centers have been proposed. ${ }^{(65-67)}$ It is conceivable that changes in the more gross features of the microstructure could be induced by a proper combination of time, temperature, and neutron exposure.

More pertinent to our metallographic observations, however, are the changes in microstructure reported by Wallack following exposure of aluminum and titanium alloys to the fast neutron flux of the Materials Testing Reactor over the range $3 \times 10^{18}$ nvt to $8.5 \times 10^{19}$ nvt and at temperatures to about $280^{\circ} \mathrm{F}$. Comparison of postirradiation microstructure with that of unirradiated controls disclosed marked changes in 2024-0 and 2024-T3 aluminum and to a lesser extent in $\mathrm{Ti}-6 \mathrm{wt} \% \mathrm{Al}-4 \mathrm{wt} \% \mathrm{~V}$ which would not be expected on the basis of time-temperature effects alone. In the case of aluminum, the changes involved an apparent agglomeration, both at grain boundaries and within grains, of the precipitate formed during the original annealing (or an additional heavy precipitation) tantamount to a radiation-induced overaging effect. In the case of the titanium alloy, only a small difference was observed, giving the irradiated specimen the appearance of overaged material. None of these effects were noted following exposure to less than $\sim 2 \times 10^{19}$ nvt (fast). ${ }^{(68)}$ 


\subsection{Electron Microscopy}

A sample of the 264-day irradiated tensile specimen with high hydrogen content and showing a marked hydride platelet concentration near the surface (Figure B-1) was mounted in copper-filled diallyl phthalate resin, metallographically polished, cathodically etched, and replicated. Typical electron micrographs of cross sections of the oxide $\left(440 \mathrm{mg} / \mathrm{dm}^{2}\right.$ on rollplane surface) at $4500 \mathrm{X}$ are shown in Figure B-6. Microcracks are fairly uniformly spaced at distances corresponding to about $10 \mathrm{mg} / \mathrm{dm}^{2}$ of oxide. The microcracks are oriented parallel to the surface of the metal substrate, and fan-shaped arrangements [micrographs in Figure B-6 (a) and (c)] appear at specimen corners or wherever gross irregularities exist in the original surface or are caused by nonuniform penetration.

The outer layer of oxide to a depth of 75 to $100 \mathrm{mg} / \mathrm{dm}^{2}$ [white region at top of micrograph Figure B-6 (b)] appeared to be of a different and more readily eroded structure than the oxide at greater depths. Typical micrographs of regions near the outer edge of the oxide and including the boundary zone between the two apparently different oxides are shown in Figure B-7 at 15,000X. Figure B-7 (a) is an enlargement of the upper left-hand corner of Figure B-6 (b). The oxide immediately below the outer layer and to a depth equivalent to at least $50 \mathrm{mg} / \mathrm{dm}^{2}$ was generally featureless and almost entirely devoid of microcracks.

For comparison purposes and to show the more gross features of the oxide, several light micrographs at $1000 \mathrm{X}$ of typical regions of oxide on this specimen are shown in Figure B-8.

Figure B-9 shows typical electron micrographs of a similar thickness (433 mg/dm ${ }^{2}$ ) of oxide formed on Zircaloy-2 out-of-reactor in water at $680^{\circ} \mathrm{F}$ (1242 days). There was a notable absence of extensive microcracking in the oxide of this specimen. Light micrographs of the oxide on this out-of-reactor specimen are shown in Figure B-10. 


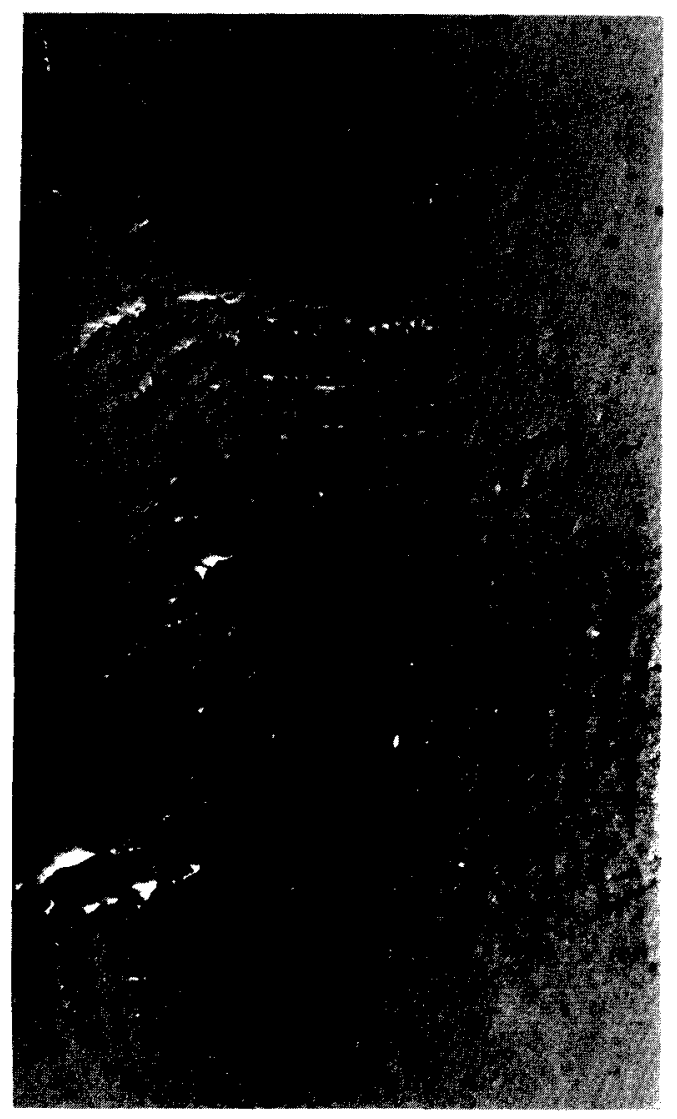

(a)

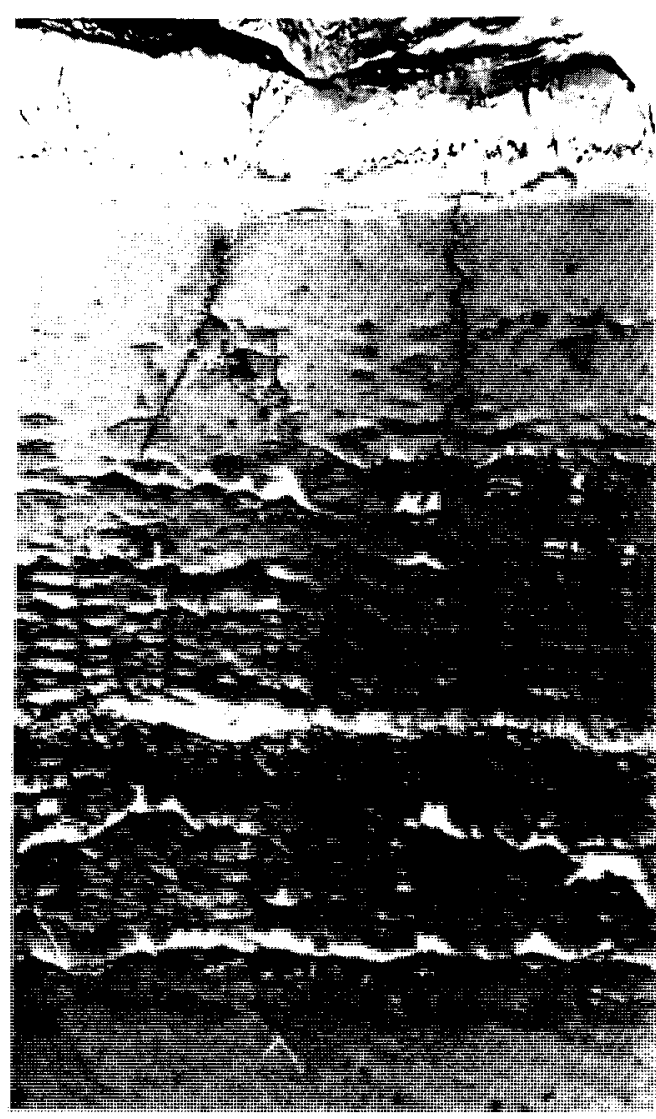

(b)

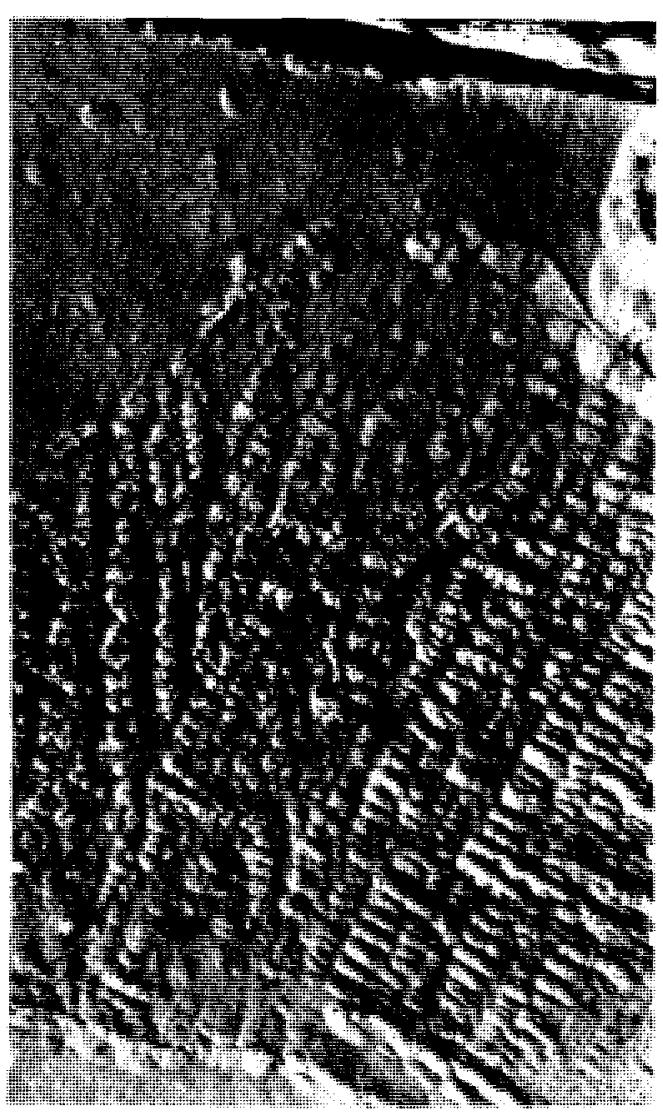

(c)

$(4500 \mathrm{X}$ reduced $\sim 20 \%)$

\section{FIGURE B-6}

Electron Micrographs of Replicas of Oxide Formed on Zircaloy-2

During 264-Day In-Reactor Exposure to $540^{\circ} \mathrm{F}$ High-Oxygen Water

(Metal substrate at bottom; shadowing angle $45^{\circ}$ ) 

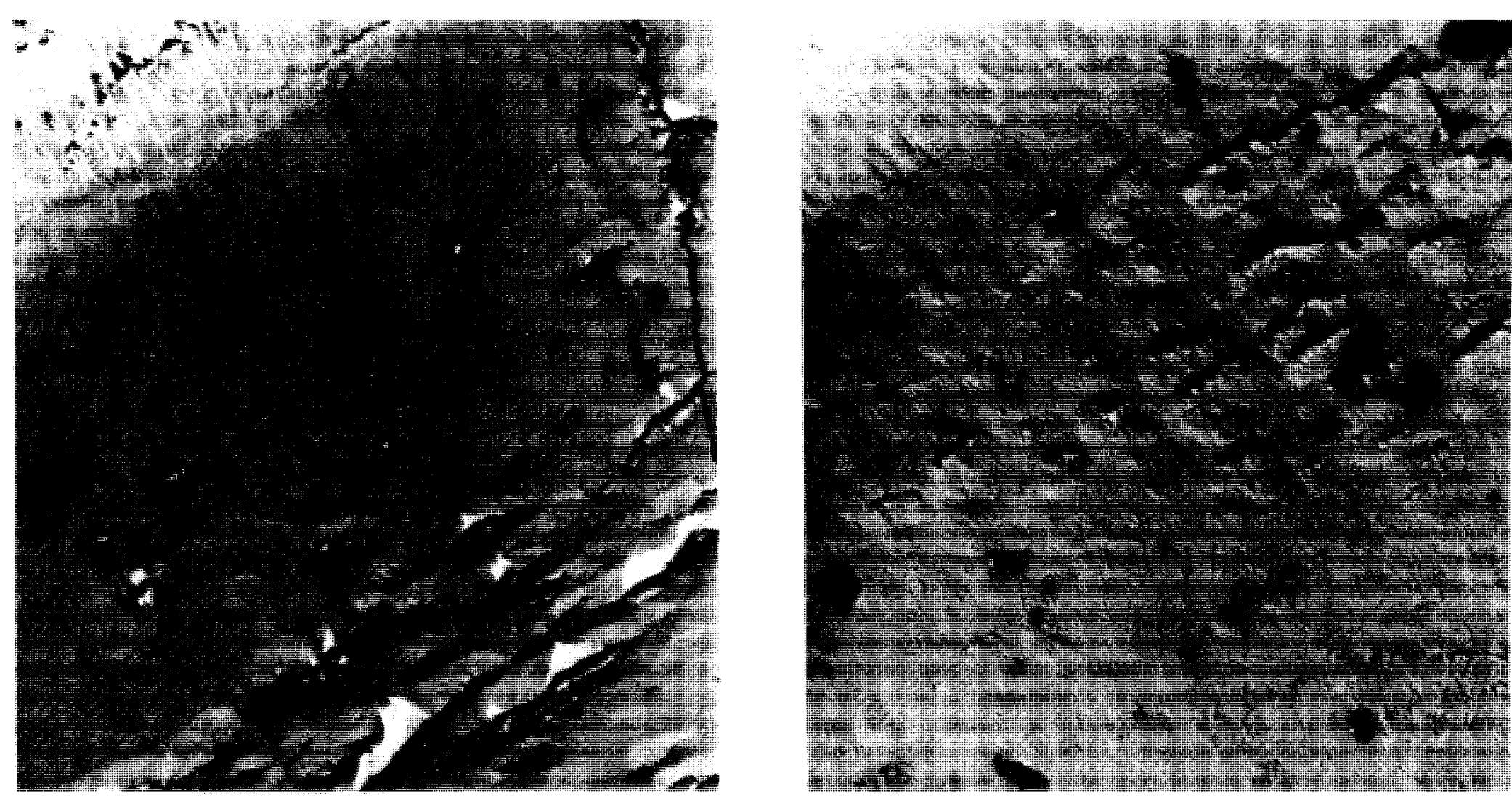

FIGURE B-7

$(15000 \mathrm{X}$ reduced $\sim 20 \%$ )

Electron Micrographs of Replicas of Oxide Formed on Zircaloy-2 During 264-Day In-Reactor Exposure to $540^{\circ} \mathrm{F}$ High-Oxygen Water

(Metal substrate at bottom; shadowing angle $45^{\circ}$ ) 

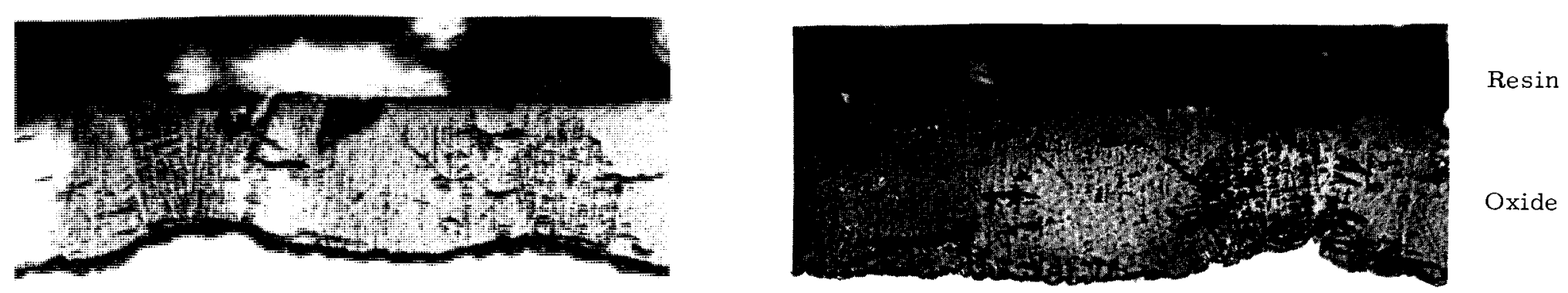

Zircaloy-2

Roll-Plane Surface
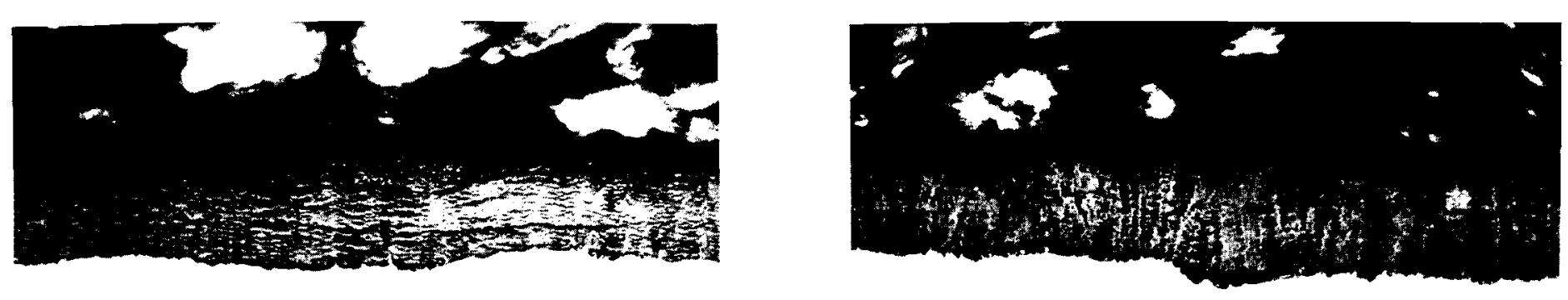

Transverse Surface

FIGURE B-8

Micrographs of Cathodically Etched Oxide on Annealed Zircaloy-2 After 264-Day Exposure to High-Oxygen Water In-Reactor at $540^{\circ} \mathrm{F}$ 


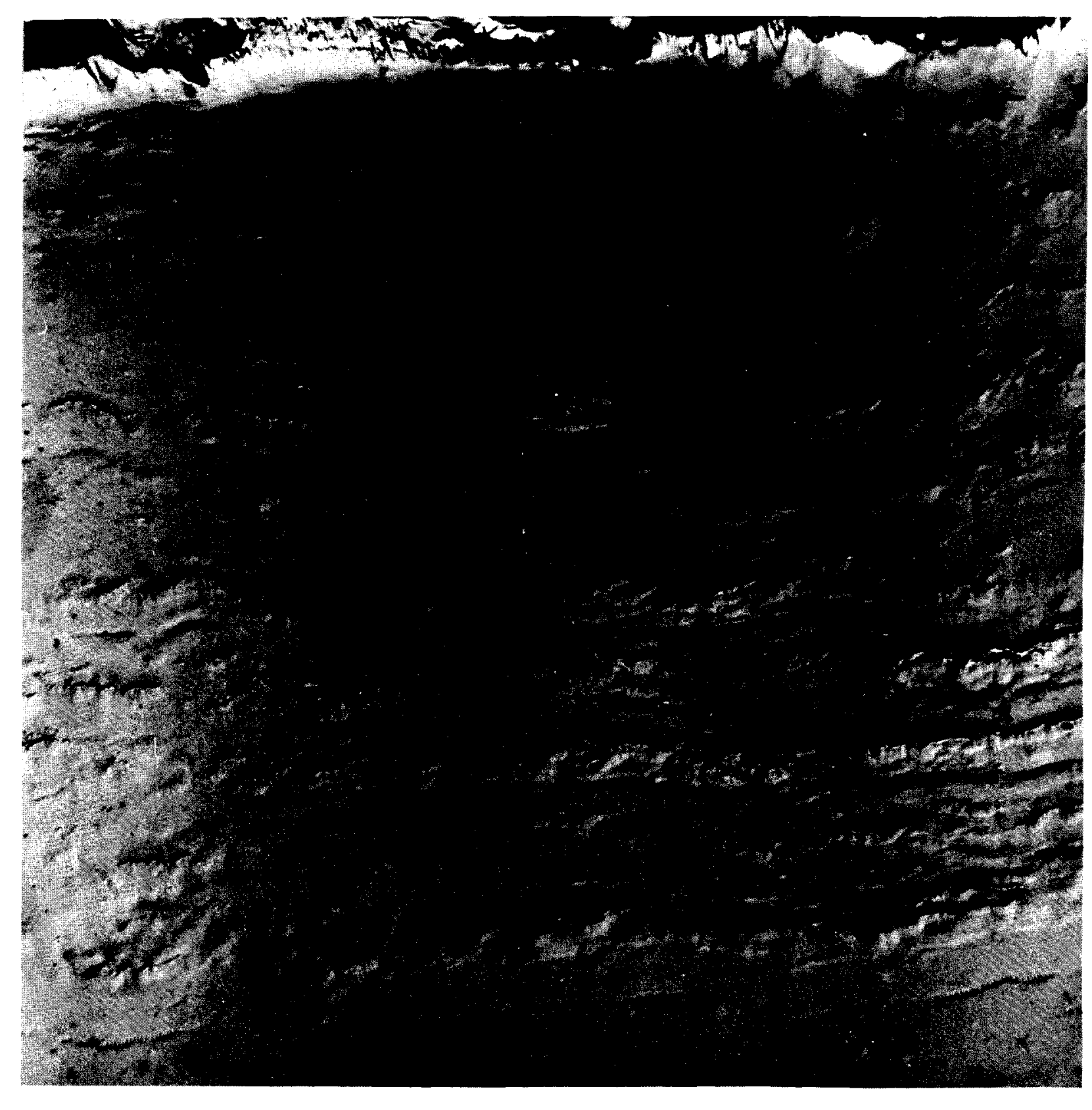

Shadowing Angle $35^{\circ}$

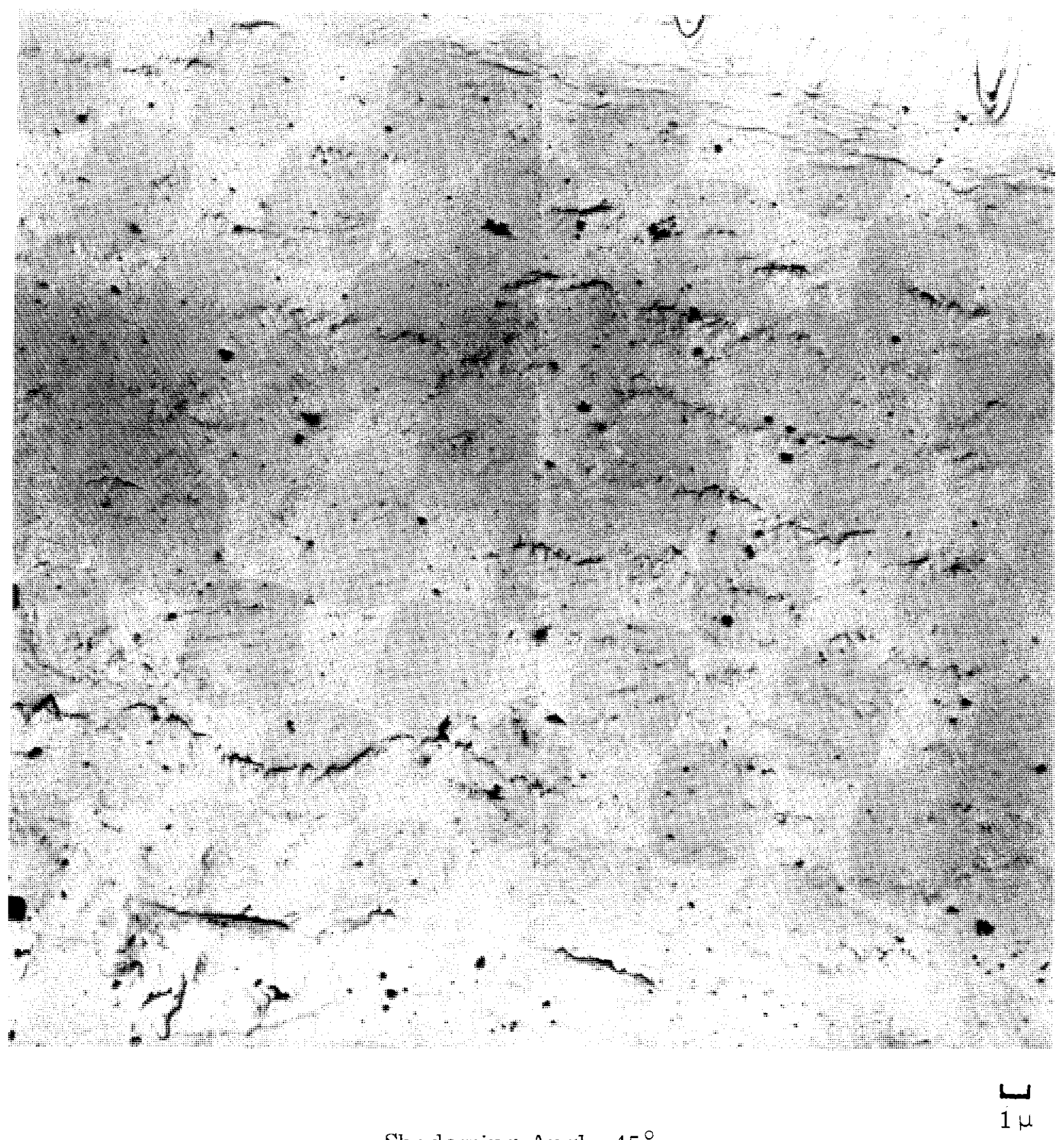

Shadowing Angle $45^{\circ}$

FIGURE B-9

Electron Micrographs of Replicas of Oxide Formed on Zircaloy-2 During 1242-Day Out-of-Reactor Exposure to $680^{\circ} \mathrm{F}$ Water (Metal substrate at bottom)
$4500 \mathrm{X}$ 


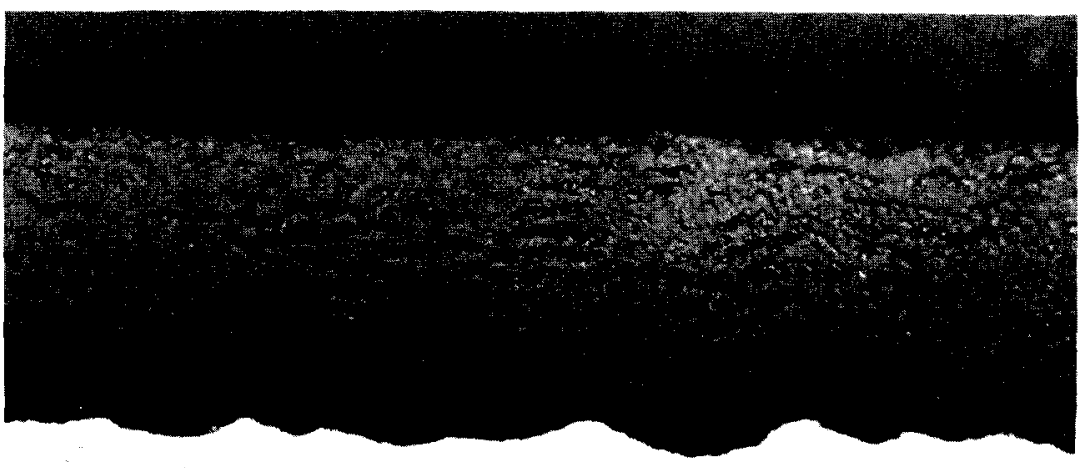

Resin

Oxide

Zircaloy-2

Roll-Plane Surface

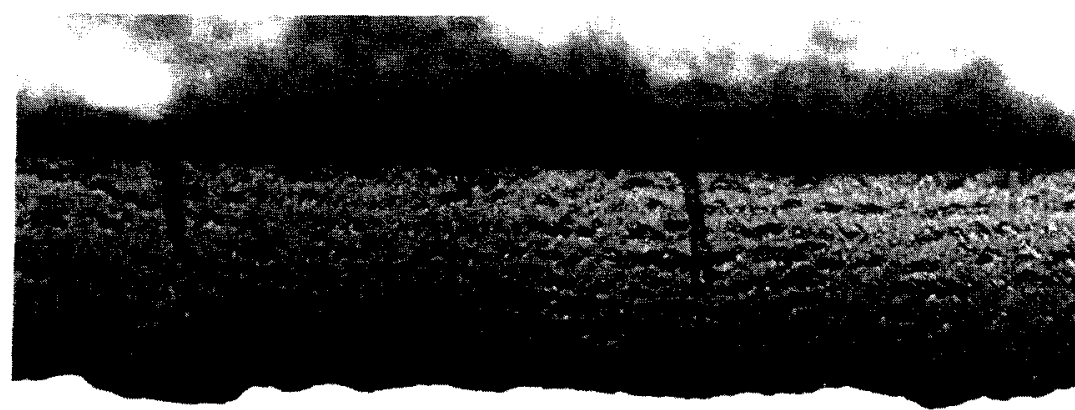

Resin

Oxide

Zircaloy-2

Transverse Surface

$1 \mathrm{mil}$

FIGURE B-10

Micrographs of Cathodically Etched Oxide Formed on Zircaloy-2

During 1242-Day Out-of-Reactor Exposure to $680^{\circ} \mathrm{F}$ Water

Neg. $465651 \mathrm{C}, 465651 \mathrm{~A}$ $1000 X$ 
Samples of irradiated and unirradiated specimens of Plate 6515 in the $10 \%$ cold-worked condition were fixed in a common mount to ensure uniformity of treatment, then polished, etched, anodized, replicated, and examined at magnifications up to 22,500X. The metal and oxide were examined following polishing and chemical etching ${ }^{*}$ and the metal was again examined following an anodizing treatment which deposited a coating of oxide about $2000 \AA$ thick. The irradiated specimen had been exposed in a fast flux of $1.9 \times 10^{13} \mathrm{nv}$ to a total integrated exposure of $4 \times 10^{19} \mathrm{nvt}$. Figure B-11 (a) and (b) compares the appearance of the freshly-etched metal at $15,000 \mathrm{X}$. In general, it can be seen that the grain boundaries of both specimens have been preferentially attacked and pitted, but there appears to be no difference in the extent of attack.

The general appea rance of lightly oxidized (anodized) surfaces is shown in (c) and (d) of Figure B-11. Here a lower magnification (4500X) has been used to show the more gross features over a larger area. The most obvious difference is the rougher appearance of the oxide on the irradiated metal.

* Etchant: 45 parts by volume $70 \% \mathrm{HNO}_{3}, 7$ parts by volume $48 \% \mathrm{HF}$, 45 parts by volume $\mathrm{H}_{2} \mathrm{O}$ 


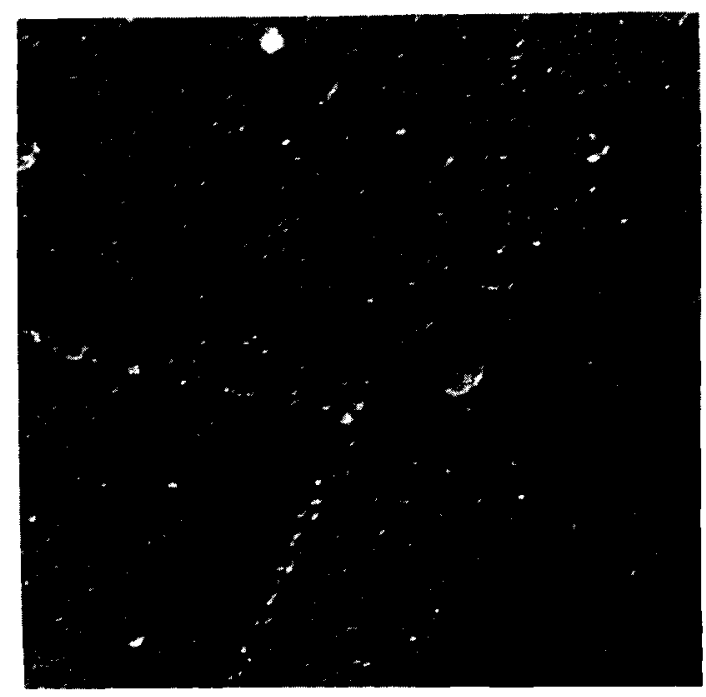

a) Unirradiated

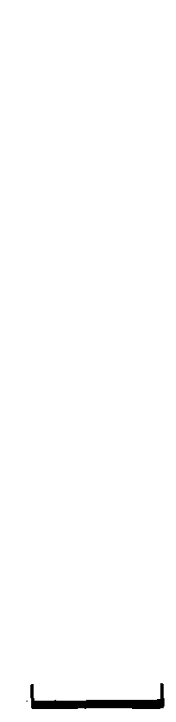

$1 \mu$

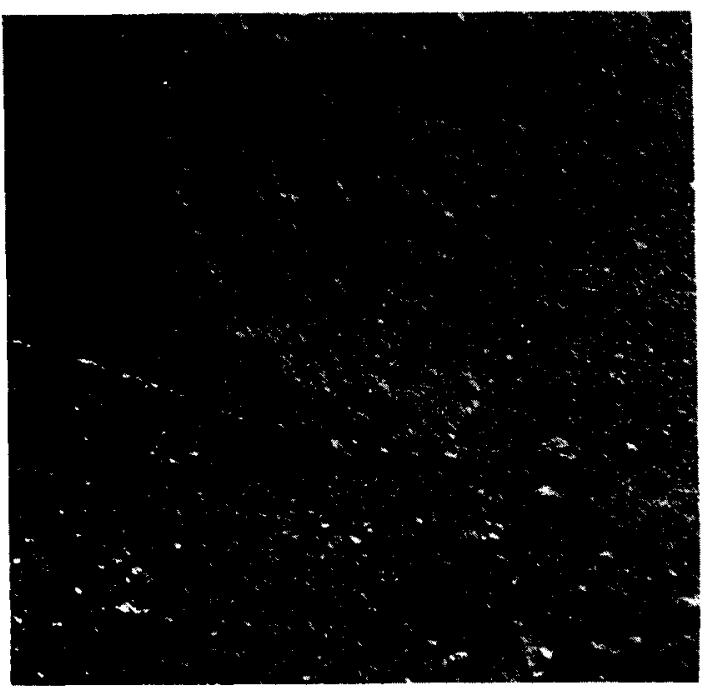

b) Irradiated, $4 \times 10^{19} \mathrm{nvt}(>1 \mathrm{MeV})$

Metallographically Polished and Etched

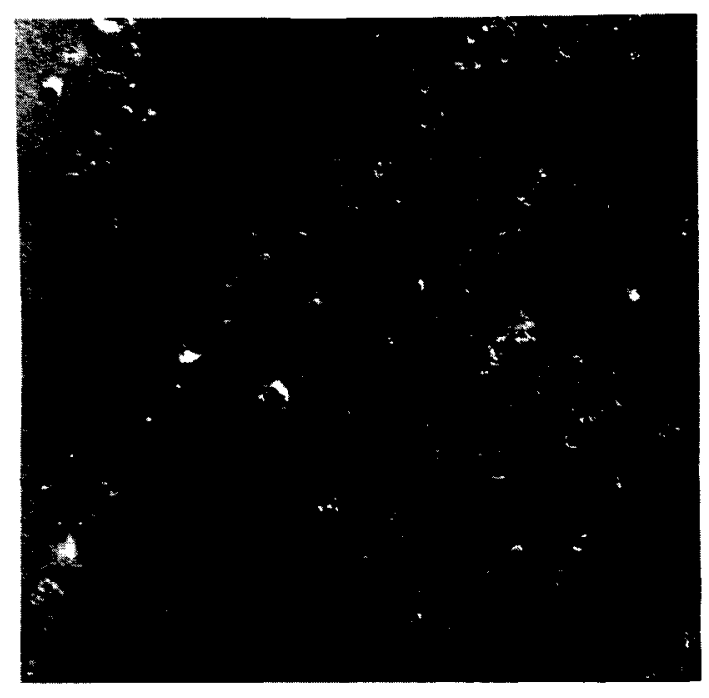

c) Unirradiated

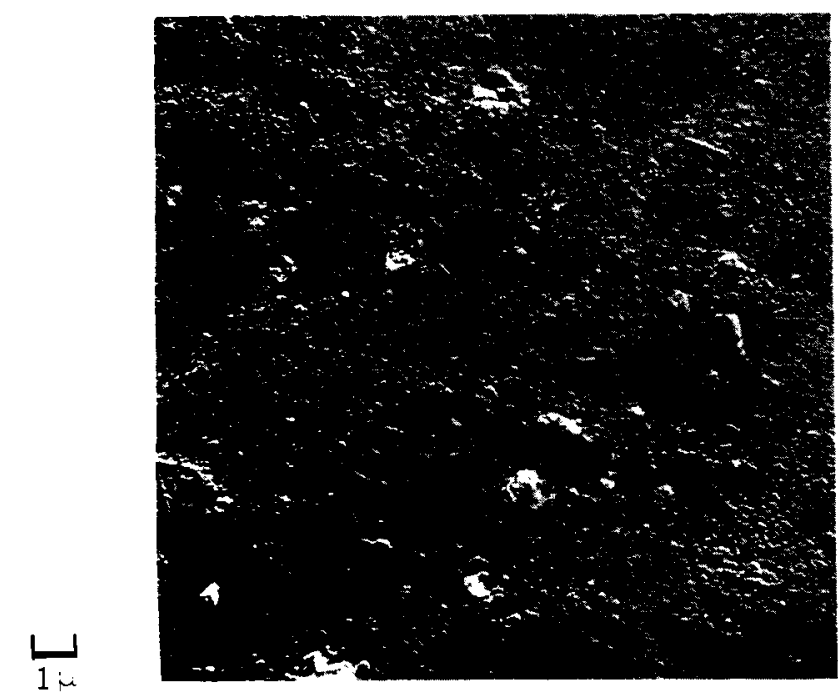

d) Irradiated, $4 \times 10^{19} \mathrm{nvt}(>1 \mathrm{MeV})$

Metallographically Polished, Etched and Anodized

a) and b) at 15000X; c) and d) at $4500 \mathrm{X}$ (reduced $\sim 15 \%$ )

\section{FIGURE B-11}

Comparison of the Appearance of Replicas of Bare and Anodized Surfaces

of Irradiated and Unirradiated Zircaloy -2 


\section{REFERENCES}

1. W. A. Burns and H. P. Maffei. Neutron Irradiation and Cold Work Effects on Zircaloy-2 Corrosion and Hydrogen Pickup-An Interim Report, HW-76636. General Electric Company, Richland, Washington. December 1962.

2. H. P. Maffei. Zircaloy-2 Pilot Plant Etching and Rinsing Facility, HW-62942. General Electric Company, Richland, Washington. December $15,1959$.

3. W. C. Morgan. FOILS: A Program for Computing Neutron Exposures from Foil-Activation Data, HW-81367. General Electric Company, Richland, Washington. April 1964.

4. R. H. Robinson and D. B. Conklin. "A Pre-Integrating Dissolved Hydrogen Analyzer," Bettis Technical Review-Reactor Chemistry and Plant Materials, Westinghouse Electric Corporation, p. 51. December 1959.

5. B. Lustman and F. Kerze. The Metallurgy of Zirconium, National Nuclear Energy Series, Division 7, McGraw-Hill Book Company, Inc. , New York, N. Y. vol. 4, p. 633.

6. H. E. Williamson, J. P. Hoffman, C. J. Baroch, and T. J. Pashos. "Comparative Performances of Similar Zircaloy and Stainless Steel Clad Fuels in the VDWR," ANS Eleventh Annual Meeting, Philadelphia, Penn. June 14-18, 1964 .

7. R. C. Nelson. "The Corrosion of Zircaloy-2 Fuel Element Cladding in a Boiling Water Reactor Environment," Proceedings of the USAEC Symposium on Zirconium Alloy Development, GEAP-4089, vol. II, pp. 17-19. November 30, 1962 .

8. J. G. Goodwin. The Effect of Heat Treating Temperature on the Corrosion Resistance of Furnace Cooled Zircaloy-2, WAPD-ZH-13, pp. 20-21. Westinghouse Electric Corporation. December 1958.

9. J. G. Goodwin. The Effect of Alpha-or Beta-Phase Heat Treatment on the Corrosion Resistance of Vacuum Melted Zircaloy-2, WAPD-ZH-16, pp. 1-11. April 1959.

10. C. M. Schwartz, D. A. Vaughn, and G. G. Cocks. Identification and Growth of Oxide Films on Zirconium in High-Temperature Water, BMI-793. Battelle Memorial Institute. December 17, 1952.

11. D. S. Kneppel. Metallurgical Aspects of the Corrosion Resistance of Zirconium, NMI-1136, Nuclear Metals Inc., Cambridge, Mass. August 1, 1955. 
12. R. G. Sowden. "Radiolytic Problems in Water Reactors," J. Nucl. Mater., vol. 8, no. 1, pp. 81-101. 1963.

13. A. O. Allen. The Radiation Chemistry of Water and Aqueous Solutions, D. Van Nostrand Co. , Inc. , New York, N. Y., 1961.

14. J. Hino. "Long-Term Corrosion Behavior of Zircaloy, " Technical Progress Report, WAPD-MRP-106, pp. 71-90. Pressurized Water Reactor (PWR) Project, Bettis Atomic Power Laboratory. October 23, 1963. (also subsequent Quarterly Reports.)

15. W. Yeniscavich, R. A. Wolfe, and R. M. Lieberman. "Hydrogen Absorption by Nickel Enriched Zircaloy-2," J. Nucl. Mater. , vol. 3, pp. 271-280. 1959.

16. L. R. Lynam. Metallurgical Examination of Fuel Rod from PWR-1 Blanket at the End of the Second Seed Life, WAPD-TM-308. Westinghouse Electric Corporation. December 1961.

17. B. Lustman, M. L. Bleiberg, E. S. Byron, J. N. Chierigos, J. G. Goodwin, and G. J. Salvaggio. "Zircaloy Cladding Performs Well in PWR," Nucleonics, vol. 19, pp. 58-63. January 1961.

18. J. E. Draley, J. A. Ayres, W. E. Berry, E. Hillner, and S. P. Rideout. "Corrosion in Aqueous Systems," A/Conf. 28/P/243, Third United Nations Conference on the Peaceful Uses of Atomic Energy. May 1964.

19. M. L. Bleiberg. "Irradiation Effects on Ceramic Fuels," Technical Progress Report, WAPD-MRP-109, pp. 45-52. Pressurized Water Reactor (PWR) Project, Bettis Atomic Power Laboratory. July 23, 1964.

20. R. C. Asher, A. Hall, C. Howard, and T. B. Kirstein. "Irradiation Effects on Zirconium-Steam Reactions," Nucl. Eng. , vol. 9, no. 96, pp. 171-175. May 1964 .

21. Heavy Water Moderated Power Reactors Progress Report DP-915, $Z$ edited by R. R. Hood, p. 10. May-June 1964.

22. R. C. Asher. "The Oxidation and Hydriding of Zirconium Alloys Under Irradiation in Steam, " Libby-Cockroft Gas Coolant Compatibility (Metals and Ceramics) Meeting, GCM/UK/B8. March 1964.

23. S. B. Dalgaard. Oxidation Mechanism of Zirconium and Effect of Reactor Flux, PR-CM-38, p. 53. June 30, 1964. 
24. G. H. Jenks and R. J. Davis. "Effects of Reactor Radiations on Zircaloy-2 Corrosion in High-Temperature Aqueous Environments," Proceedings of the Third Conference on Nuclear Reactor Chemistry, Gatlinburg, Tennessee. October 9-11, 1962.

25. S. Kass. The Development of the Zircaloys, WAPD-1549. Westinghouse Electric Corporation. October 1962.

26. Stanley Kass. "The Development of the Zircaloys," ANS Transactions, vol. 6, no. 2, p. 366. November 1963.

27. H. H. Klepfer. "Zirconium-Niobium Binary Alloys for Boiling Water Reactor Service, Part I-Corrosion, Part II-Cor rosion Hydrogen Embrittlement," J. Nucl. Mater., vol. 9, no. 1, pp. 65-84. June 1963.

28. B. Cox, P. G. Chadd, and J. F. Short. The Oxidation and Corrosion of Zirconium and Its Alloys XV. Further Studies of ZirconiumNiobium Alloys, AERE-R4134, Great Britain. August 1962.

29. B. Cox and Mrs. J. A. Read. Oxidation of a $\mathrm{Zr}-2-1 / 2 \% \mathrm{Nb}$ Alloy in Steam and Air. AERE-R4459, Great Britain. October 1963.

30. S. B. Dalgaard. The Corrosion Resistance of $\mathrm{Zr}-\mathrm{Nb}$ and $\mathrm{Zr}-\mathrm{Nb}-\mathrm{Sn}$ Alloys in High-Temperature Water and Steam, CRMet-911, also AECL-993. Chalk River, Ontario, Canada. March 1960.

31. D. L. Douglass and B. E. Dearing. Effect of Heat Treatment on the Corrosion of Zirconium-2 at. \% Tin-2 at. \% Niobium, KAPL-2071. Knolls Atomic Power Laboratory. January 20, 1960.

32. A. A. Kiselev, V. A. Myshkin, A. V. Kozhevnikov, S. I. Korolev, and E. G. Shorina. Research on the Corrosion of Zirconium Alloys in Water and Stea $m$ at High Temperature and Pressure, AECL-1724. Chalk River, Ontario, Canada. April 1963. (Translated from the Proceedings of the IAEA Conference on Corrosion of Reactor Materials, Salzburg, Austria, June 4-8, 1962.)

33. C. E. Ellis, S. B. Dalgaard, W. Evans, and W. R. Thomas. "Development of Zirconium-Niobium Alloys," A/Conf. 28/P/22, Third United Nations Conference on the Peaceful Uses of Atomic Energy. May 1964.

34. H. Richter and J. C. Tverberg. "Development of $\mathrm{Zr}-\mathrm{Nb}-\mathrm{Sn}$ Alloys for Reactor Applications," Proceedings of the USAEC Symposium on Zirconium Alloy Development, Castlewood, Pleasanton, California, GEAP-4089, vol. 1, pp. 4-0 to 4-58. November 30, 1962. 
35. W. R. Thomas and J. E. LeSurf. The Engineering Program on the Corrosion and Hydriding of Zirconium Alloys, MET-I-43. Chalk River, Ontario, Canada. July 1964.

36. S. B. Dalgaard. "Factors Affecting Oxidation and Hydriding of Zirconium Alloys," ANS Transactions, vol. 6, no. 2, p. 370. November 1962.

37. Heavy Water Moderated Power Reactors Progress Report, DP-925, edited by R. R. Hood, p. 17. July-August 1964.

38. D. W. Shannon. "Electrical Properties of $\mathrm{ZrO}_{2}$ Corrosion Films, Interim Report No. 1, Electrical Resistance Measurements, "' Proceedings of the USAEC Symposium on Zirconium Alloy Development, Castlewood, Pleasanton, California, GEAP-4089, vol, II. November $12-14,1962$.

39. P. J. Harrop and J. N. Wanklyn. Influence of Gamma Flux on the Electrical Conductivity of $\mathrm{ZrO}_{2}$ Films and its Relevance to Corrosion in Nuclear Reactors, AERE-R4703. Great Britain. September 1964.

40. R. J. Davis. "Oxide Growth and Capacitance on Preirradiated Zircaloy - 2," Reactor Chemistry Division Annual Progress Report for Period ending January 31, 1964, ORNL-3591. Oak Ridge National Laboratory. pp. 80-83.

41. Battelle Memorial Institute. V. "Microgravimetric Investigation into the Mechanisms of Corrosion of Reactor Materials in the Presence of Nuclear Radiation," Quarterly Report No. 5, EURAEC-616. March 31, 1963.

42. M. L. Bleiberg and L. S. Castleman. Recovery of Irradiated Crystal Bar Zirconium, WAPD-107. Westinghouse Electric Corporation. April 23, 1954.

43. T. Rockwell and P. Cohen. "Pressurized Water Reactor (PWR) Water Chemistry," Proceedings of the International Conference on the' Peaceful Uses of Atomic Energy, Geneva, vol. 9, p. 536. August 8-10, $\overline{1955 .}$

44. J. M. Tobin. A Study of Copper Oxidation ard Some Irradiation Effects, GA-3349. General Dynamics Corporation. February 6, 1963.

45. C. R. Breden. "Boiling Water Reactor Technology Status of the Art Report," Water Chemistry and Corrosion, ANL-6562. Argonne National Laboratory, vol. II, p. 73. February 1963.

46. H. P. Maffei. Corrosion Tests on KER-1 Zircaloy-2 Process Tube, HW-71771. General Electric Company, Richland, Washington. September 1961 . 
47. B. Griggs, H. P. Maffei, and D. W. Shannon. Multiple Rate Transitions in the Aqueous Corrosion of Zircaloy, HW-67818 REV. General Electric Company, Richland, Washington. December 1960.

48. E. Hillner. Hydrogen Absorption in Zircaloy During Aqueous Corrosion, Effect of Environment, WAPD-TM-411. Westinghouse Electric Corporation. November 1964.

49. K. M. Goldman and D. E. Thomas. Hydrogen Pickup During Corrosion Testing of Zirconium and Zircaloy-2, WAPD-MM-184. Westinghouse Electric Corporation. February 19, 1953.

50. H. P. Maffei. Effect of Oxygen on Hydrogen Pickup of Zircaloys During Autoclaving, HW-72266, General Electric Company, Richland, Washington. January 9, 1962.

51. J. N. Wanklyn, D. R. Silvester, J. Dalton, and N. J. M. Wilkins. The Corrosion of Zirconium and Its Alloys in High Temperature Steam, Part II. The Uptake of Hydrogen During Corrosion, $\bar{A} \overline{E R E-R-3768 . ~ A t o m i c ~ E n e r g y ~ R e s e a r c h ~ E s t a b l i s h m e n t, ~ H a r w e l l, ~}$ Berks, England. July 1961.

52. B. Cox. The Oxidation and Corrosion of Zirconium and Its Alloys, XII. Hydrogen Absorption by Zircaloy-2 and Some Other Alloys During Corrosion in Steam, AERE-R-3556. Atomic Energy Research Establishment, Harwell, Berks, England. January 1961.

53. B. Cox. Unpublished Data, Atomic Energy of Canada Ltd. . (Personal Communication).

54. C. M. Schwartz and D. A. Vaughn. Effect of Hydrogen Pickup on Corrosion Behavior of Zirconium in Water, BMI-1120. Battelle Memorial Institute. August 1, 1956.

55. A. E. Bibb. Aqueous Corrosion of Zirconium Single Crystals, KAPL-2257. Knolls Atomic Pow er Laboratory. October 1962.

56. G. Östberg and H. P. Myers. "Aspects of Swedish Studies of Cladding Materials for Water-Cooled Reactors," A/Conf. 28/F/419, Third United Nations Conference on the Peaceful Uses of Atomic Energy. May 1964.

57. A. E. Bibb. Unpublished Data, Knolls Atomic Power Laboratory. (Personal Communication)

58. G. R. Piercy and R. H. Tuxworth. The Effect of Fast Neutron Irradiation on the Density, X-Ray Lattice Parameter and Line Breadth of Metals, CRRM-1010. Atomic Energy of Canada Ltd, Chalk River, Ontario. March 1961. 
59. R. K. McGeary and B. Lustman. Preferred Orientation in Zirconium, WAPD-8. Westinghouse Electric Corporation. March 10, 1950.

60. A. L. Bement, J. C. Tobin, and R. G. Hoagland. Effects of Neutron Irradiation on the Flow and Fracture Behavior of Zircaloy-2, HW-82102. General Electric Company, Richland, Washington. April 1, 1964.

61. M. L. Picklesimer. A Preliminary Examination of the Formation and Utilization of Texture and Anisotropy in Zircaloy-2, ORNL-TM-460. Oak Ridge National Laboratory. February 28, 1963

62. F. P. Butra. "The Influence of Neutron Irradiation on the Structure Molybdenum," The Physics of Metals and Metallography, vol. 10, no. 2, pp. 65-67. May 1961 .

63. S. T. Konobeyevskii, N. F. Pravdyuk, and V. I. Kutaitsev. "The Effect of Irradiation on the Structure and Properties of Structural Materials, "Proceedings of the International Conference on the Peaceful Uses of Atomic Energy, Geneva. August 8-20, 1955.

64. C. A. Bruch, W. E. McHugh, and L. J. Doig. "Metallographic Studies of Neutron Irradiated Non-Fissionable Metals," Proceedings Second Nuclear Engineering and Science Conference, 57-NESC-15, ASTM, Philadelphia, Pennsylvania, March 11-14, 1957.

65. C. Motoc and I. Teodorescu. "Radiation Effects in Thin Films," Symposium on Radiation Damage in Solids and Reactor Materials, SM-25/7, IAEA, Venice, Italy. May 7-11, 1962.

66. M. C. Wittels and F. A. Sherrill. 'Irradiation Induced Phase Transformation in Zirconia," J. Applied Physics, vol. 27, p. 643. June 1956.

67. J. Fleeman and G. J. Dienes. "Effect of Reactor Irradiation on White to Grey Tin Transformation," J. Applied Physics, vol. 26, p. $652,1955$.

68. S. Wallack. The Effect of Radiation on the Physical and Mechanical Properties of Metals and Alloys, WADC-TR-58-605. Wright Air Development Center. February 1959. 


\section{ONSITE DISTRIBUTION}

\section{Copy Number}

Pacific Northwest Laboratory

1
2
3
4
5
$6-55$
56
57
58
59
60
61
62
63
64
65
66
67
68
69
70
71
72
73
74
75
76
77
$78-82$
83
$84-85$

F. W. Albaugh

T. W. Ambrose

J. A. Ayres

A. L. Bement

T. K. Bierlein

W. A. Burns

S. H. Bush

J. J. Cadwell

T. T. Claudson

D. R. de Halas

T. W. Evans

B. Griggs

H. Harty

J. E. Irvin

A. B. Johnson

G. A. Last

W. R. Lewis

H. P. Maffei

J. E. Minor

J. W. Riches

W. E. Roake

D. W. Shannon

R. A. Thiede

E. E. Voiland

R. E. Westerman

R. G. Wheeler

O. J. Wick

R. Widrig

Technical Information Files

Technical Publications-300 Area

Technical Publications-700 Area

General Electric Company, Richland

D. H. Curtiss

W. J. Ferguson

M. C. Leverett

M. Lewis

GETA File Copy

Richland Operations Office 


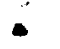

$\varphi_{i}$

4 